Supporting Information

\title{
Substrate, Catalyst and Solvent: The Triune Nature of Multitasking Reagents in
}

\section{Hydroboration and Cyanosilylation}

Ruchi Dixit, ${ }^{a d}$ Milan Kumar Bisai, ${ }^{b d}$ Sandeep Yadav, ${ }^{b d}$ Vinita Yadav, ${ }^{c d}$ Sakya S. Sen $* b d$ and Kumar Vanka*ad

aPhysical and Material Chemistry Division, CSIR-National Chemical Laboratory, Dr. Homi

Bhabha Road, Pashan, Pune - 411008 (India). E-mail: k.vanka@ncl.res.in

'Inorganic Chemistry and Catalysis Division, CSIR-National Chemical Laboratory, Dr. Homi

Bhabha Road, Pashan, Pune - 411008 (India). E-mail: ss.sen@ncl.res.in

'Organic Chemistry Division, CSIR-National Chemical Laboratory, Dr. Homi Bhabha Road, Pune - 411008 (India).

dAcademy of Scientific and Innovative Research (AcSIR), Ghaziabad - 201002 (India). 
Energetic Span Model (ESM). To find the turn over frequency (TOF) in the case of the cyanosilylation mechanism, we have calculated the relative efficiency with the AUTOF ${ }^{1}$ program, using the "Energetic Span Model" (ESM), developed by Shaik and coworkers. 2,3 The ESM provides a method to calculate the turnover frequencies (TOFs) based on their computed energy profiles of catalytic cycles. The turnover frequency calculations consider the principal rate-determining transition state, potentially rate-influencing transition states, and the intermediates. The turnover frequency (TOF) is calculated by the following equation:

$T O F=\frac{K B T}{h} e^{-\delta E / R T}$

$\boldsymbol{\delta} \boldsymbol{E}=\mathbf{T}_{\text {TDTS }}-\mathbf{I}_{\text {TDI }}$ if TDTS appears after TDI

$\boldsymbol{\delta} \boldsymbol{E}=\mathbf{T}_{\mathrm{TDTS}}-\mathbf{I}_{\mathrm{TDI}}+\Delta \mathbf{G}_{\mathbf{r}}$ if TDTS appears before TDI

$\delta \mathrm{E}$ is the effective activation barrier of the global reaction. The TDTS and TDI are the transition states, and the intermediate respectively, that maximize $\delta \mathrm{E}$. This model has been employed to calculate the TOFs at respective reaction temperatures.

\section{Calculation of dielectric constant of HBpin}

In the Turbomole software, when the COSMO solvation model is employed, then the dielectric constant is set to the value of the solvent. In COSMO and CPCM solvation models, the only parameter required to describe the solvent is the permittivity epsilon. No other parameter such as a solvent size radius is required: the cavity that is built depends on the solute only.

As the dielectric constant of HBpin has not been reported yet, we have estimated the dielectric constant of HBpin using the electric field-IR frequency correlation. The calibration line was constructed using the experimentally obtained carbonyl stretching frequencies of acetone in different polar and non-polar solvents and the estimated electric fields from Onsager electric field theory. The calibration line and the experimental carbonyl frequency of acetone in HBpin allowed the estimation of the Onsager field exerted by HBpin. As the reaction field is a function of the solvent dielectric, the dielectric constant of HBpin was estimated from the Onsager field. 


\section{Different Free Energy Profiles Discussed in the Manuscript.}

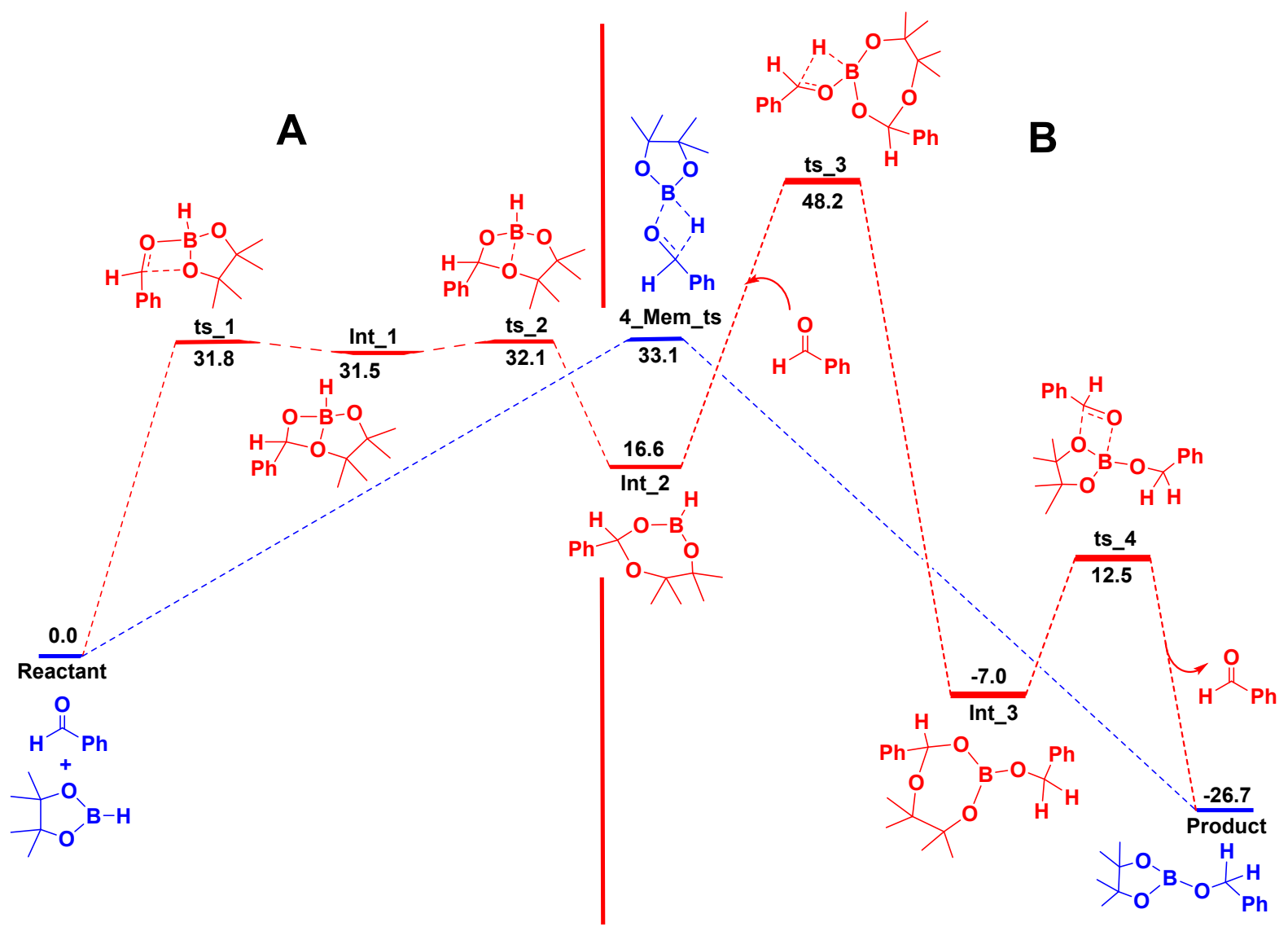

Figure S1. The free energy profile of the desired hydroboration reaction and the undesired side reaction for benzaldehyde with HBpin, in liquid HBpin. The Gibbs free energy values (in $\mathrm{kcal} / \mathrm{mol}$ ) have been calculated at the PBE/TZVP level of theory. 


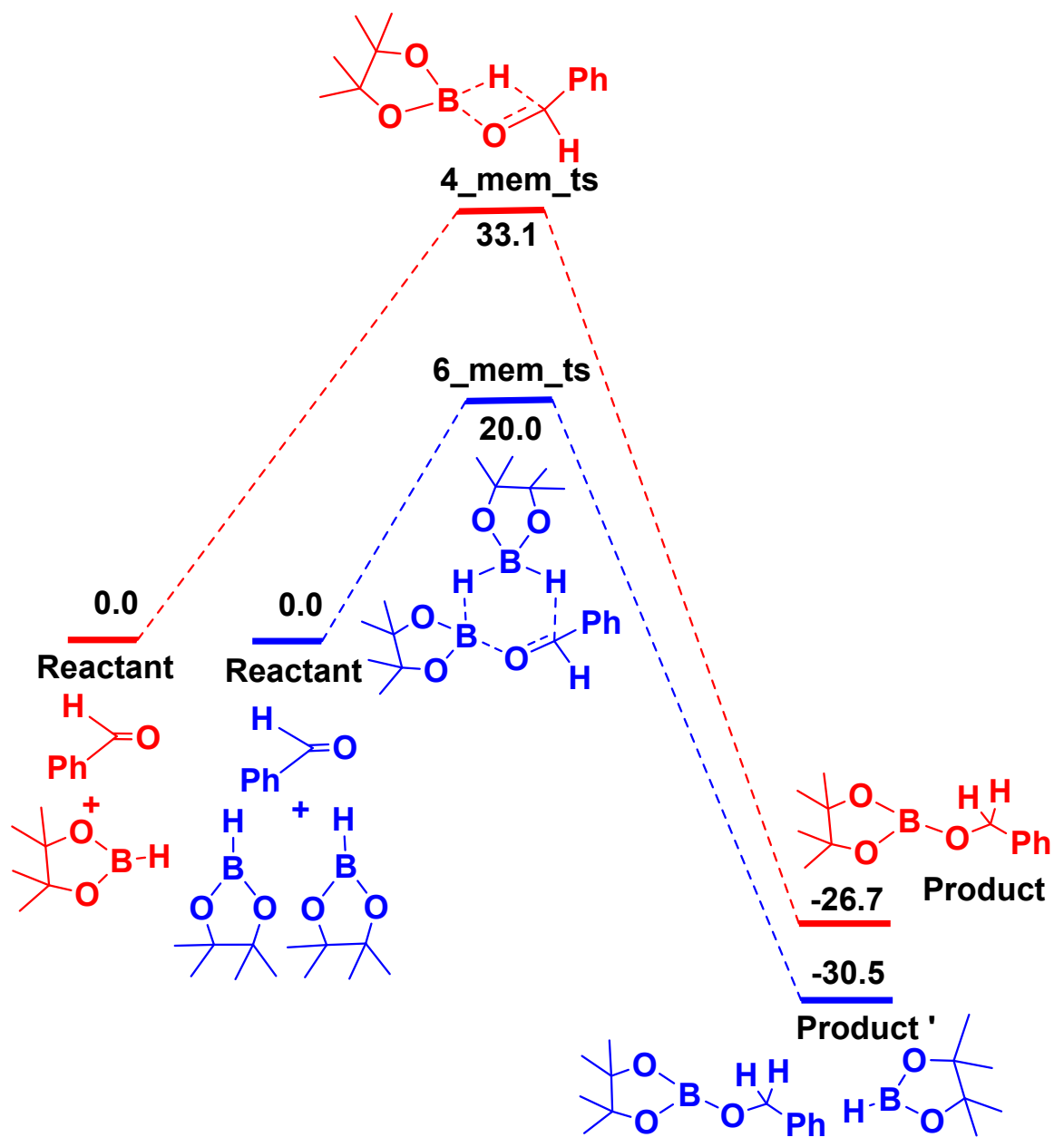

Figure S2. Free energy profiles for different competing reactions, now considering an additional HBpin as a hydride relaying catalyst, in liquid HBpin. The Gibbs free energy values (in $\mathrm{kcal} / \mathrm{mol}$ ) have been calculated at the PBE/TZVP level of theory. 


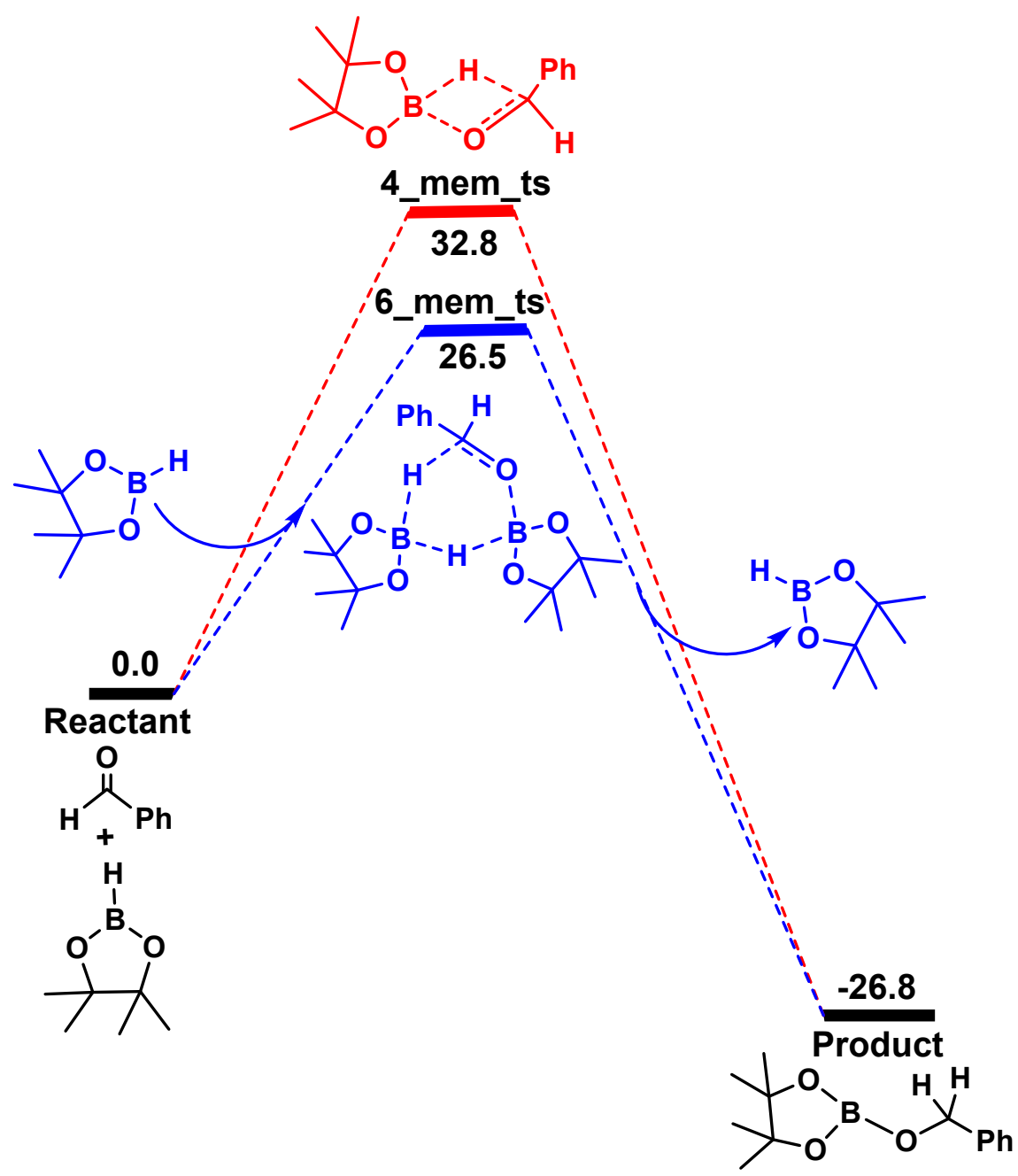

Figure S3. Free energy profiles for different competing reactions, now considering an additional HBpin as a hydride relaying catalyst, in benzene solvent. The Gibbs free energy values (in $\mathrm{kcal} / \mathrm{mol}$ ) have been calculated at the PBE/TZVP level of theory. 


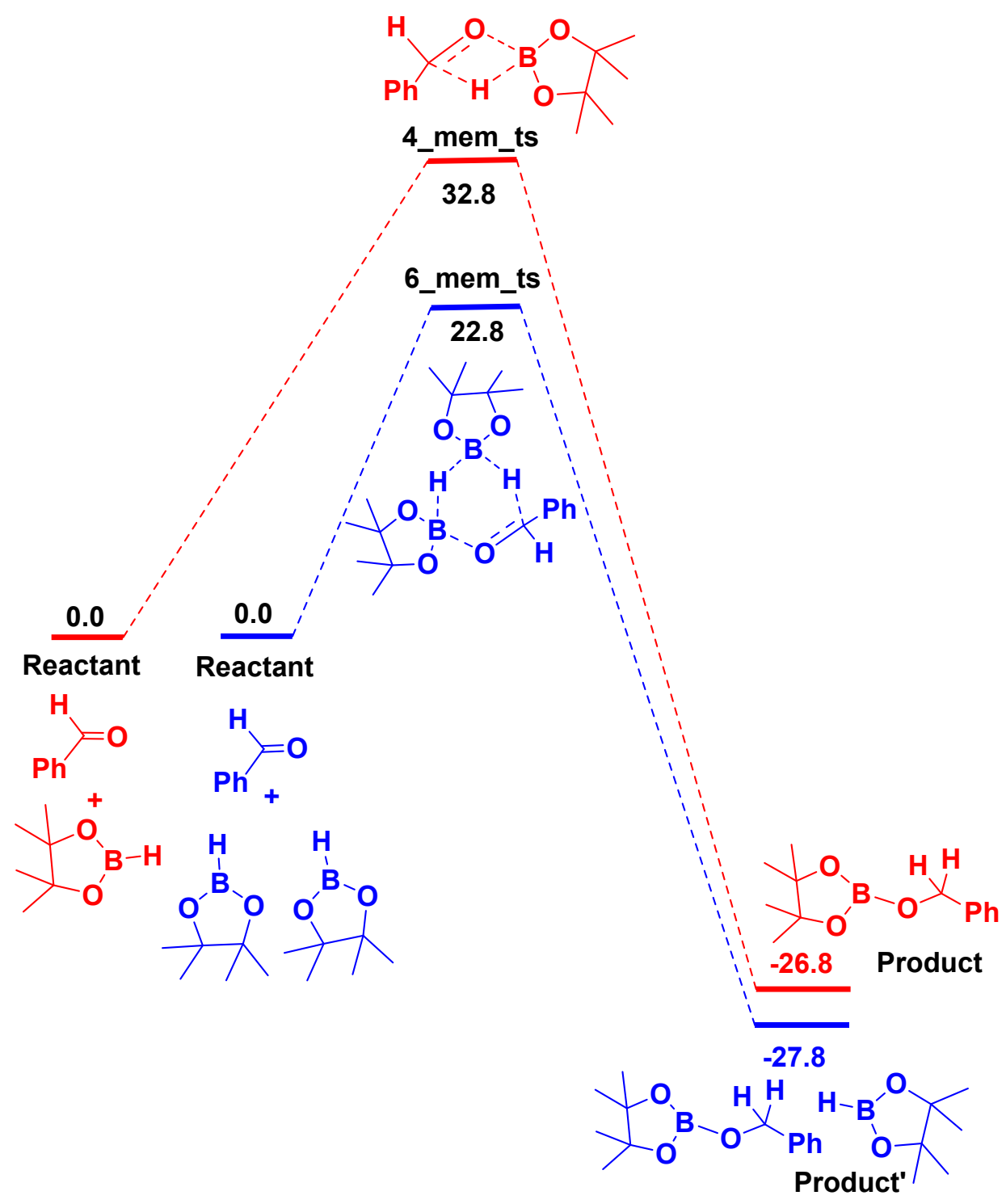

Figure S4. Free energy profiles for different competing reactions, now considering an additional HBpin as a hydride relaying catalyst, in significant excess of HBpin in benzene solvent. The Gibbs free energy values (in $\mathrm{kcal} / \mathrm{mol}$ ) have been calculated at the PBE/TZVP level of theory.

The TOF values calculated using the ESM model for the benzaldehyde hydroboration reaction.

Table S1. The values for the relative efficiency obtained for benzaldehyde hydroboration reaction in the benzene solvent, for the cases shown in Figure S3 and Figure S4.

\begin{tabular}{|c|c|}
\hline Mechanism & TOF \\
\hline The mechanism in red in Figure S3 & $5.63 * 10^{-12} / \mathrm{sec}$ \\
\hline
\end{tabular}




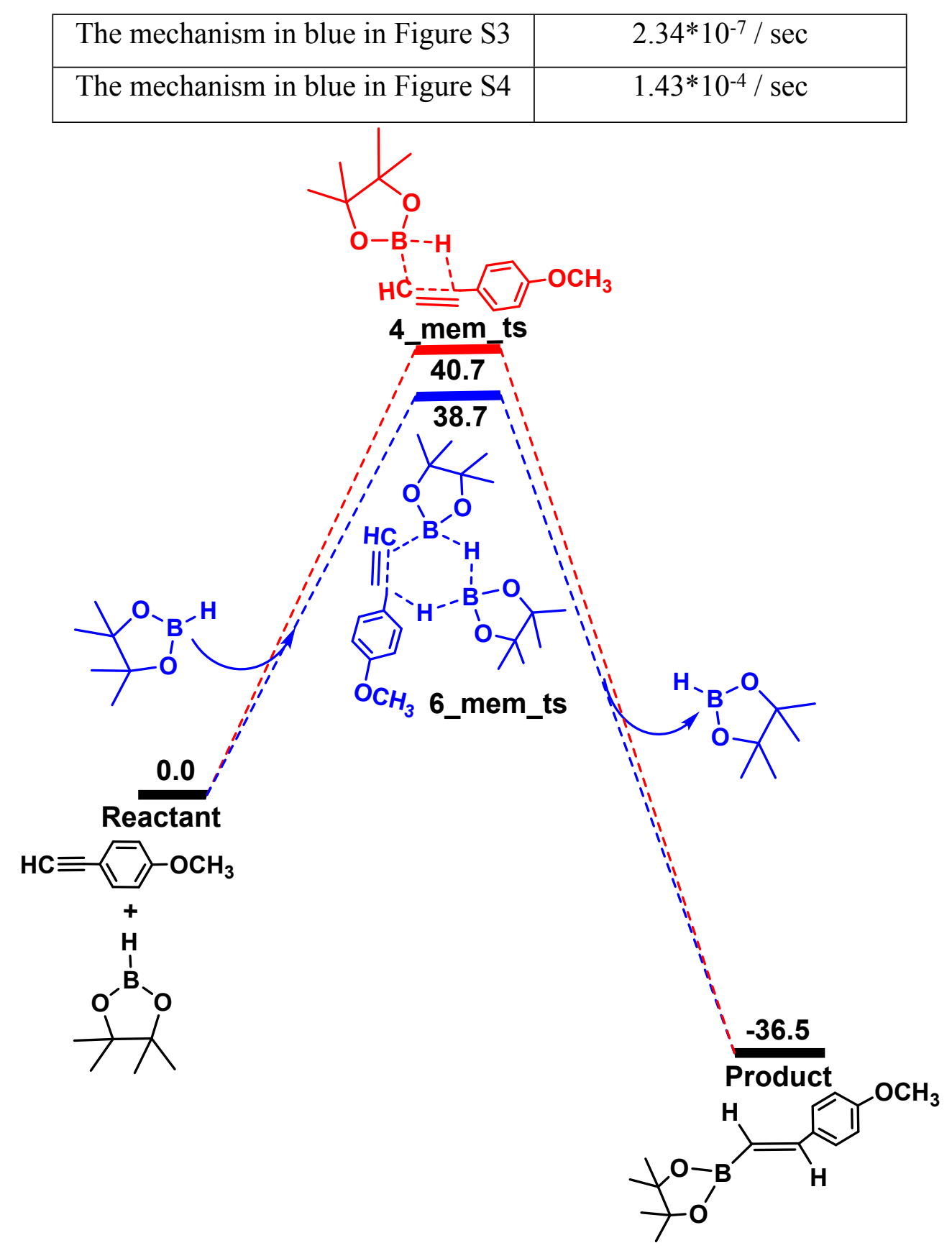

Figure S5. The free energy profiles of the desired hydroboration reaction with and without the assistance of an additional HBpin molecule for the $p$-methoxyphenylacetylene substrate in liquid HBpin solvent. The Gibbs free energy values (in $\mathrm{kcal} / \mathrm{mol}$ ) have been calculated at the PBE/TZVP level of theory. 


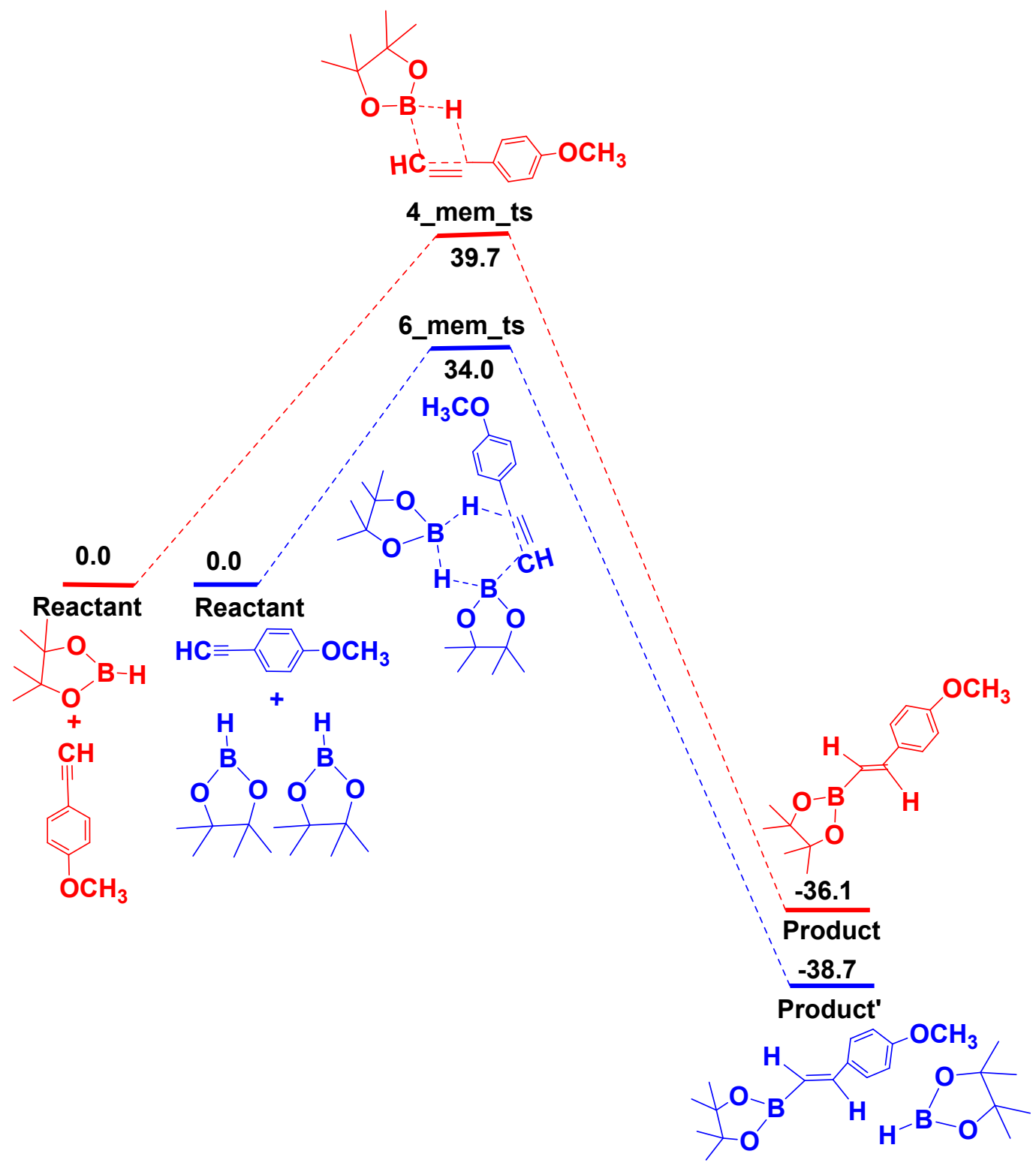

Figure S6. The free energy profiles of the desired hydroboration reaction with and without the assistance of an additional HBpin molecule for the $p$-methoxyphenylacetylene substrate and significant excess of HBpin in liquid HBpin solvent. The Gibbs free energy values (in $\mathrm{kcal} / \mathrm{mol}$ ) have been calculated at the PBE/TZVP level of theory.

The TOF values calculated using the ESM model for alkyne hydroboration reaction.

Table S2. The values for the relative efficiency obtained for the alkyne hydroboration reaction in benzene solvent, for the cases shown in Figure 6 and Figure 7.

\begin{tabular}{|c|c|}
\hline Mechanism & TOF \\
\hline The mechanism in red in Figure 6 & $4.36^{*} 10^{-11} / \mathrm{sec}$ \\
\hline
\end{tabular}




\begin{tabular}{|c|c|}
\hline The mechanism in blue in Figure 6 & $9.79^{*} 10^{-11} / \mathrm{sec}$ \\
\hline The mechanism in blue in Figure 7 & $9.5^{*} 10^{-8} / \mathrm{sec}$ \\
\hline
\end{tabular}

Hydroboration with Ketones. Leung and co-workers ${ }^{4}$ have done the hydroboration of ketone with HBpin, in the absence of solvent and external catalyst, taking acetophenone as the ketone. Like in Case I, the possibility of an additional HBpin molecule acting as a catalyst, in this case, would create separation in favorability between the six-membered transition state and the four-membered transition state, favoring the former over the latter (see Figure S7 below). Hence, the calculations indicate that the same factors are in play in the case of ketones, as was observed for the aldehyde case. Likewise, calculations indicate that the additional HBpin molecule acting as a catalyst would also lead to greater efficiency of the hydroboration in solution (specifically the toluene solvent - see Figure S8).

Furthermore, the efficiency for the hydroboration reaction in solution calculated using the Energetic Span Model (ESM), has been shown in Table S3. The results indicate that reaction mechanism involving the six-membered transition state is 71.6 times more efficient than the reaction mechanism involving the four-membered transition state in toluene solvent.

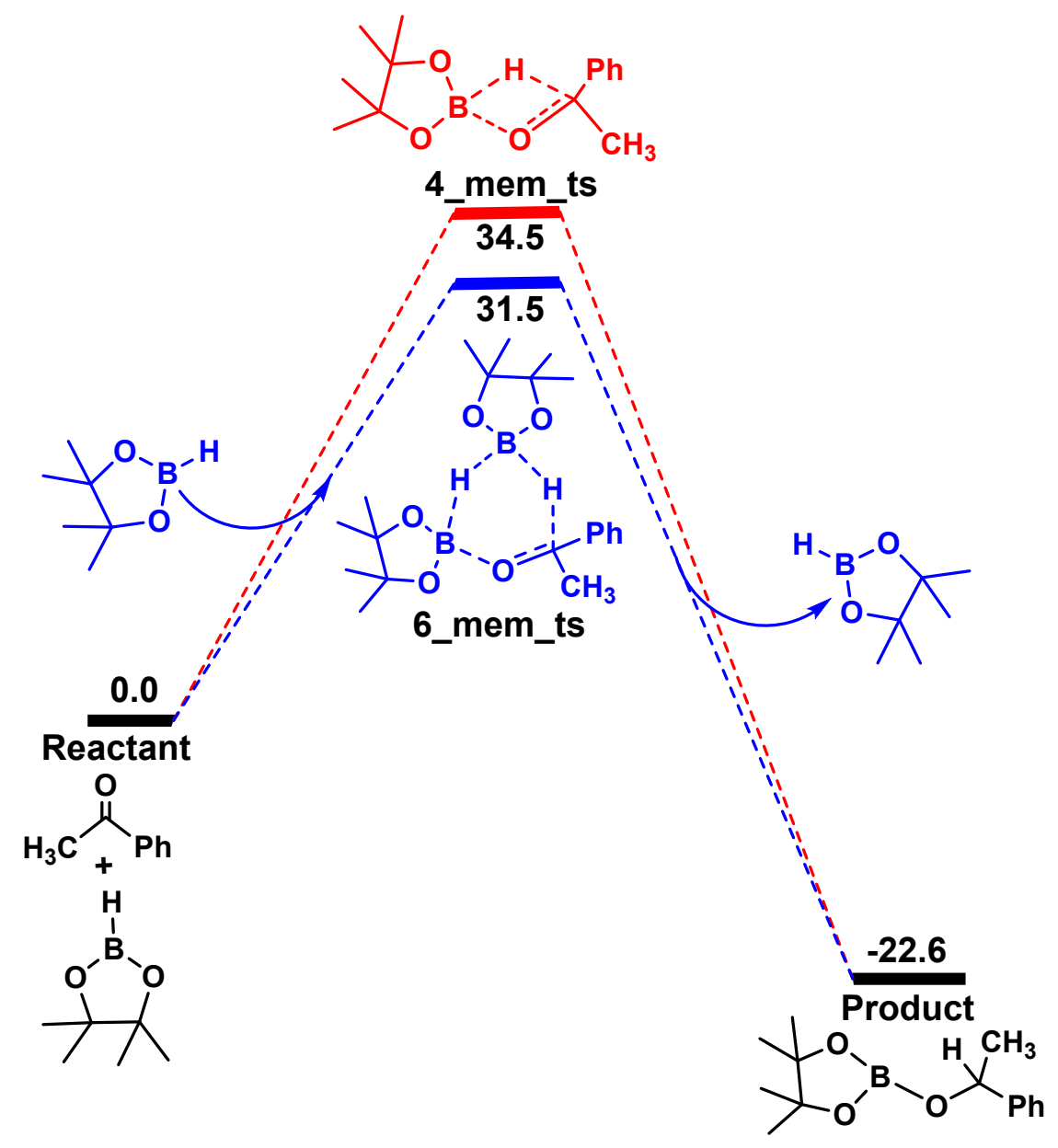


Figure S7. Free energy profiles for different competing reactions for the ketone substrate, with and without an additional HBpin as a hydride relaying catalyst, with liquid HBpin as the solvent. The Gibbs free energy values (in $\mathrm{kcal} / \mathrm{mol}$ ) have been calculated at the PBE/TZVP level of theory.

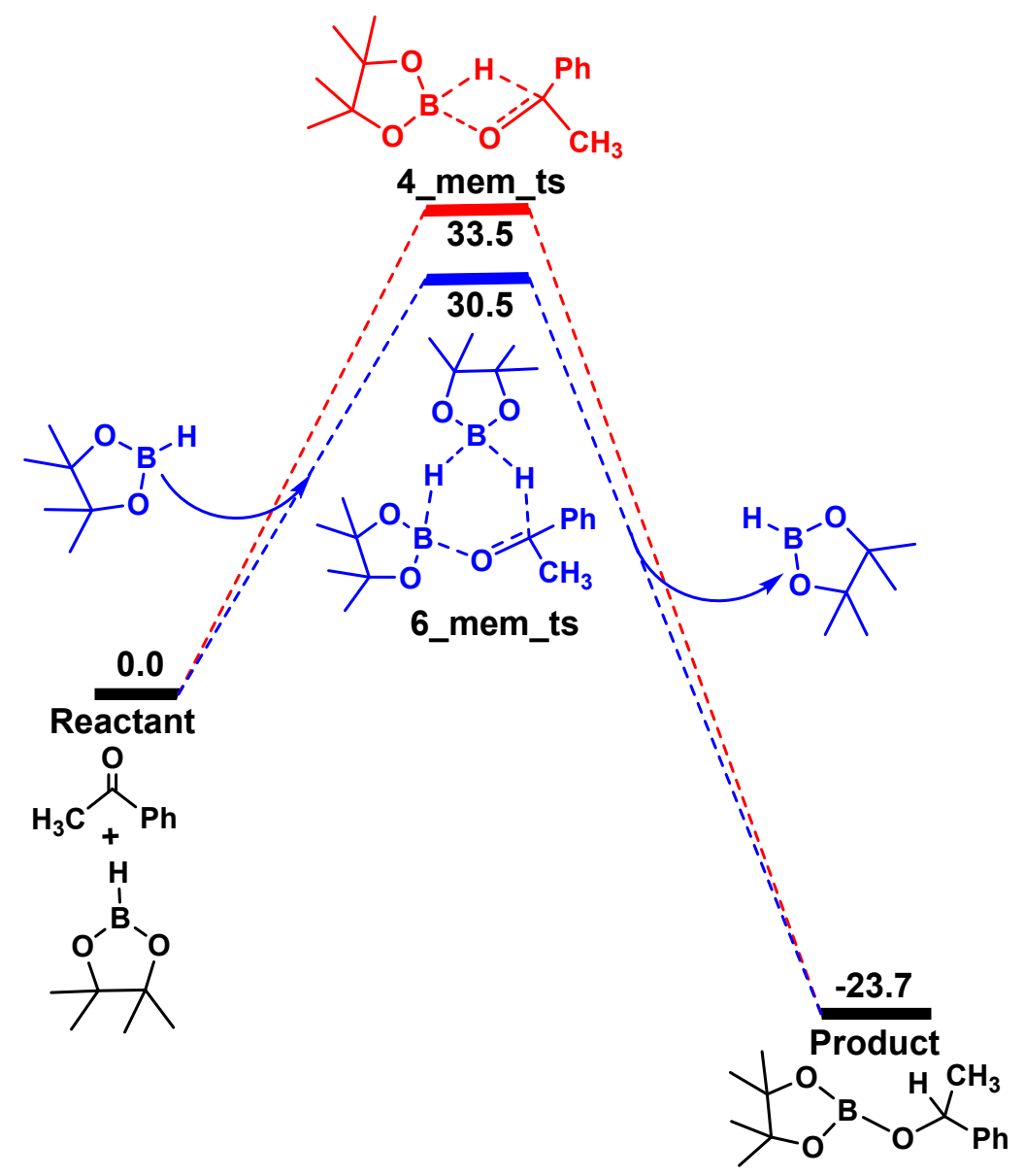

Figure S8. Free energy profiles for different competing reactions for the ketone substrate, with and without an additional HBpin as a hydride relaying catalyst, with toluene as solvent. The Gibbs free energy values (in $\mathrm{kcal} / \mathrm{mol}$ ) have been calculated at the PBE/TZVP level of theory.

The TOF values calculated using the ESM model for ketone hydroboration reaction.

Table S3. The values for the relative efficiency obtained for the ketone hydroboration reaction in toluene solvent, for the case shown in Figure S8.

\begin{tabular}{|c|c|}
\hline Mechanism & TOF \\
\hline in red & $1.37 * 10^{-8} / \mathrm{sec}$ \\
\hline
\end{tabular}




\begin{tabular}{|c|c|}
\hline in blue & $9.82 * 10^{-7} / \mathrm{sec}$ \\
\hline
\end{tabular}

Hydroboration with Carboxylic acid. Panda, Ma and Xue, and their co-workers ${ }^{5}$ were successful in doing the hydroboration of a carboxylic acid with HBpin, in the absence of solvent and external catalyst, taking benzoic acid as the substrate. The hydroboration was achieved in this case at room temperature. The mechanism that they had proposed involves multiple steps and several four-membered transition states. We have studied the mechanism in the experimentally employed hexane solvent, as well as in liquid HBpin (see Figures S9, Figure S10, and Figure S11). As shown in Figure S9 below, The barriers were seen to be reduced considerably by the inclusion of an additional HBpin molecule as a catalyst, as shown in Figure S10 and Figure S10 below. Moreover, as shown in Table S4, the TOF was calculated using the Energetic Span Model (ESM), which also indicates that hydroboration takes place with high efficiency through the mechanism proposed involving a six-membered transition state with HBpin as the internal catalyst, as shown in Figure S10: the process is $1.9 * 10^{5}$ times more efficient in comparison to the mechanism shown in Figure S9(b). Similarly, in hexane solvent (as shown in Figure S11), the mechanism involving a sixmembered transition state with HBpin as the internal catalyst is 17.4 times more efficient than the mechanism shown in Figure S9(a).

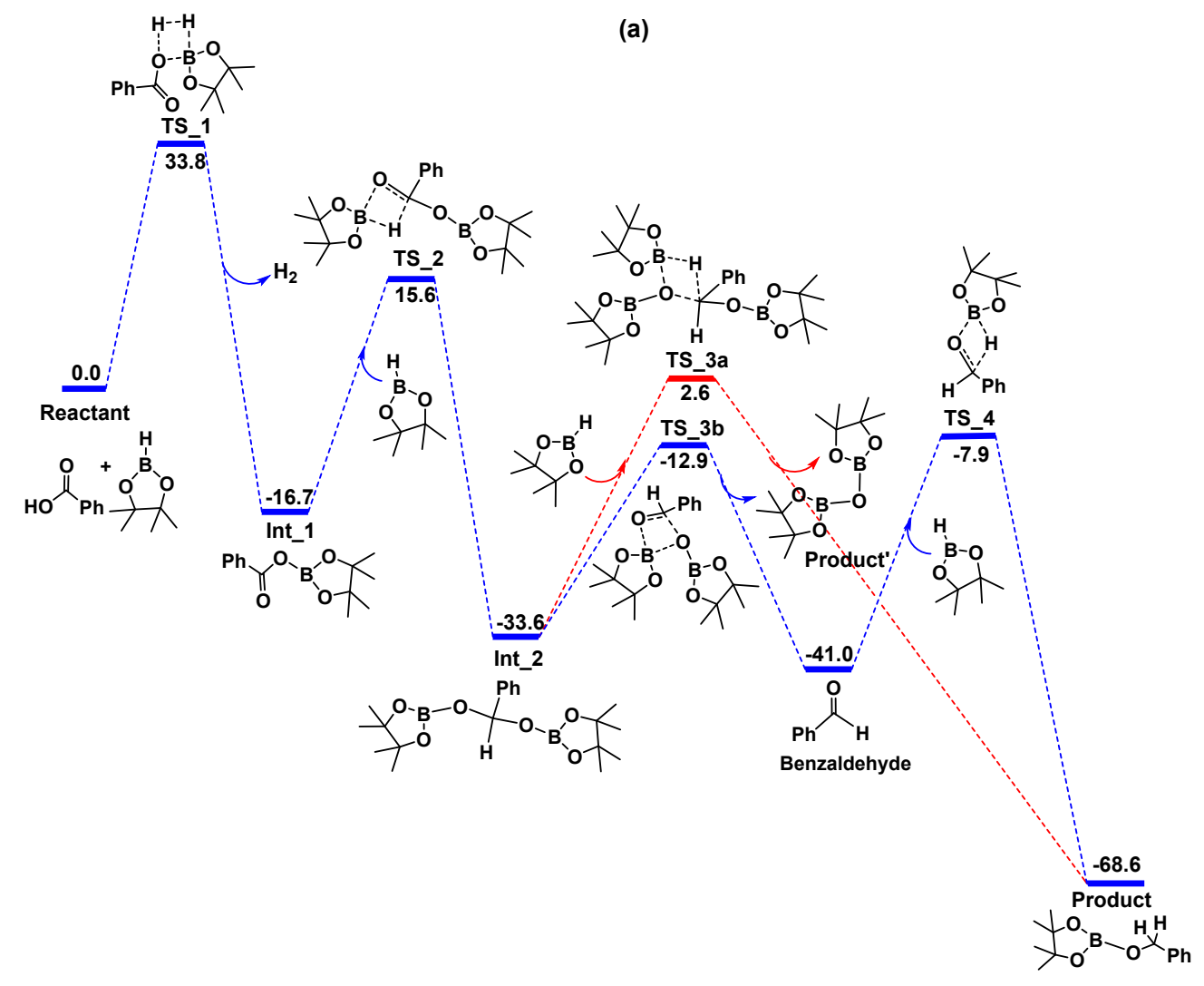




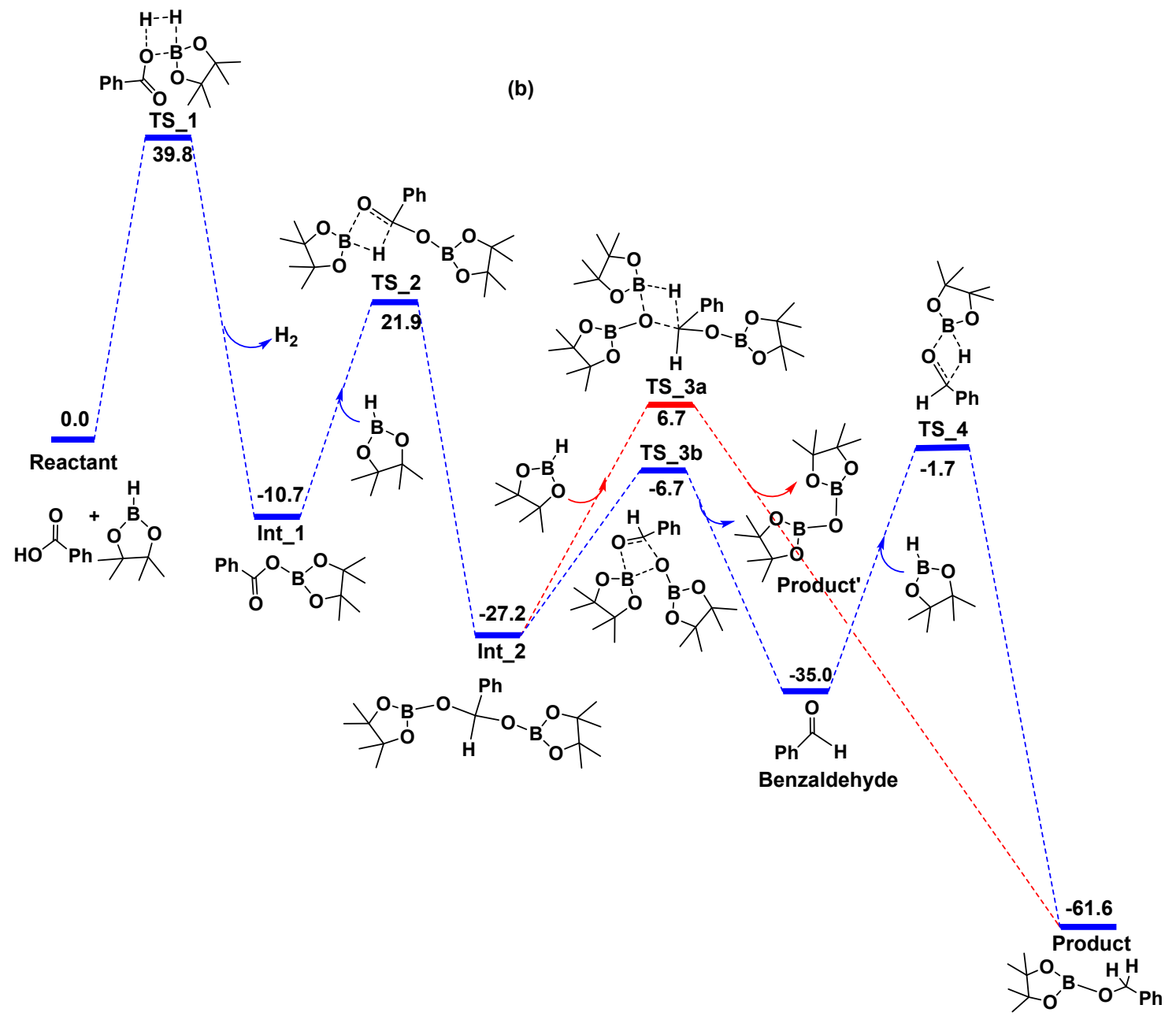

Figure S9. The free energy profile of the desired hydroboration reaction for the benzoic acid substrate with HBpin, without the assistance of an additional HBpin molecule, in (a) hexane solvent, and in (b) liquid HBpin. The Gibbs free energy values (in $\mathrm{kcal} / \mathrm{mol}$ ) have been calculated at the PBE/TZVP level of theory. 


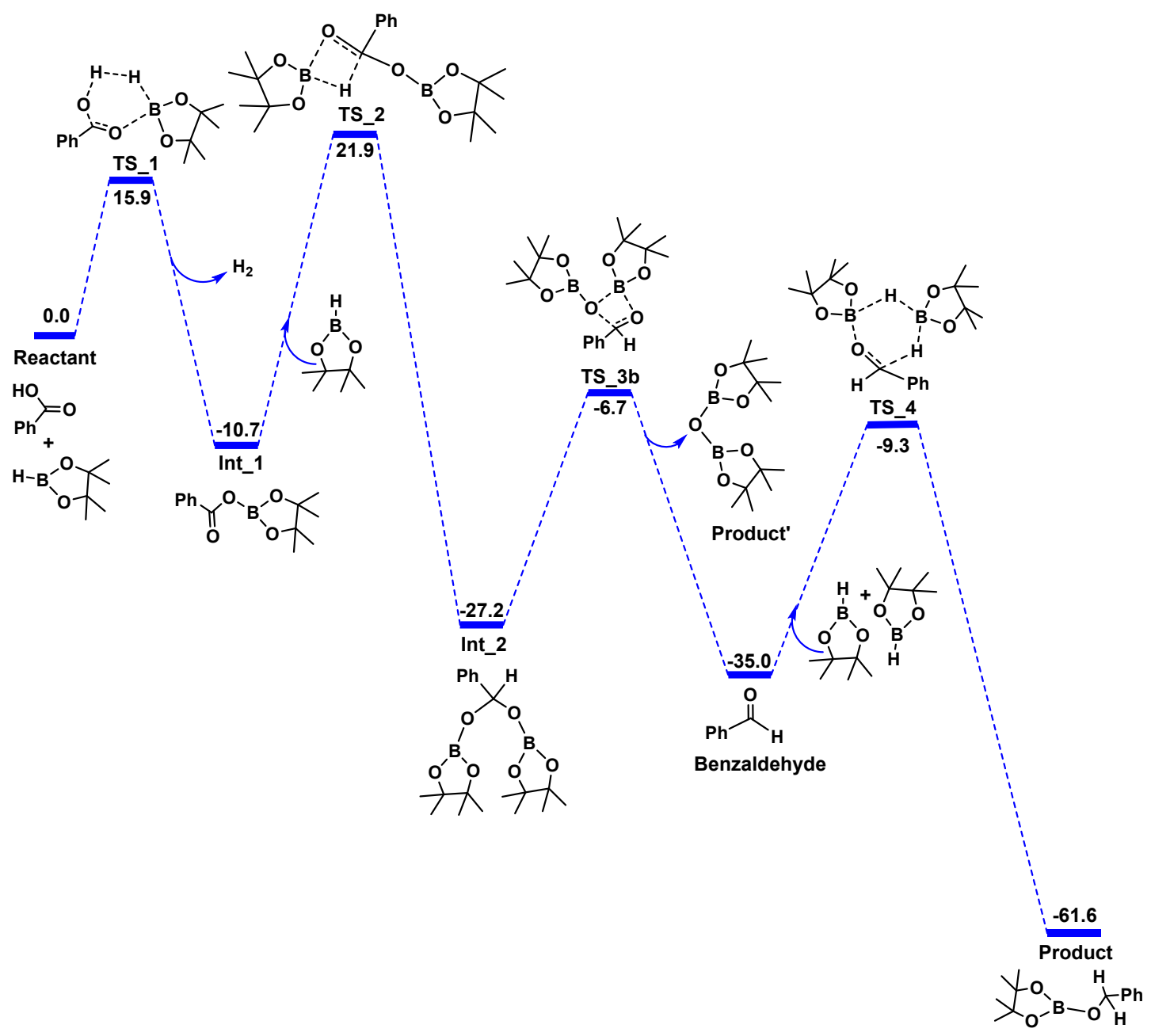

Figure S10. The free energy profiles for benzoic acid hydroboration with HBpin, in liquid HBpin, considering an additional HBpin as a catalyst. The Gibbs free energy values (in $\mathrm{kcal} / \mathrm{mol}$ ) have been calculated at the PBE/TZVP level of theory. 


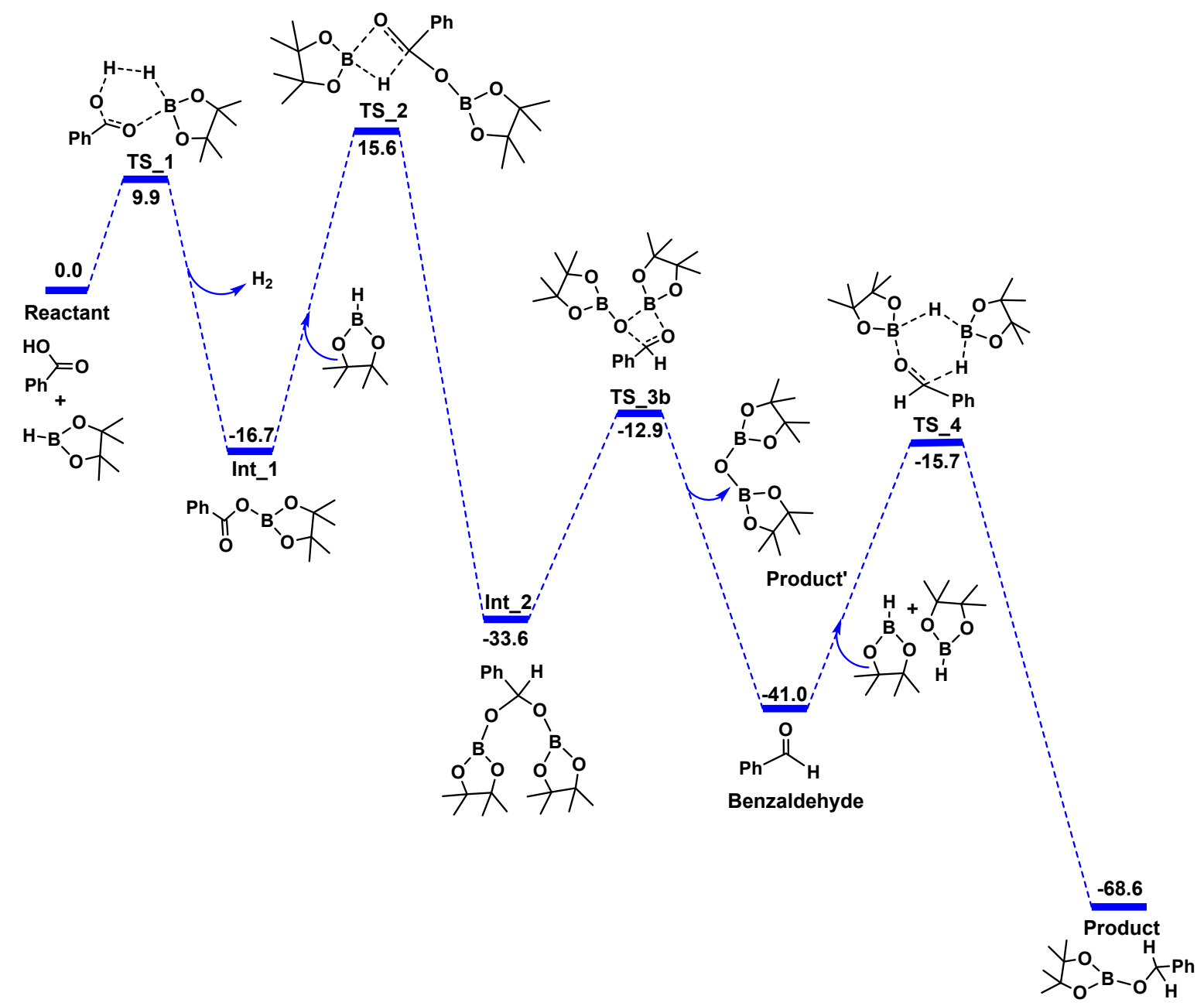

Figure S11. The free energy profile of the desired hydroboration reaction for the benzoic acid substrate with HBpin, with the assistance of an additional HBpin molecule, in hexane solvent. The Gibbs free energy values (in $\mathrm{kcal} / \mathrm{mol}$ ) have been calculated at the PBE/TZVP level of theory.

The TOF values calculated using the ESM model for carboxylic acid hydroboration reaction.

Table S4. The values for the relative efficiency obtained for carboxylic acid hydroboration reaction in hexane as well as HBpin solvent, for the cases shown in Figures 9a, 9b, 10, and 11.

\begin{tabular}{|c|c|}
\hline Mechanism & TOF \\
\hline Mechanism in Figure 9a (in blue) & $7.52^{*} 10^{-13} / \mathrm{sec}$ \\
\hline The mechanism in Figure 11 & $1.31^{*} 10^{-11} / \mathrm{sec}$ \\
\hline Mechanism in Figure 9b (in blue) & $4.17^{*} 10^{-17} / \mathrm{sec}$ \\
\hline
\end{tabular}




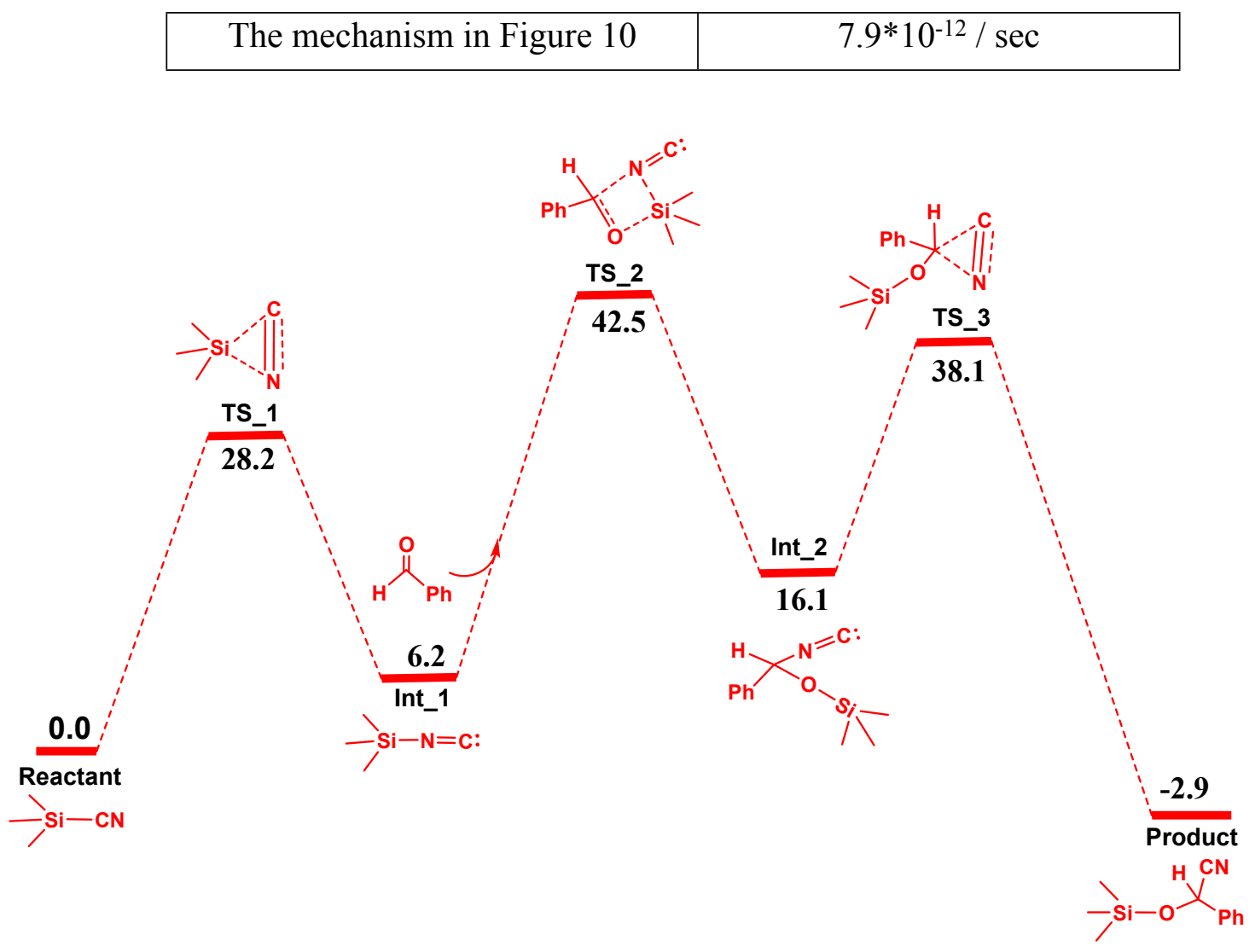

Figure S12. The free energy profile of the reaction of benzaldehyde with TMSCN in benzene solution without the assistance of an extra TMSCN molecule. The Gibbs free energy values (in $\mathrm{kcal} / \mathrm{mol}$ ) have been calculated at the PBE/TZVP level of theory.

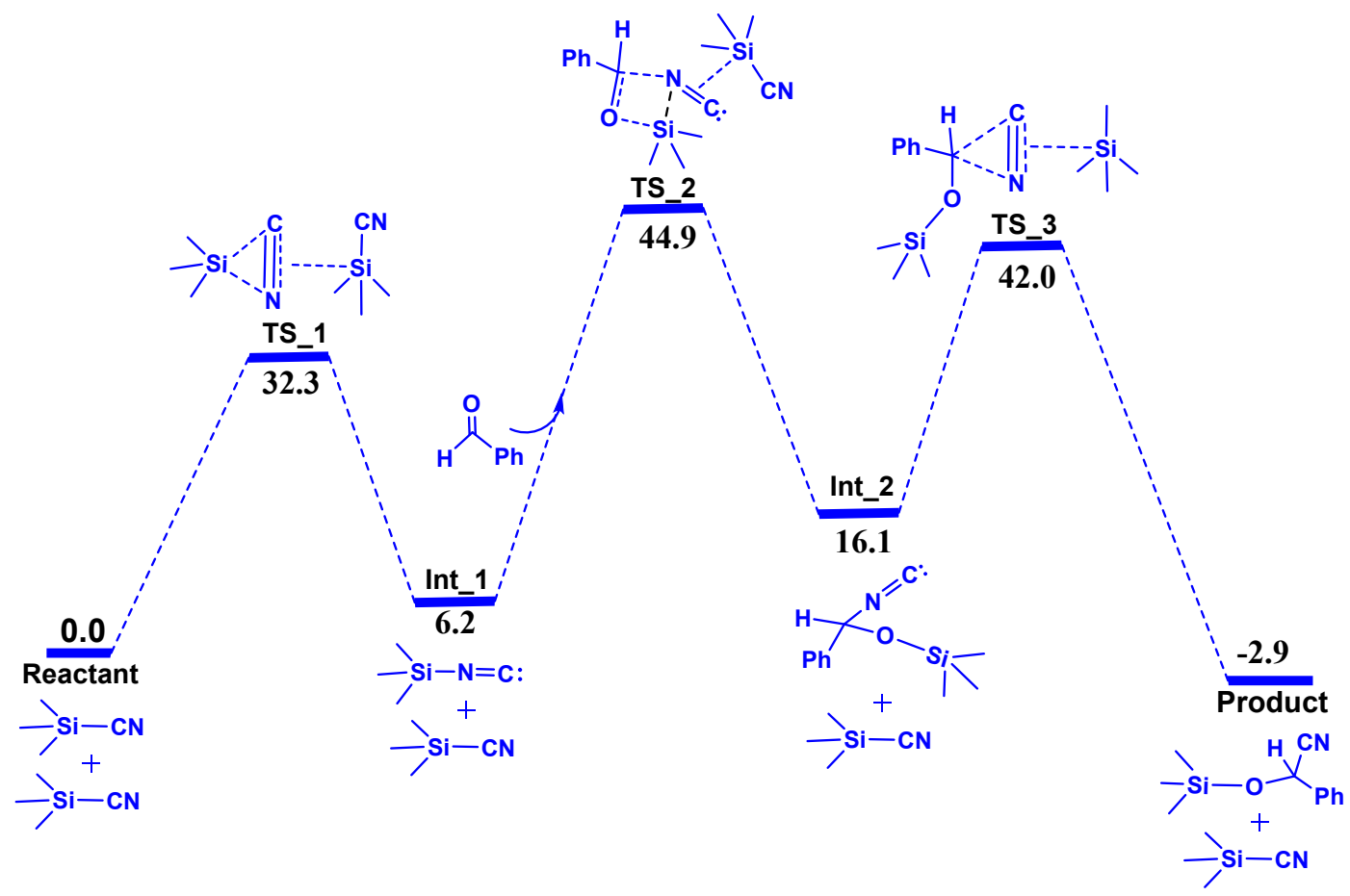


Figure S13. The free energy profile of the reaction of benzaldehyde with TMSCN in benzene solution with the assistance of an extra TMSCN molecule. The Gibbs free energy values (in $\mathrm{kcal} / \mathrm{mol}$ ) have been calculated at the PBE/TZVP level of theory.

\section{The TOF values calculated using the ESM model for the cyanosilylation reaction.}

Table S5. The values for the relative efficiency obtained for cyanosilylation in the benzene solvent for the desired reaction as well as with TMSCN acting as the catalyst.

\begin{tabular}{|c|c|}
\hline Mechanism & TOF \\
\hline The mechanism in Figure S12 & $1.04 * 10^{-17} / \mathrm{sec}$ \\
\hline The mechanism in Figure S13 & $9.94 * 10^{-16} / \mathrm{sec}$ \\
\hline The mechanism in Figure 8 & $1.28^{*} 10^{-12} / \mathrm{sec}$ \\
\hline
\end{tabular}

\section{NCI-plot}

The NCI plot ${ }^{6}$ iso-surfaces have been used to characterize noncovalent interactions. They correspond to both favorable and unfavorable interactions, as differentiated by the sign of the second-density Hessian eigenvalue and defined by the isosurface color. The color scheme is a red yellow-green-blue scale with red for $\rho$ cut $^{+}$(repulsive) and blue for $\rho$ cut $^{-}$ (attractive). ${ }^{7}$ The Turbomole 7.1 suite of programs, using the PBE/TZVP level of the theory have been employed to generate the NCI plots.

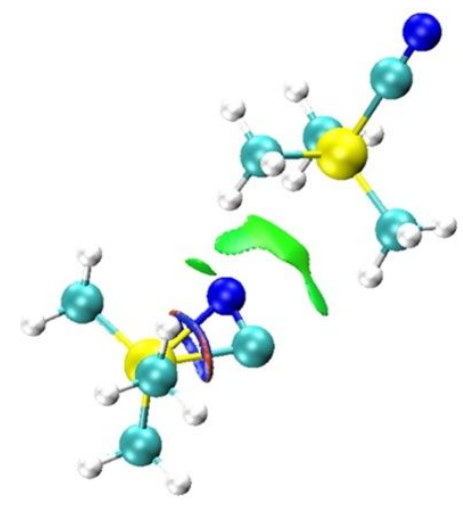

TS_1

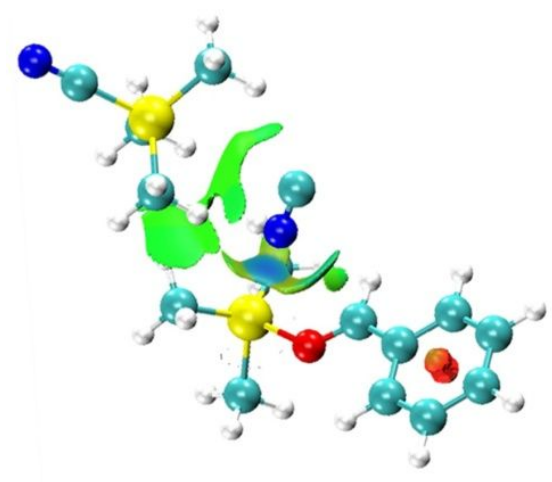

TS_2

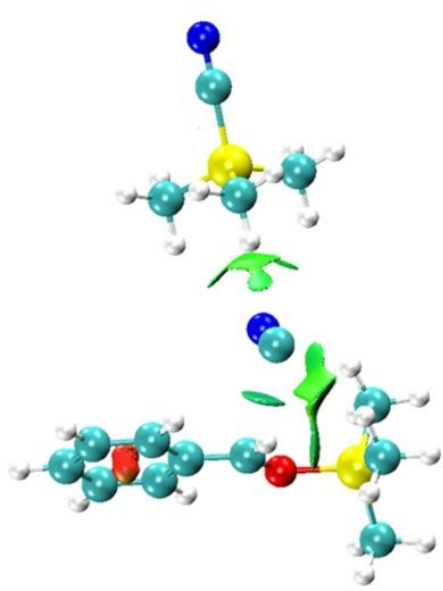

TS 3

Figure S14. NCI plots indicating non-covalent interactions (shown in green) between the silicon of an additional TMSCN molecule and the $\mathrm{CN}$ or NC group of the reacting TMSCN. 


\section{Procedure for Rate-order determination}

The rate order of the hydroboration reaction with respect to various components of the reaction was determined using the initial rate method. The data of the concentration $(\mathrm{M})$ of the product vs time (min.) plot was fitted to linear using Origin Pro 8. The slope of the linear fitted curve represents the reaction rate. The order of the reaction was determined by plotting the $\log ($ rate $)$ vs $\log ($ conc.) of that particular component.

Representative procedure: Rate order determination on pinacol borane (HBpin). To determine the order of the hydroboration reaction on pinacol borane, the initial rates at different initial concentrations of pinacol borane were recorded. The final data was obtained by averaging the results of two independent runs for each experiment. To an oven-dried 15 $\mathrm{mL}$ screw cap pressure tube, p-methoxyphenylacetylene $(0.25 \mathrm{mmol}, 1$ eq. $)$, a specific amount of pinacol borane (as shown in Table S6), mesitylene $(0.25 \mathrm{mmol}, 1$ eq.) as an internal standard, and benzene $(1 \mathrm{~mL})$ were added. The reaction mixture was then heated at $100^{\circ} \mathrm{C}$ in a pre-heated oil bath. At regular intervals $(10 \mathrm{~min}, 20 \mathrm{~min}, 30 \mathrm{~min}, 40 \mathrm{~min}, 50 \mathrm{~min}$, $60 \mathrm{~min}$ ), the reaction mixture was cooled to ambient temperature and an aliquot of mixture was taken in a GC vial. The GC sample was diluted with acetone and subjected to gas chromatographic analysis. The concentration of the product obtained in each sample was determined with respect to the mesitylene internal standard. The rate of the reaction at different initial concentrations of pinacol borane has been provided in Table S6 and used to plot the $\log ($ rate) vs $\log$ (conc.) plot (Figure S15) to determine the order of the reaction with respect to pinacol borane.

Table S6. Rate of the hydroboration reaction at different initial concentrations of pinacol borane (HBpin).

\begin{tabular}{|c|c|c|c|c|}
\hline Experiment & $\begin{array}{c}\text { 4-OMe } \\
\text { phenylacetylene: } \\
\text { HBpin }\end{array}$ & $\begin{array}{c}\text { Amount of } \\
\text { HBpin (g) }\end{array}$ & $\begin{array}{c}\text { The initial } \\
\text { concentration of } \\
\text { HBpin (M) }\end{array}$ & $\begin{array}{c}\text { Initial rate } \\
\text { [mmol/min] } \\
\mathbf{1 0}^{-4}\end{array}$ \\
\hline 1 & $1: 1$ & 0.032 & 0.25 & 0.254 \\
\hline 2 & $1: 2$ & 0.064 & 0.50 & 0.709 \\
\hline 3 & $1: 4$ & 0.128 & 1.00 & 2.145 \\
\hline 4 & $1: 5$ & 0.160 & 1.25 & 3.201 \\
\hline
\end{tabular}




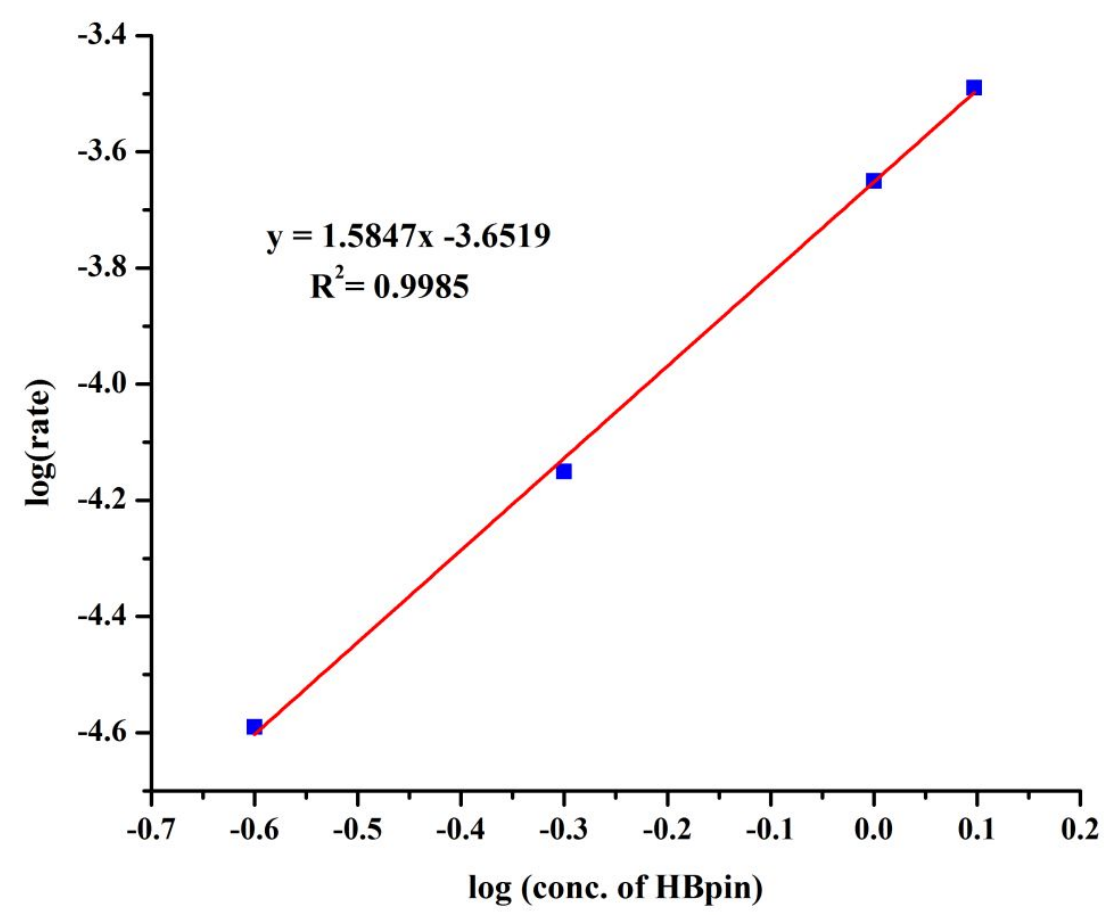

Figure S15. $\log ($ rate) versus $\log$ (conc. of pinacol borane).

For Case I (the aldehyde case) further single point calculations have been done using the hybrid functional B3-LYP and the TZVP basis set, with dispersion corrections. These calculations, too, validate our hypothesis and show the same trend as was observed when employing the PBE/TZVP level of theory. 


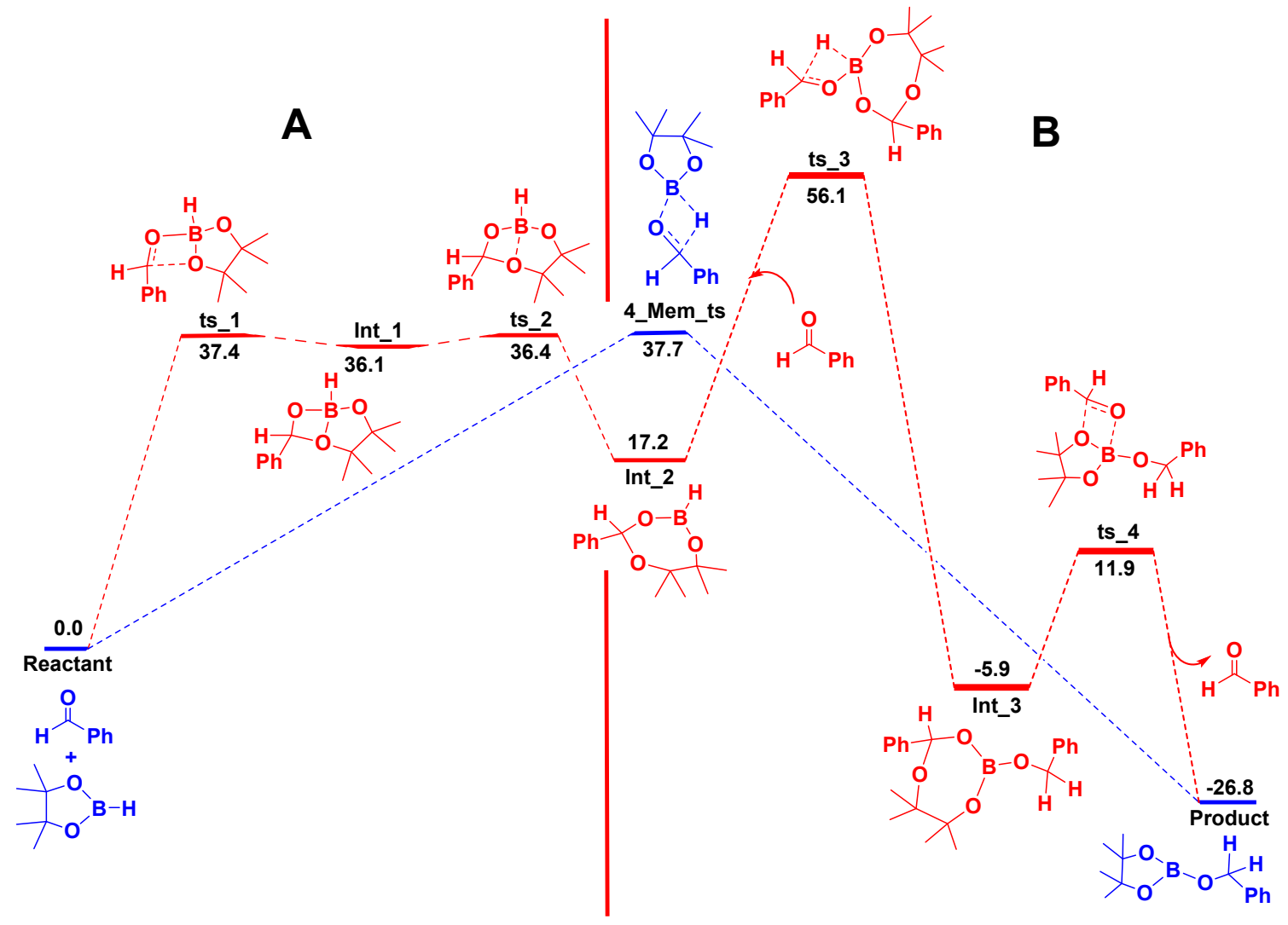

Figure S16. The free energy profile of the desired hydroboration reaction and the undesired side reaction for benzaldehyde with HBpin, in benzene solvent. The Gibbs free energy values (in $\mathrm{kcal} / \mathrm{mol}$ ) have been calculated at the PBE/TZVP/B3-LYP/TZVP level of theory. 


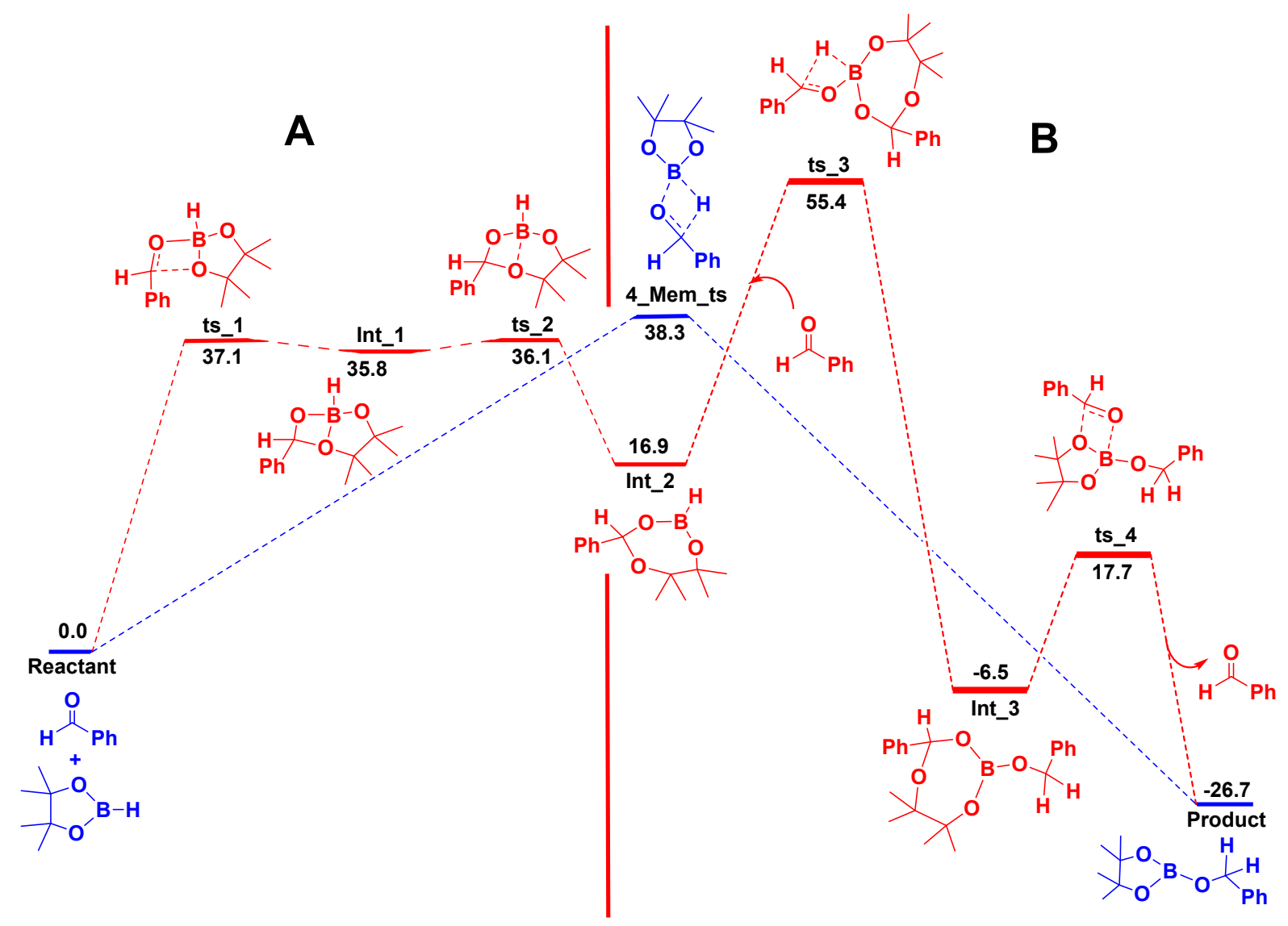

Figure S17. The free energy profile of the desired hydroboration reaction and the undesired side reaction for benzaldehyde with HBpin, in HBpin solvent. The Gibbs free energy values (in $\mathrm{kcal} / \mathrm{mol}$ ) have been calculated at the PBE/TZVP/B3-LYP/TZVP level of theory. 


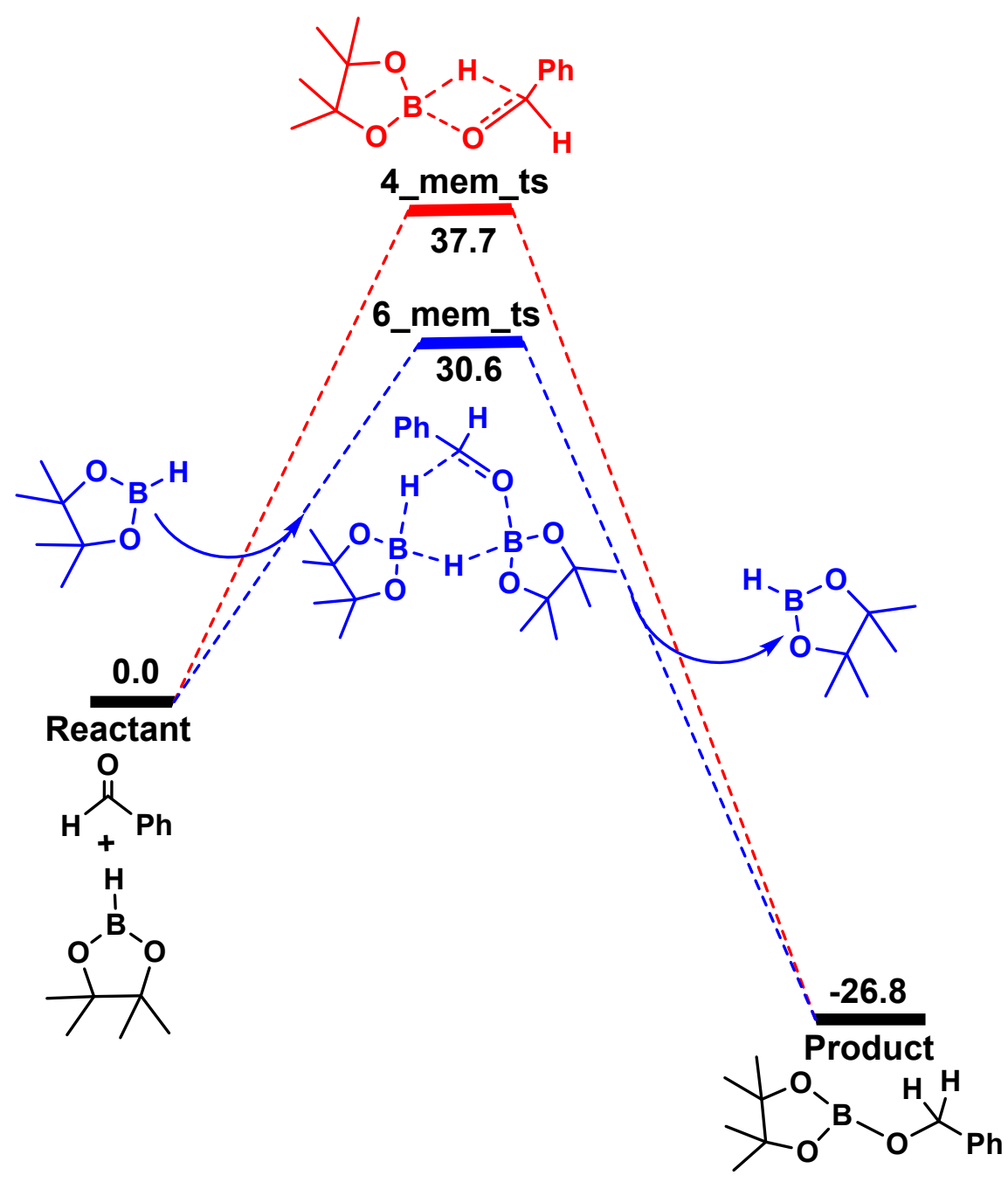

Figure S18. Free energy profiles for different competing reactions, now considering an additional HBpin as a hydride relaying catalyst, in benzene solvent. The Gibbs free energy values (in $\mathrm{kcal} / \mathrm{mol}$ ) have been calculated at the PBE/TZVP/B3-LYP/TZVP level of theory. 


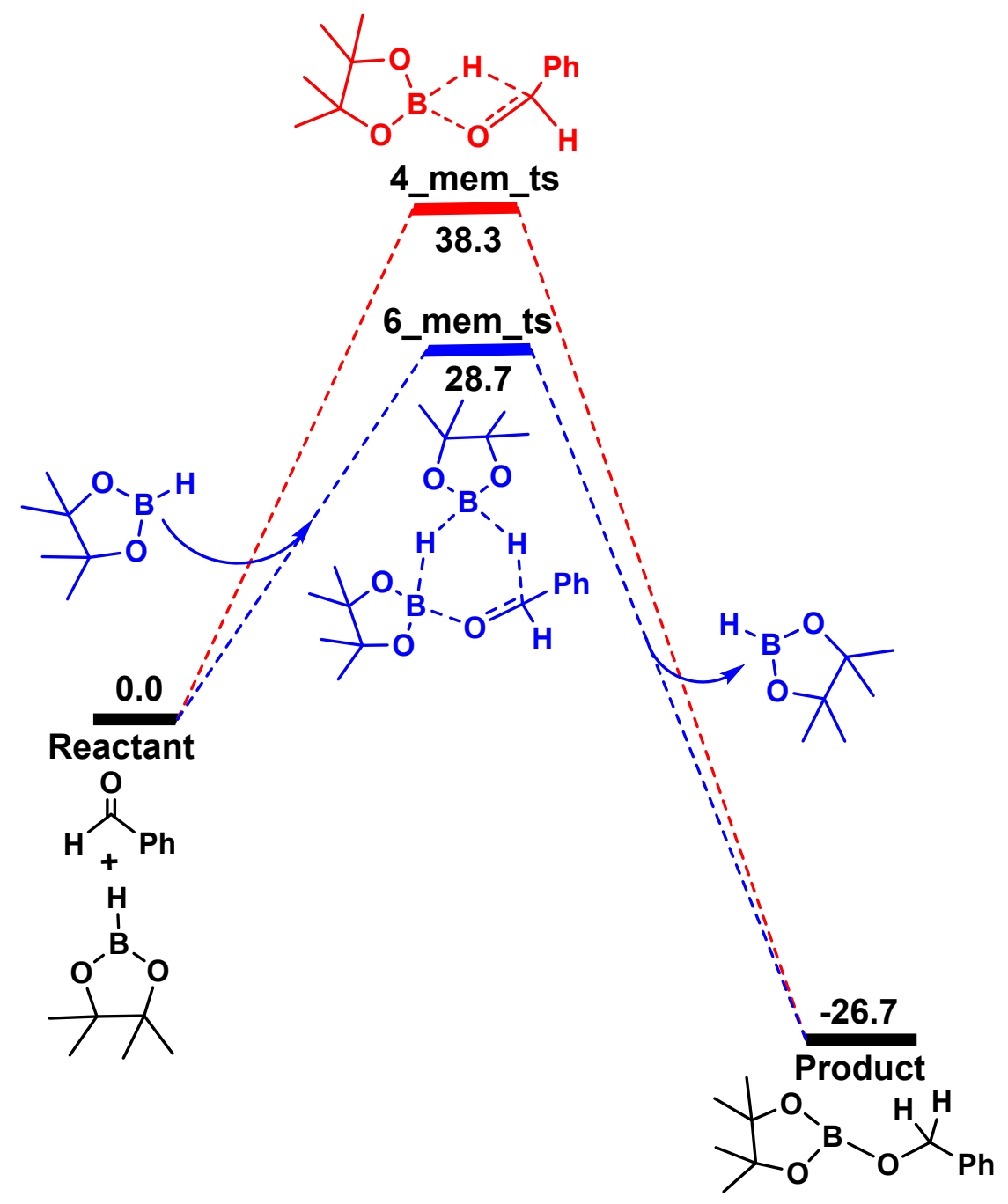

Figure S19. Free energy profiles for different competing reactions, now considering an additional HBpin as a hydride relaying catalyst, in HBpin solvent. The Gibbs free energy values (in $\mathrm{kcal} / \mathrm{mol}$ ) have been calculated at the PBE/TZVP/B3-LYP/TZVP level of theory.

\section{Ab initio Molecular Dynamics Simulations (AIMD)}

The AIMD simulations performed with the TeraChem quantum chemistry and AIMD software packages ${ }^{8-14}$ using the B3LYP ${ }^{15}$ electronic wave function and 3-21g Gaussian basis set $^{16}$ to calculate the Born-Oppenheimer potential energy surface The Newton's equations of motion were calculated using Langevin dynamics with an equilibrium temperature of $1800 \mathrm{~K}$ (also the starting temperature of the dynamics). We have used very high temperature to increase the average kinetic energy of the reactant molecules and for faster dynamics which breaks all kind of non-covalent interactions without breaking the covalent bonds. The calculations were feasible because of the efficiency of TeraChem, which accelerates the 
calculation by evaluating the two-electron integrals on the GPU. We have used the ADIIS (augmented direct inversion in the iterative subspace) algorithm ${ }^{17}$ available in TeraChem, as an alternative tool for self-consistent field calculation at each AIMD step, in which the default DIIS algorithm ${ }^{18}$ failed to converge. Spherical boundary conditions apply to prevent the molecules from flying away which is called "evaporation" event. The molecules were restricted to move inside a spherical volume by a boundary potential.

$\mathrm{V}(\mathrm{r}, \mathrm{t})=\mathrm{f}(\mathrm{t}) \mathrm{U}(\mathrm{r}, \mathrm{k})$

Where $\mathrm{k}=0.5 \mathrm{kcal} \mathrm{mol}^{-1} \AA^{-2}, \mathrm{r}=4.5 \AA$

We have run AIMD simulations with 3 HBpin molecules atoms (66 atoms) for a total time of $\sim 30 \mathrm{ps}$ with a timestep of $0.5 \mathrm{fs}$.

\section{Possibility of trimer formation in HBpin: ab initio molecular dynamics (AIMD) simulations.}

The results discussed in manuscript lead to an interesting question: since we have now shown that the B-O bonds in HBpin are susceptible to attack, why cannot HBpin molecules interact among each other in the absence of benzaldehyde (or any other) substrate? In other words, HBpin molecules in close proximity could potentially form heterocyclic species too, through mutual interaction. This is shown in Figure S20 below, where we illustrate the possibility of three HBpin molecules associating to form a trimeric species in liquid HBpin.

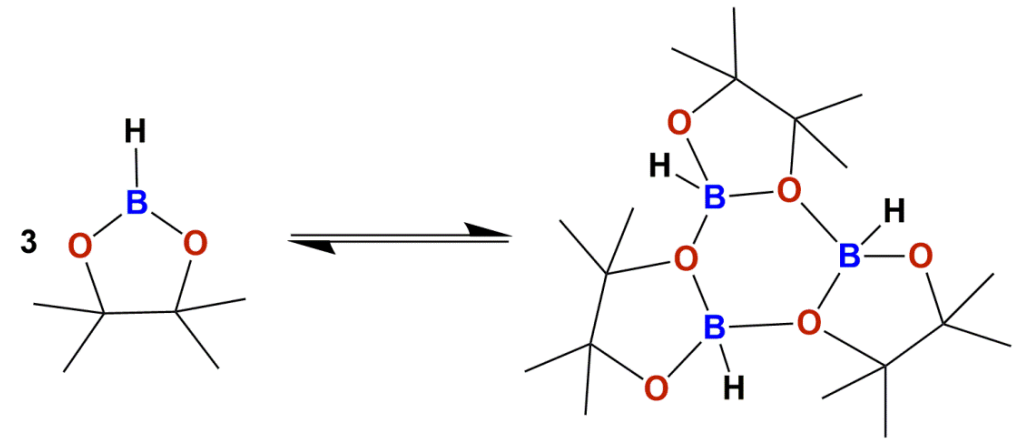

Monomer HBpin

Trimer HBpin

Figure S20. The possibility of monomer-trimer equilibria in liquid HBpin.

We have investigated this possibility with computational studies with DFT. Figure S21 shows the free energy profile for this process. The barrier for the formation of the trimer is quite low: $16.8 \mathrm{kcal} / \mathrm{mol}$, which indicates its feasibility, but the trimer lies $11.4 \mathrm{kcal} / \mathrm{mol}$ 
higher in energy in comparison to the trio of monomers shown in Figure S21 below. This indicates that the equilibrium between HBpin monomers and the trimer would lie significantly towards the side of the monomers. However, the low barrier suggests that such equilibria might still exist in liquid HBpin.

Furthermore, we have also conducted ab initio molecular dynamics (AIMD) simulations in order to investigate the possibility of capturing such equilibria. Since B-O bond forming and bond breaking processes are involved, which would require considerably long simulation times, we accelerated the process by conducting AIMD simulations at 1800 $\mathrm{K}$, which allowed us to observe the conversion of three monomers to the trimer and vice versa after only $10 \mathrm{ps}$ of simulation. Such an approach has been adopted in AIMD simulations before. ${ }^{19}$ Snapshots of the AIMD simulations after different timesteps, indicating the association of the monomers to yield the trimer, and its subsequent dissociation to the monomers again, are shown in Figure S22. A gif file movie.gif is also provided as ESI, showing the interconversion between the monomeric and the trimeric species. The corresponding dimeric species was not observed in the AIMD simulations, and this is probably due to the disfavouring steric strain that would be present in the four-membered dimer.

However, since the calculations indicate that the equilibrium would lie significantly towards the side of the monomers, the trimer represents a minor species in liquid HBpin. It is conceivable, nevertheless, that benzaldehyde could approach such a trimeric species rather than a monomer in liquid HBpin. In such a case, the only possibility would be the desired hydroboration reaction, as shown in the free energy profile in Figure $\mathrm{S} 21$, because access to the B-O bonds in HBpin would be cut off in the trimer. As Figure S21 shows, the interaction between benzaldehyde and HBpin would result in the formation of the desired hydroborated product, with the concomitant dissociation of two HBpin molecules from the trimer. The barrier for the process, however, was seen to be high: $41.0 \mathrm{kcal} / \mathrm{mol}$. Overall, the results therefore suggest that species like the HBpin trimer represent interesting, but minor players in hydroboration chemistry. 


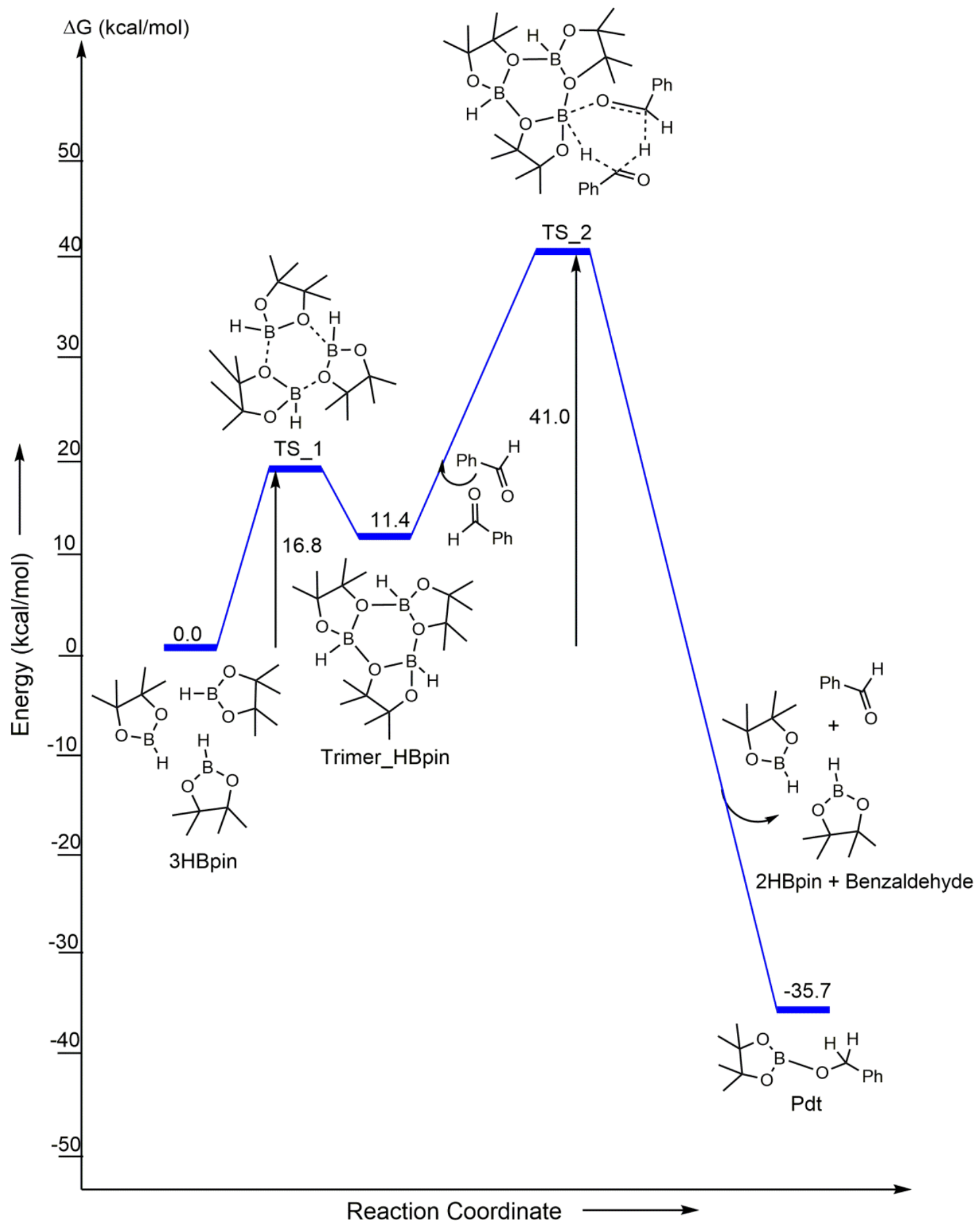

Figure S21. The free energy profile for the trimerization equilibrium of the HBpin monomer, and the subsequent hydroboration of the benzaldehyde with the HBpin trimer as the hydroborating agent, in the solvent free system (HBpin considered as solvent). The values (in $\mathrm{kcal} / \mathrm{mol}$ ) have been calculated at the PBE/TZVP level of theory. 


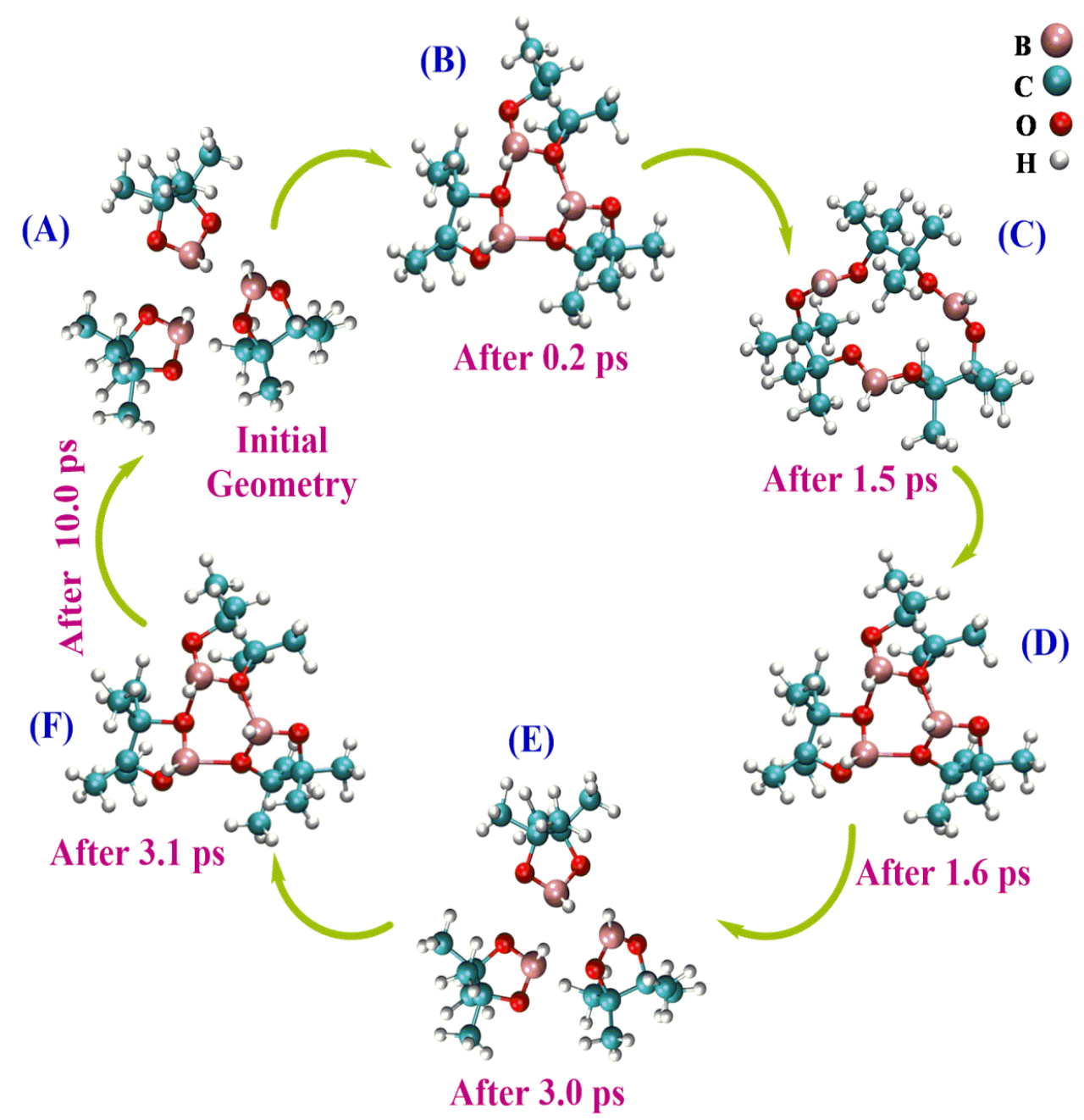

Figure S22. Snapshots indicating the state of the chemical system during the progress of $a b$ initio molecular dynamics (AIMD) simulations with time. It is seen that three HBpin molecules combine to form a trimer and then break, as the AIMD simulations progress in time.

General experimental information: All reactions were performed under an argon atmosphere using Schlenk techniques or inside a MBraun glove box. Pinacolborane (HBpin), TMSCN, benzaldehyde, and p-methoxyphenylacetylene were purchased from SigmaAldrich, and TCI and used without further purification. Benzene solvent was dried by SPS and further dried by molecular sieves before use. Benzene, toluene- $\mathrm{d}_{8}$, and chloroform were purchased from Sigma- Aldrich, and all were degassed by three freeze-pump-thaw cycles and stored over molecular sieves. ${ }^{1} \mathrm{H}$ spectra were recorded on Bruker $\mathrm{AV}-200 \mathrm{MHz}$ and referenced to the resonances of the internal standard with respect to the deuterated solvent used. 


\section{General catalytic procedure for the hydroboration of benzaldehydes:}

For a 1:1 stoichiometry reaction, benzaldehyde $(0.25 \mathrm{mmol})$, pinacolborane $(0.25$ mmol), with benzene $(1 \mathrm{~mL})$ were charged in a Schlenk tube inside the glove box. The reaction mixture was allowed to stir at room temperature. The progress of the reaction was monitored by ${ }^{1} \mathrm{H}$ NMR, which indicated the completion of the reaction by the disappearance of the aldehyde proton and the appearance of a new $\mathrm{CH}_{2}$ peak. Upon completion of the reaction, the solvent was removed using a high vacuum in a Schlenk line and mesitylene (0.25 mmol) as internal standard, was added while making the NMR in chloroform-d. The remaining reactions were also performed using the same procedure just by changing the stoichiometry of Pinacolborane in absence of external catalyst conditions for $12 \mathrm{~h}$ at room temperature in benzene solution. Product yields were determined by ${ }^{1} \mathrm{H}$ NMR integration relative to mesitylene as an internal standard.

Table S7. Optimization table for the hydroboration of benzaldehyde.

Reaction conditions: benzaldehyde $(0.25 \mathrm{mmol})$, HBpin $(0.25 \mathrm{mmol}$ for the stoichiometric ratio), $12 \mathrm{~h}$ reaction at room temperature in $1 \mathrm{~mL}$ benzene solvent. Yields are calculated with respect to mesitylene as an internal standard.

$63.0 \%$ product yield was observed when 4.0 equivalents of HBpin was treated with one equivalent of benzaldehyde. To identify the actual stoichiometry of HBpin needed to achieve the best yield, a series of reactions using 4.2, 4.4, 4.6, and 4.8 equivalent of HBpin was carried out and the quantitative product formation was observed for the reaction in the presence of 4.6 equivalents of HBpin.

\begin{tabular}{|c|c|c|c|}
\hline Entry & Substrate & Aldehyde: HBpin & $\begin{array}{c}\text { NMR Yield } \\
(\%)\end{array}$ \\
\hline 1. & $1: 1$ & 20 \\
\hline 2. & & $1: 2$ & 32 \\
\hline 3. & \\
\hline
\end{tabular}




\begin{tabular}{|c|c|c|}
\hline & $1: 4.0$ & 64 \\
\hline 5. & $1: 4.4$ & 78 \\
\hline 5. & & $1: 4.2$ \\
\hline
\end{tabular}

\section{General catalytic procedure for the hydroboration of alkynes:}

p-methoxyphenylacetylene $(0.25 \mathrm{mmol})$, pinacolborane $(0.25 \mathrm{mmol}$ for $1: 1$ reaction, or according to the ratio of reaction) were charged in a screw cap NMR tube with mesitylene as an internal standard $(0.25 \mathrm{mmol})$ in $0.6 \mathrm{~mL}$ benzene- $\mathrm{d}_{6}$ and heated at $100{ }^{\circ} \mathrm{C}$ for $12 \mathrm{~h}$. The progress of the reaction was monitored by ${ }^{1} \mathrm{H}$ NMR, which indicated the completion of the reaction by the disappearance of the alkyne $(\mathrm{RC} \equiv \mathrm{CH})$ proton and the appearance of new $\mathrm{C} H=\mathrm{C} H$ resonance.

\section{Table S8. Optimization table for the hydroboration of $p$-methoxyphenylacetylene.}

Reaction conditions: alkyne (0.25 mmol), HBpin ( $0.25 \mathrm{mmol}$ for stoichiometric ratio), $12 \mathrm{~h}$ reaction at $100{ }^{\circ} \mathrm{C}$ temperature in $1 \mathrm{~mL} \mathrm{C}_{6} \mathrm{D}_{6}$ solvent. Yields are calculated with respect to mesitylene as an internal standard.

The reaction was monitored by ${ }^{1} \mathrm{H}$ NMR spectroscopy and the yields were calculated based on the integration area of the product and starting material signals using mesitylene as an internal standard. The experiments indicated that a good yield (68.0\%) was obtained for the hydroborated product under these conditions.

\begin{tabular}{|c|c|c|c|c|}
\hline Entry & Substrate & Alkyne: HBpin & solvent & NMR Yield (\%) \\
\hline
\end{tabular}




\begin{tabular}{|c|c|c|c|c|}
\hline 1. & & $1: 1$ & Neat & 64 \\
\hline 2. & & $1: 1$ & Benzene- $\mathrm{d}_{6}$ & 5 \\
\hline 3 . & & $1: 2$ & Benzene- $d_{6}$ & 12 \\
\hline 4. & & $1: 3$ & Benzene- $d_{6}$ & 16 \\
\hline 5. & & $1: 5$ & Benzene- $d_{6}$ & 64 \\
\hline 6. & & $1: 8$ & Benzene- $\mathrm{d}_{6}$ & 68 \\
\hline
\end{tabular}

For the equimolar reaction under neat conditions, the corresponding vinyl boronate ester was formed with a $64.0 \%$ yield for the hydroboration of $p$-methoxyphenylacetylene (Table S8, Entry 1). However, there is a huge drop in yield in the presence of a solvent such as benzene. Only a trace amount $(\sim 5.0 \%)$ of product formation was achieved under similar reaction conditions (Entry 2). To verify the concentration dependency of the reaction in the presence of a solvent, a series of reactions with a gradually increased concentration of HBpin was carried out (Table S8, Entries 2-6). For the 1:5 and 1:8 reactions of HBpin and $p$ methoxyphenylacetylene, the corresponding product formation was observed with $64.0 \%$ and $68.0 \%$ yields.

These experiments provide further proof that hydroboration of different substrates with HBpin can proceed without the aid of external catalysts in solution.

\section{Analytical data of boronate esters of corresponding alkynes:}


(E)-2-(4-methoxystyryl)-4,4,5,5-tetramethyl-1,3,2-dioxaborolane : ${ }^{1} \mathrm{H}$ NMR (chloroform-

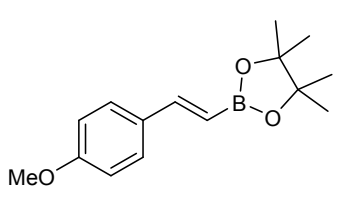

d, $200 \mathrm{MHz}, 298 \mathrm{~K}): \delta$ 7.54-7.45 (d, 1H, ArCH), 7.41-7.25 (m, 3H, $\operatorname{ArH})$, 6.76-6.71 (m, 1H, ArH), 6.17-6.07 (d, $1 \mathrm{H},{ }^{3} J_{\mathrm{H}-\mathrm{H}}=18.41 \mathrm{~Hz}$, $\mathrm{ArCHCH}), 3.47\left(\mathrm{~s}, 3 \mathrm{H}, \mathrm{OCH}_{3}\right), 1.20\left(\mathrm{~s}, 12 \mathrm{H}, \mathrm{CH}_{3}\right) \mathrm{ppm}$.

\section{General catalytic procedure for the cyanosilylation of benzaldehydes:}

Benzaldehyde (0.25 mmol), TMSCN (0.25 mmol for 1:1 reaction, or according to the ratio of reaction) were charged in a screw cap NMR tube inside the glove box. After the addition of $0.5 \mathrm{~mL}$ of benzene- $\mathrm{d}_{6}$, the reaction mixture was heated at $80{ }^{\circ} \mathrm{C}$ for $18 \mathrm{~h}$. Upon completion, mesitylene $(0.25 \mathrm{mmol})$ as an internal standard was added and submitted for NMR measurement. The progress of the reaction was monitored by ${ }^{1} \mathrm{H}$ NMR, which indicated the completion of the reaction by the disappearance of aldehyde ( $\mathrm{RCHO}$ ) proton and the appearance of a new RCHCN(OTMS) resonance.

Table S9. Optimization table of cyanosilylation of PhCHO.

\begin{tabular}{|l|l|l|l|l|l|}
\hline Entry & $\begin{array}{l}\text { Aldehyde: } \\
\text { TMSCN }\end{array}$ & $\begin{array}{l}\text { Temperature } \\
\left({ }^{\circ} \mathrm{C}\right)\end{array}$ & Solvent & NMR Yield \\
\hline & & $1: 5$ & \\
\hline
\end{tabular}




\section{Analytical data of cyanosilylated products of corresponding aldehydes:}

2-phenyl-2-((trimethylsilyl)oxy)acetonitrile : ${ }^{1} \mathrm{H}$ NMR (chloroform- $\mathrm{d}, 200$ TMS MHz, $298 \mathrm{~K}$ ): $\delta 7.35-7.27$ (m, 2H, ArH), 7.17-7.09 (m, 3H, ArH), 5.32 (s, 1H,<smiles>CCCC(C=N)CC</smiles>
$\left.\mathrm{CHOSi}\left(\mathrm{CH}_{3}\right)_{3}\right), 0.06\left(\mathrm{~s}, 9 \mathrm{H}, \mathrm{Si}\left(\mathrm{CH}_{3}\right)_{3}\right)$ ppm.

\section{Representative NMR Spectrum:}

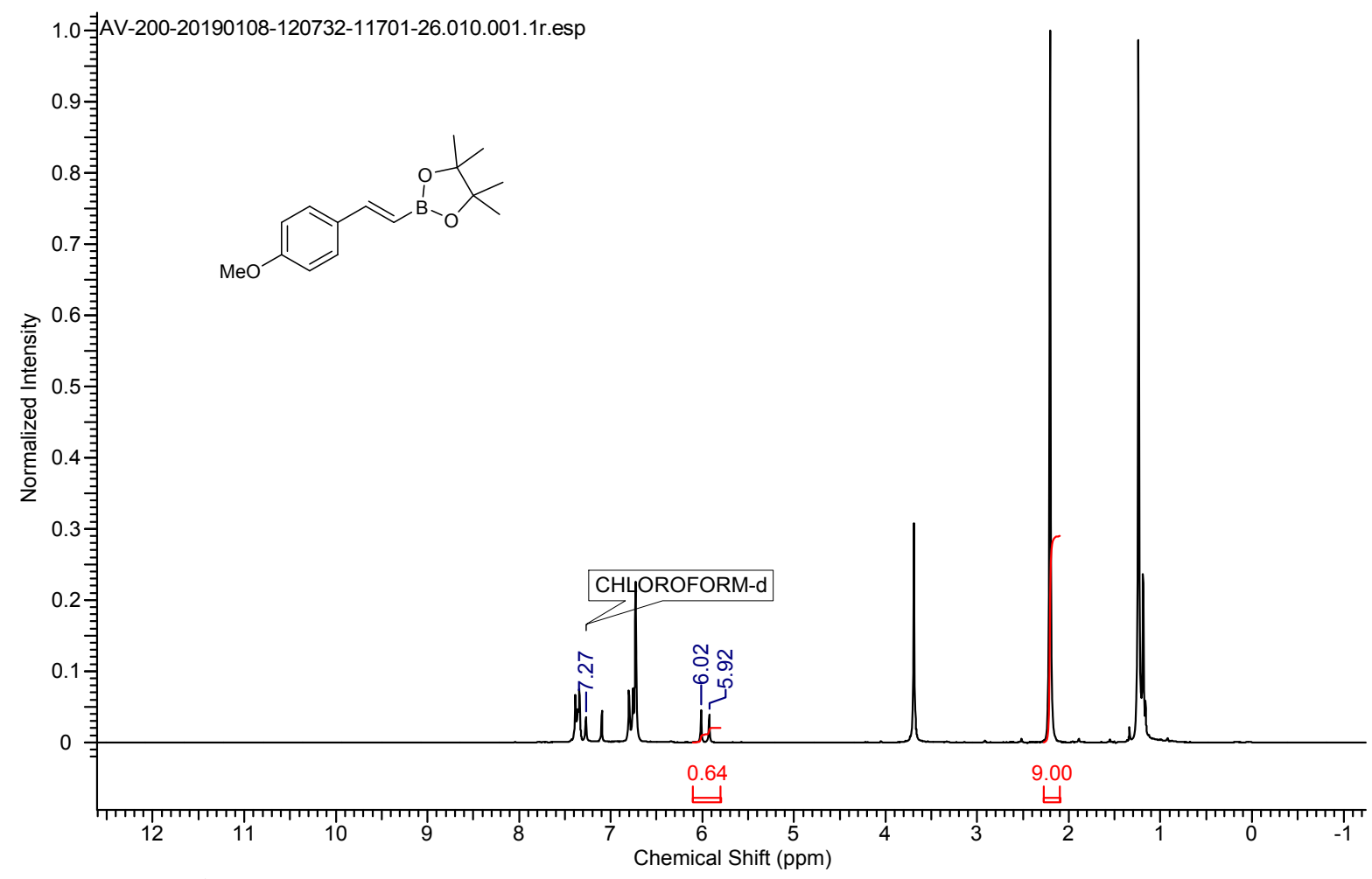

Figure S23. ${ }^{1} \mathrm{H}$ NMR spectrum of 1:1 reaction-without solvent (chloroform-d, $200 \mathrm{MHz}, 298$

$\mathrm{K})$ 


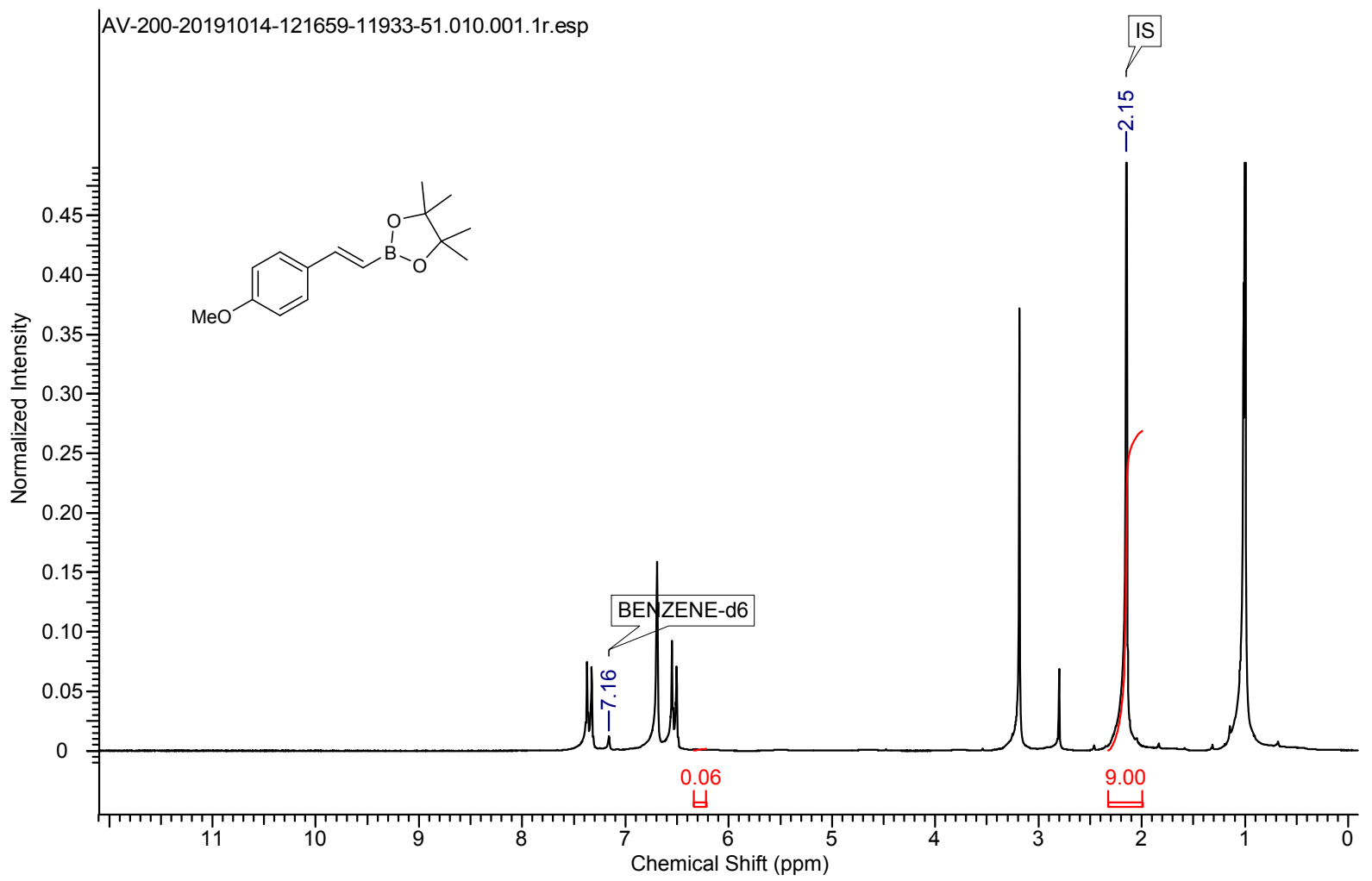

Figure S24. ${ }^{1} \mathrm{H}$ NMR spectrum of 1:1 reaction in benzene (benzene- $\mathrm{d}_{6}, 200 \mathrm{MHz}, 298 \mathrm{~K}$ )

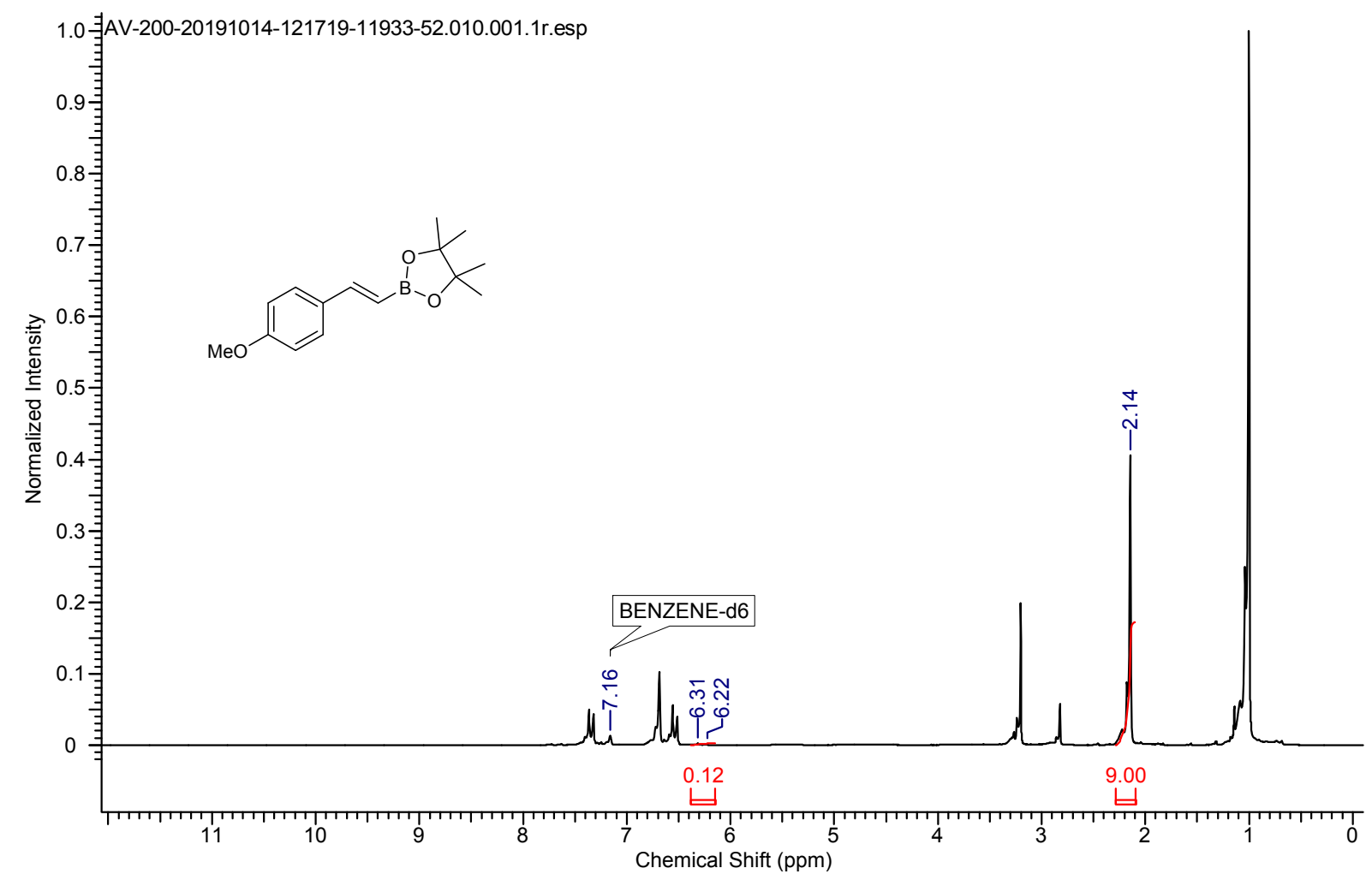

Figure S25. ${ }^{1} \mathrm{H}$ NMR spectrum of 1:2 reaction in benzene (benzene-d ${ }_{6} 200 \mathrm{MHz}, 298 \mathrm{~K}$ ) 


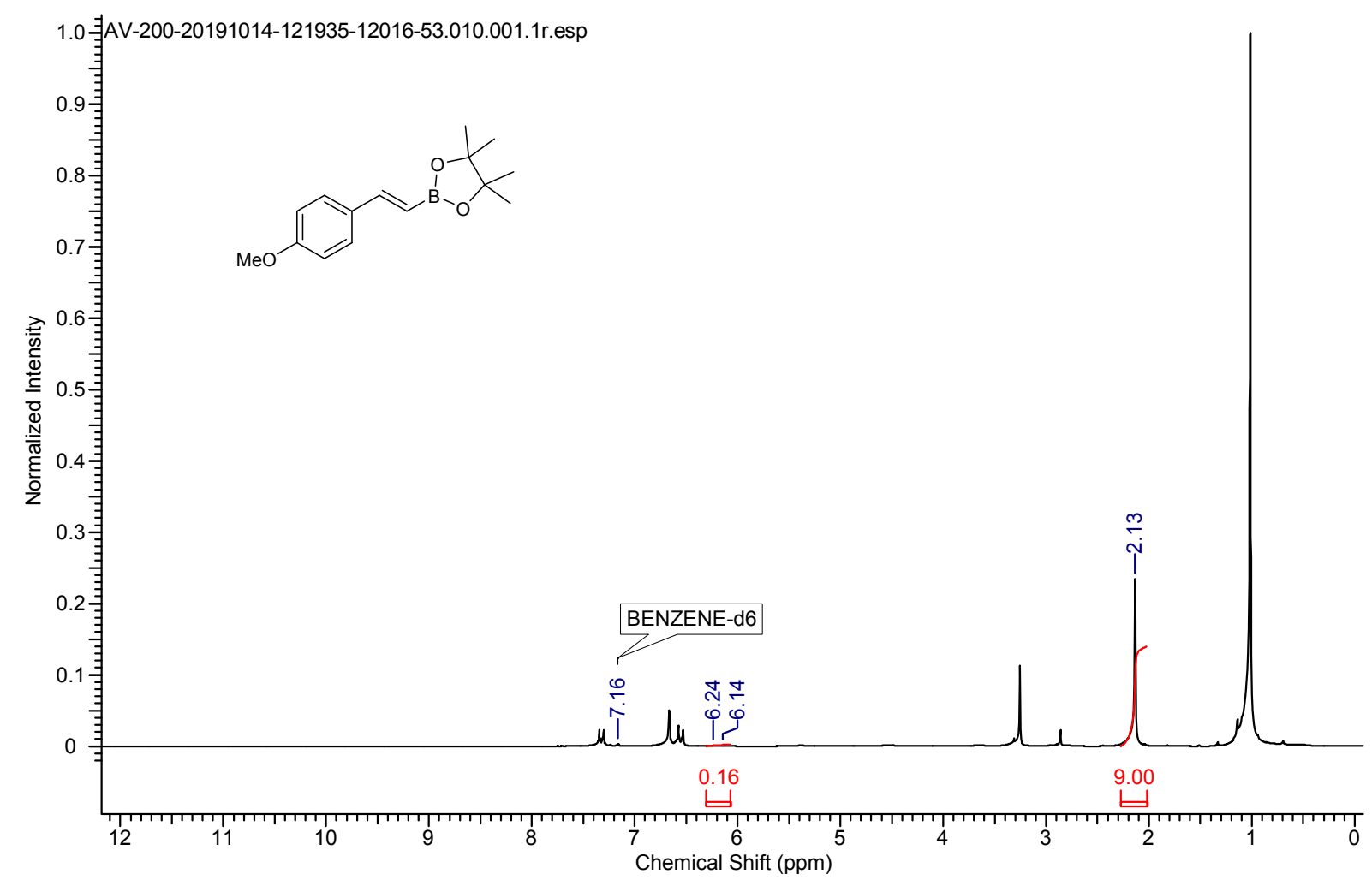

Figure S26. ${ }^{1} \mathrm{H}$ NMR spectrum of $1: 3$ reaction in benzene (benzene- $\mathrm{d}_{6}, 200 \mathrm{MHz}, 298 \mathrm{~K}$ )

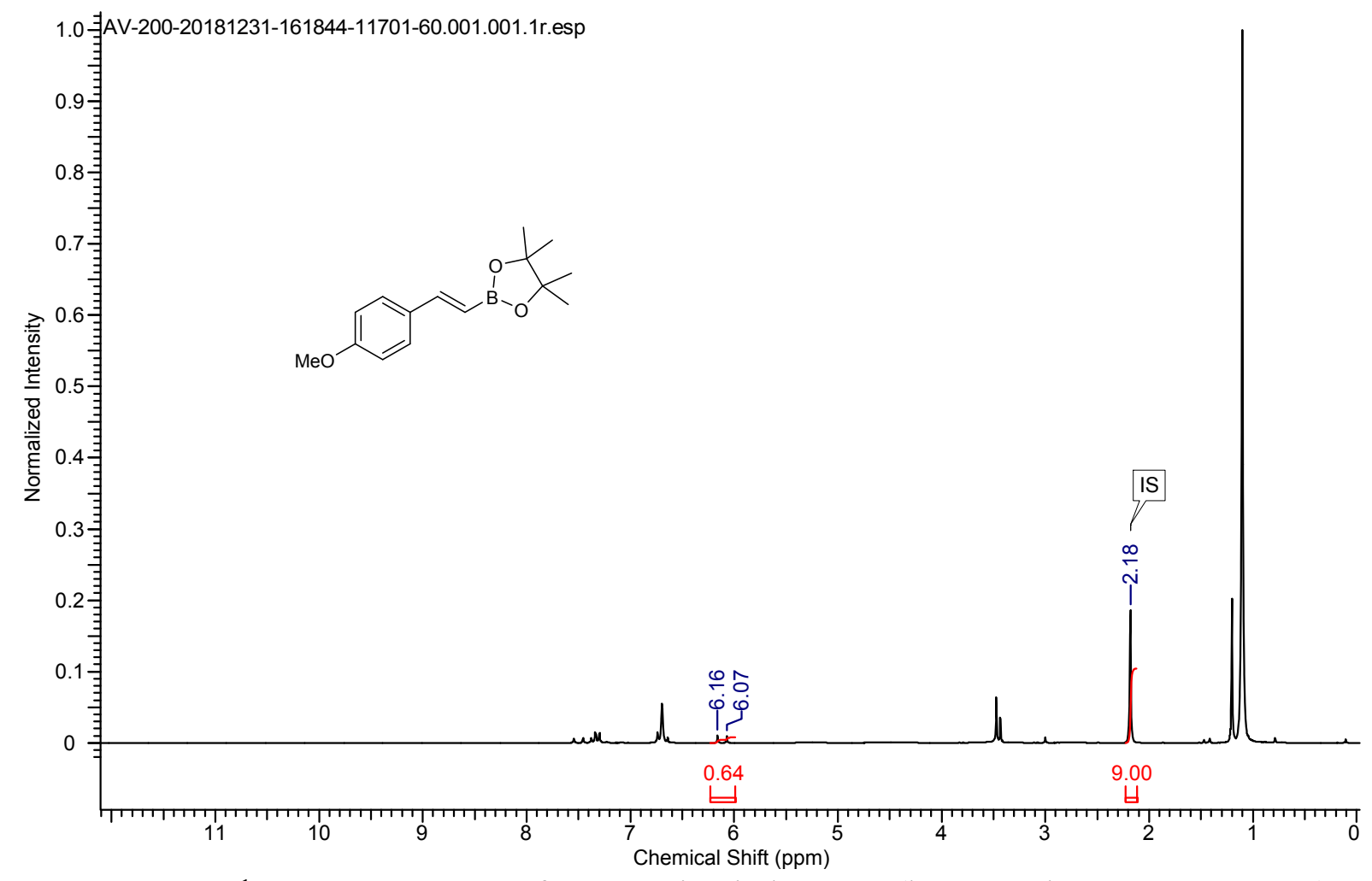

Figure S27. ${ }^{1} \mathrm{H}$ NMR spectrum of 1:5 reaction in benzene (benzene-d $\mathrm{d}_{6}, 200 \mathrm{MHz}, 298 \mathrm{~K}$ ) 


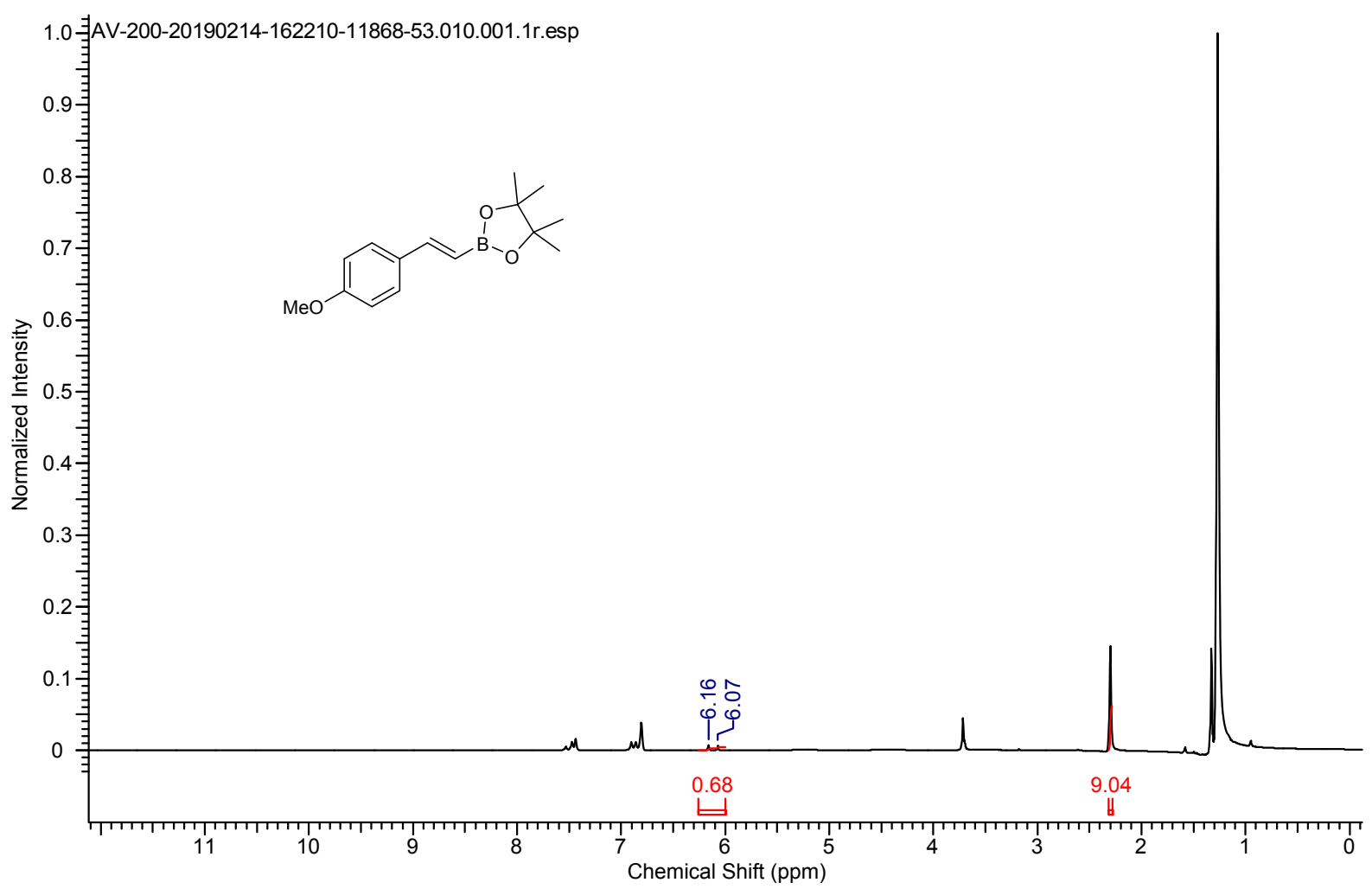

Figure S28. ${ }^{1} \mathrm{H}$ NMR spectrum of 1:8 reaction in benzene (benzene-d $\mathrm{d}_{6}, 200 \mathrm{MHz}, 298 \mathrm{~K}$ )

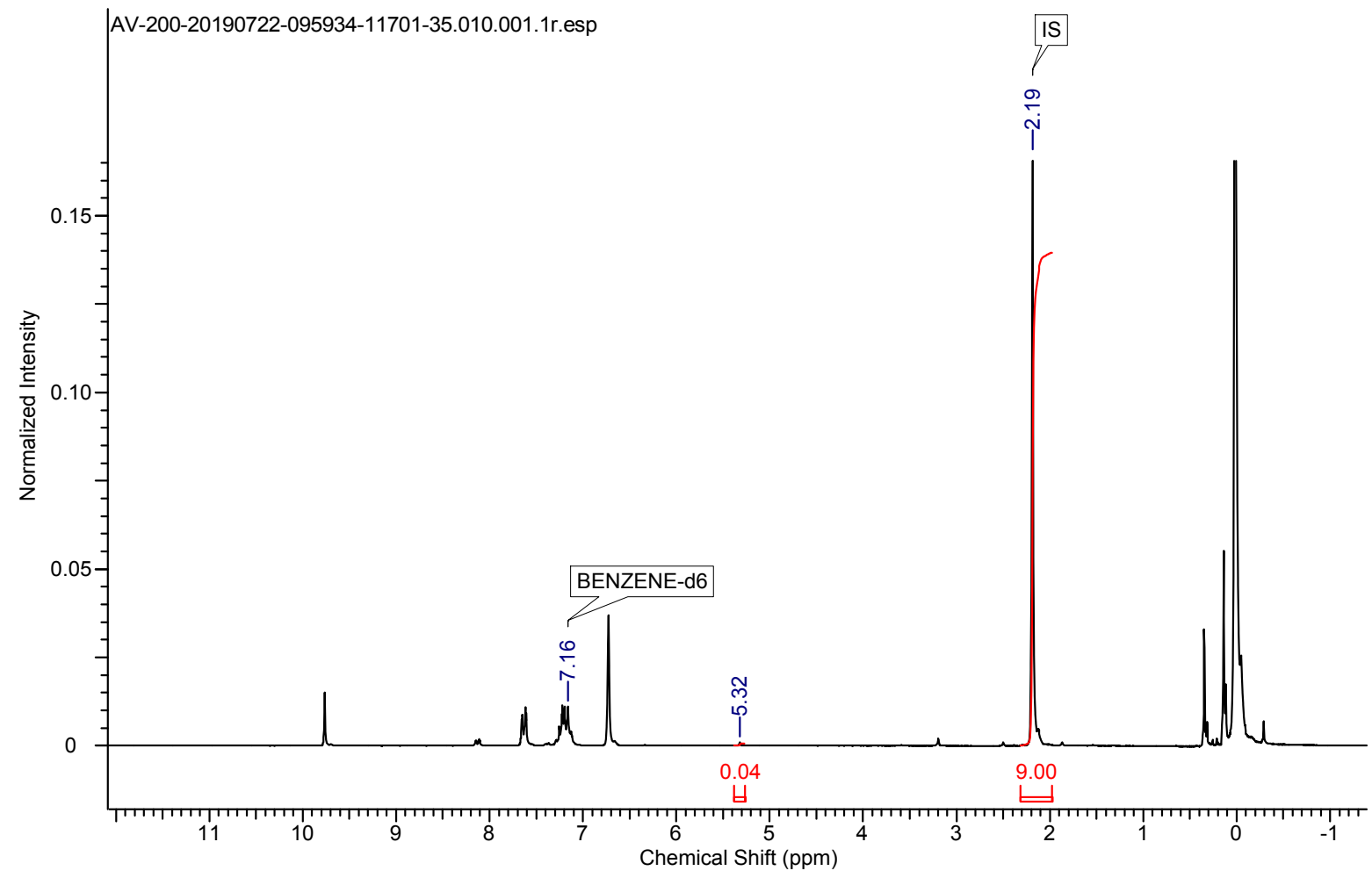

Figure S29. ${ }^{1} \mathrm{H}$ NMR spectrum of 1:5 cyanosilylation reaction at $\mathrm{rt}$ (benzene-d $\mathrm{d}_{6}, 200 \mathrm{MHz}$, $298 \mathrm{~K})$ 


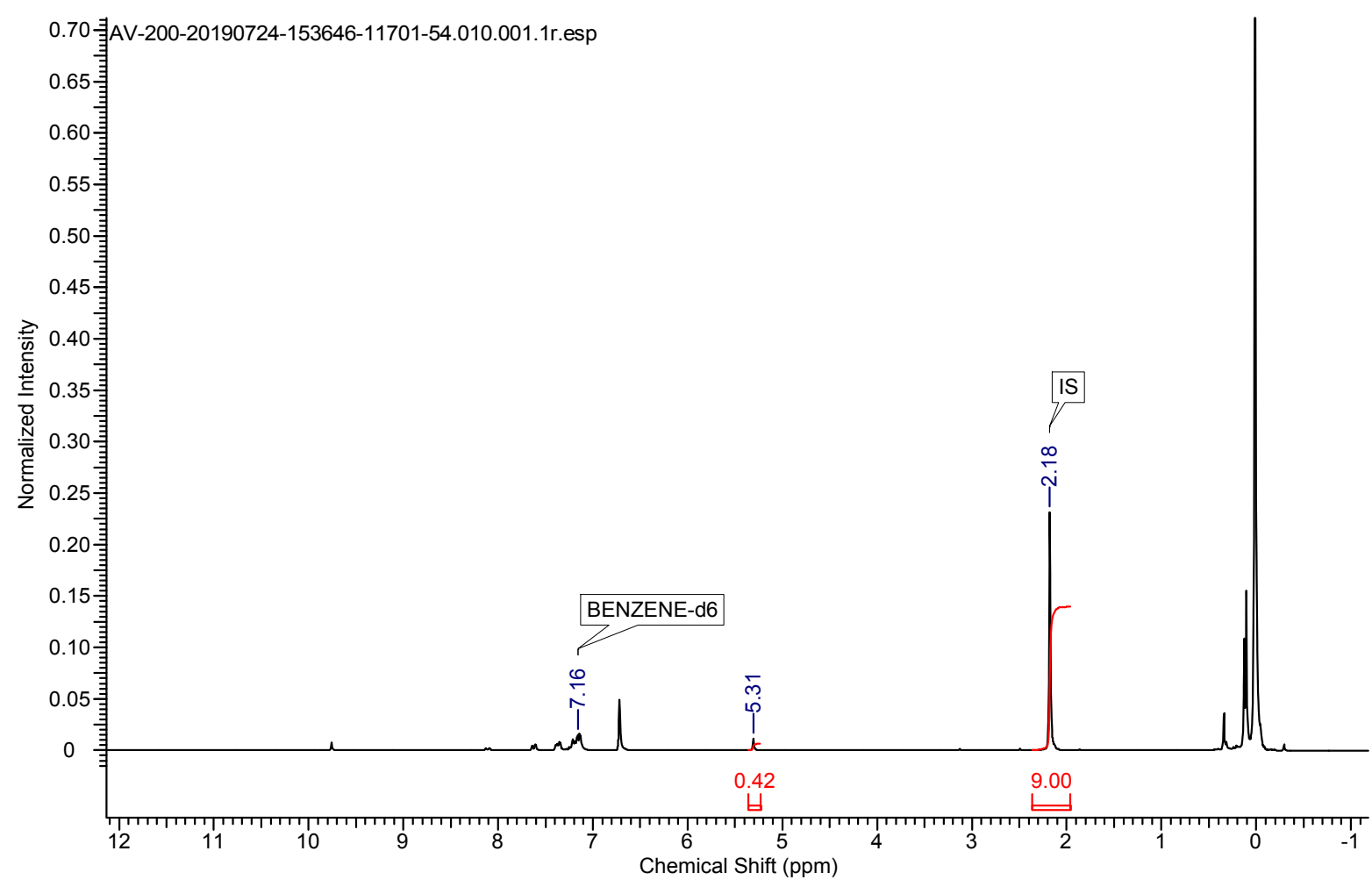

Figure S30. ${ }^{1} \mathrm{H}$ NMR spectrum of $1: 5$ cyanosilylation at $80{ }^{\circ} \mathrm{C}$ (benzene- $\mathrm{d}_{6,}, 200 \mathrm{MHz}, 298$ $\mathrm{K})$

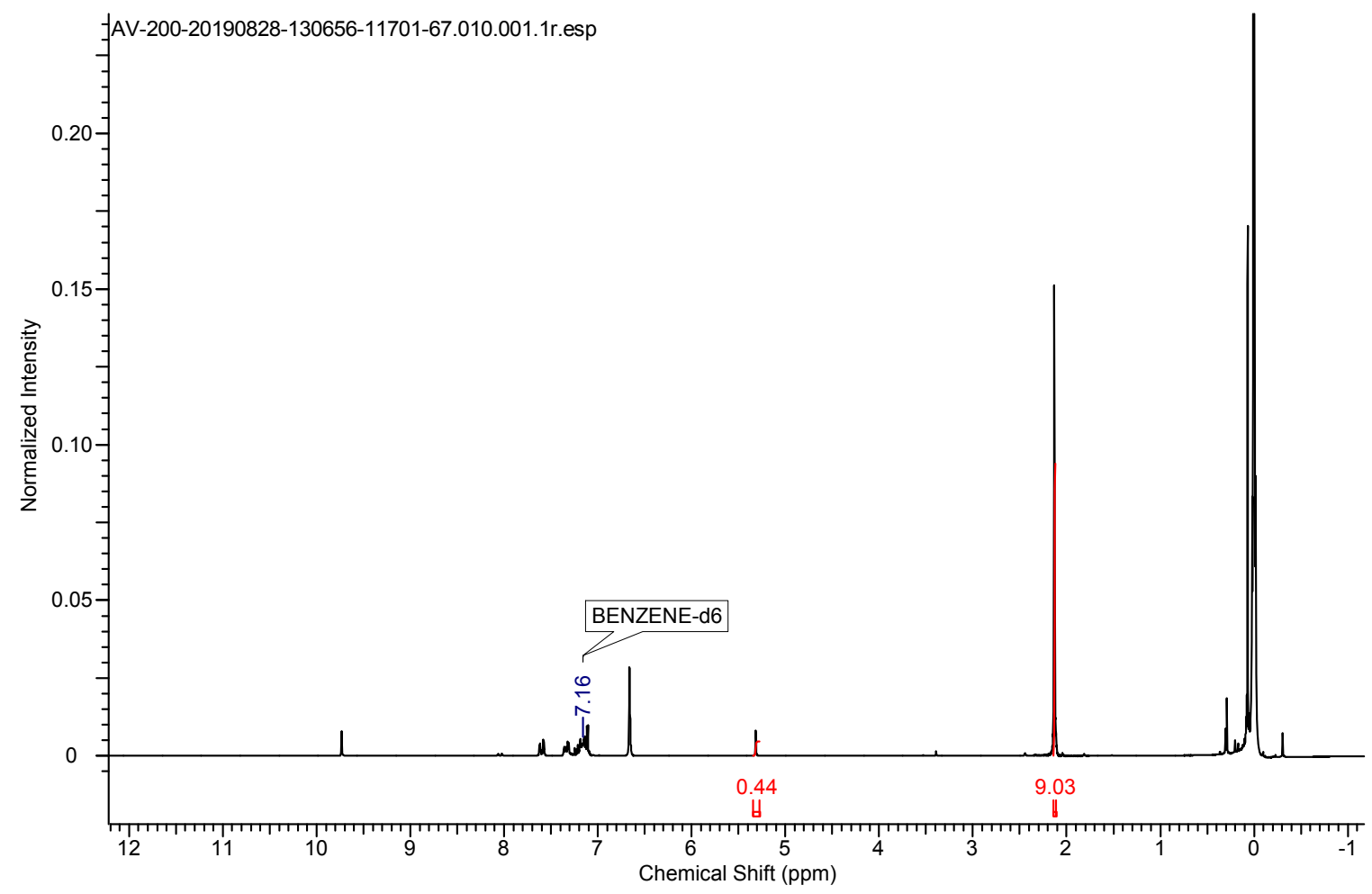

Figure S31. ${ }^{1} \mathrm{H}$ NMR spectrum of $1: 7$ cyanosilylation at $80{ }^{\circ} \mathrm{C}$ (benzene- $\mathrm{d}_{6,}, 200 \mathrm{MHz}, 298$ $\mathrm{K})$ 


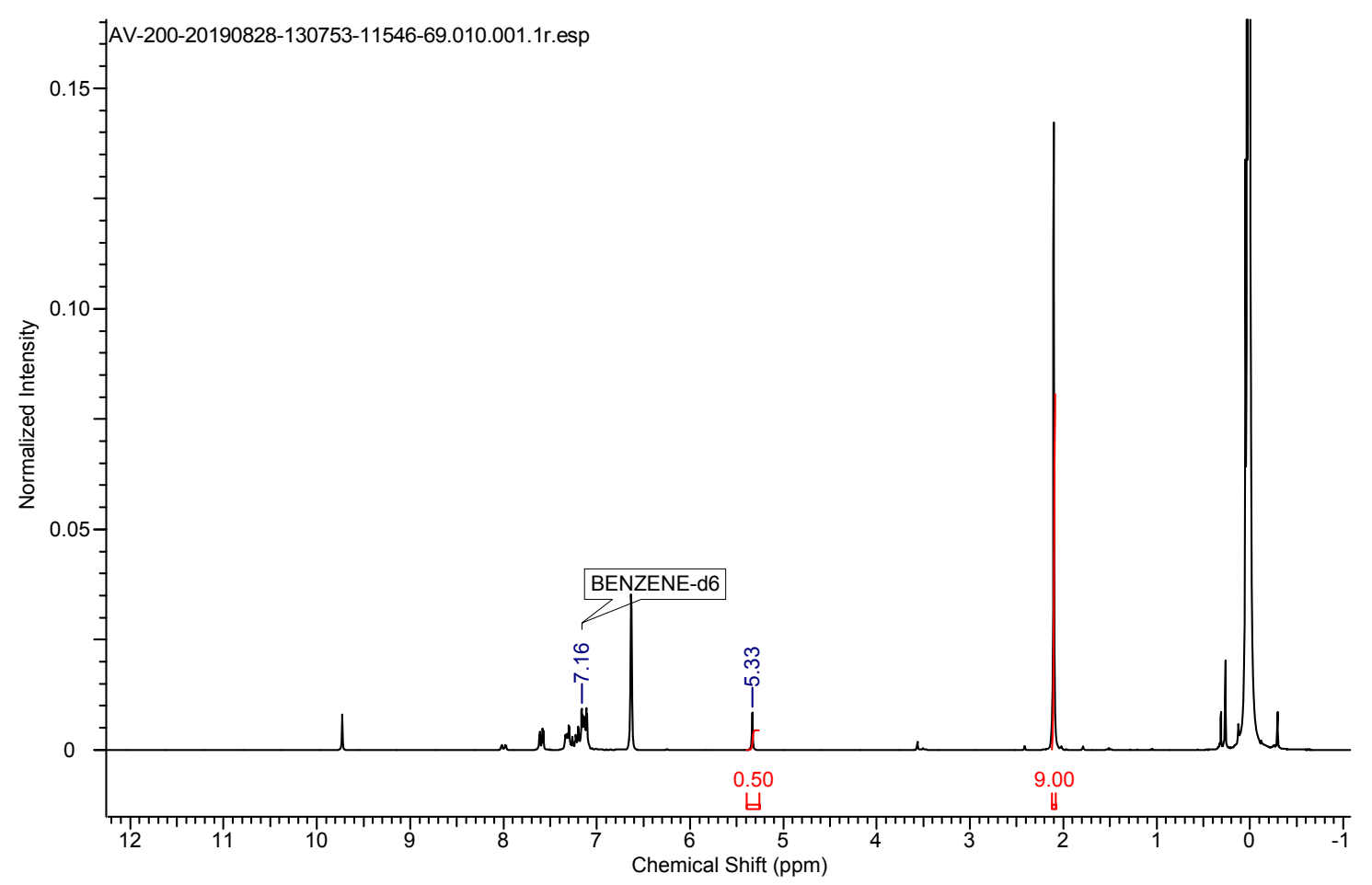

Figure S32. ${ }^{1} \mathrm{HNMR}$ spectrum of $1: 8$ cyanosilylation at $80{ }^{\circ} \mathrm{C}$ (benzene- $\mathrm{d}_{6}, 200 \mathrm{MHz}, 298 \mathrm{~K}$ )

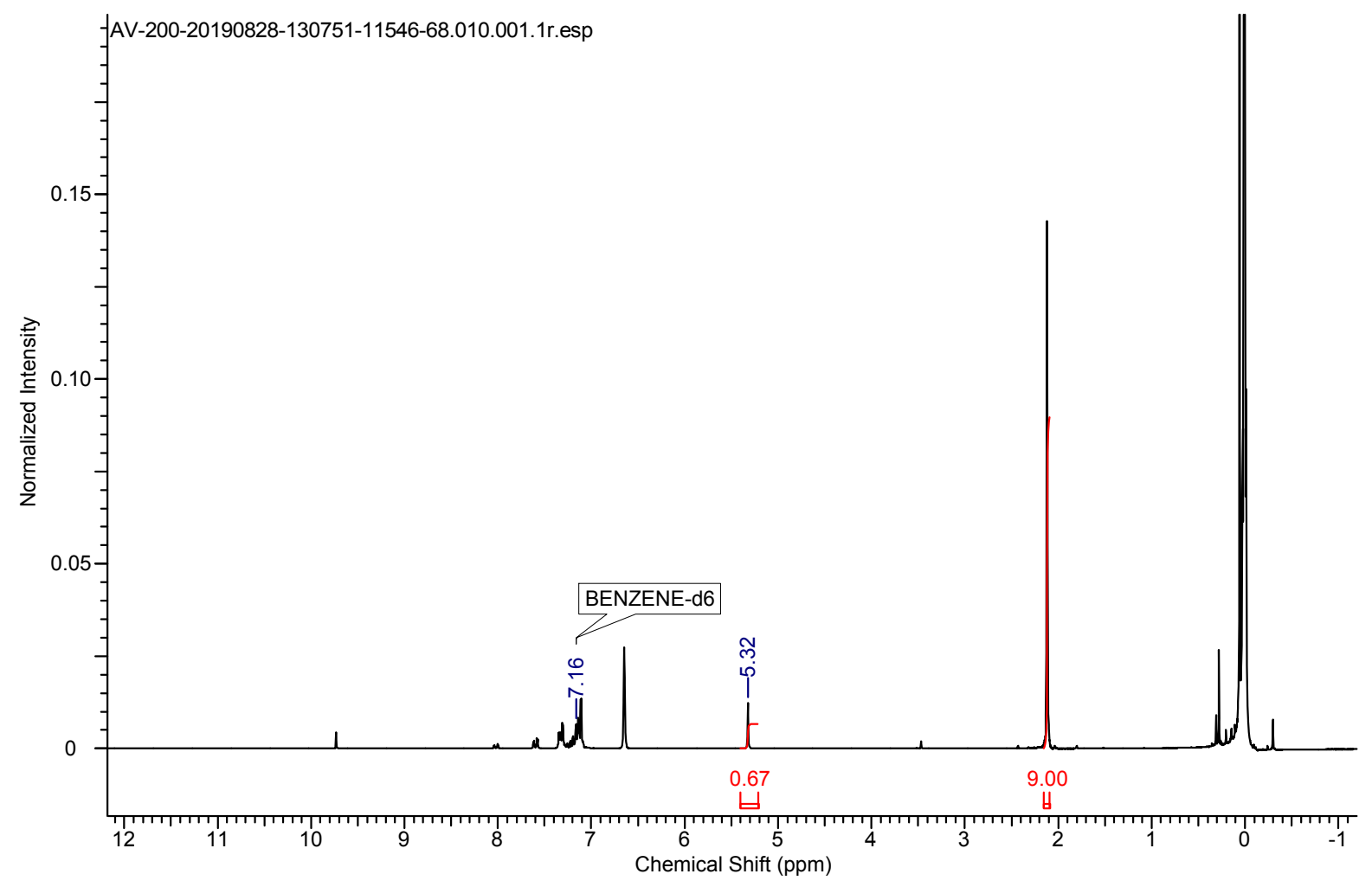

Figure S33. ${ }^{1} \mathrm{H}$ NMR spectrum of $1: 9$ cyanosilylation at $80{ }^{\circ} \mathrm{C}$ (benzene- $\mathrm{d}_{6}, 200 \mathrm{MHz}, 298$ $\mathrm{K})$ 


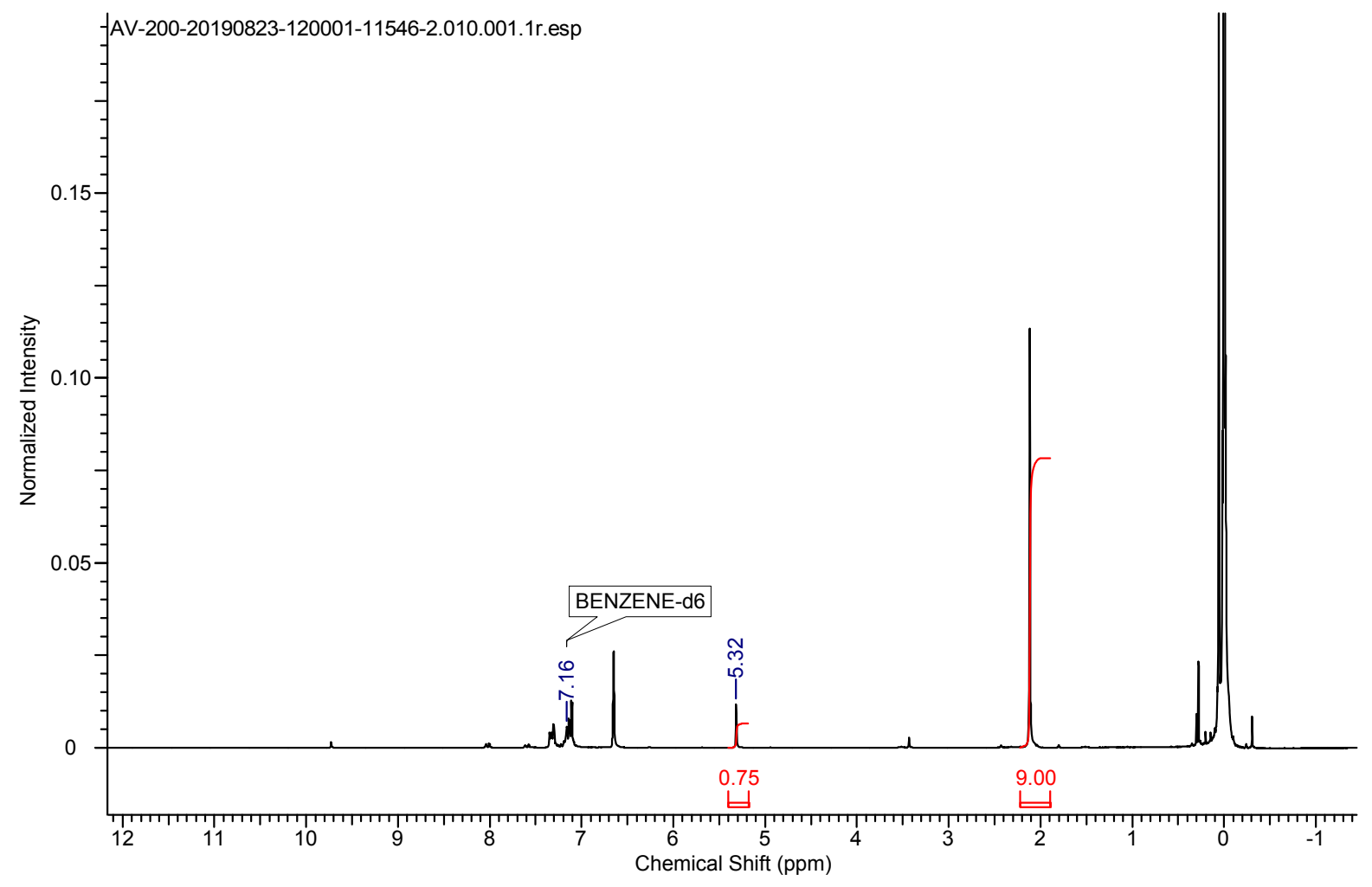

Figure S34. ${ }^{1} \mathrm{H}$ NMR spectrum of $1: 10$ cyanosilylation at $80{ }^{\circ} \mathrm{C}$ (benzene-d ${ }_{6}, 200 \mathrm{MHz}, 298$

$\mathrm{K})$

Table S10: The different terms determined in the calculation of the Gibbs free energy.

Here, E=Electronic Energy; $\mathrm{H}=$ Enthalpy, including zero point energy contributions; $\mathrm{Tr}=$ Translational Entropy; $\mathrm{Rt}=$ Rotational Entropy; $\mathrm{Vb}=$ Vibrational Entropy; $\mathrm{S}=$ Total Entropy; $\mathrm{T}=$ Temperature; $\mathrm{G}=$ Free Energy; $\# \mathrm{E}=\mathrm{Change}$ in Electronic Energy; $\# \mathrm{G}=\mathrm{Change}$ in Gibbs Free Energy

\begin{tabular}{|c|c|c|c|c|c|c|c|c|c|c|c|c|c|}
\hline & E & E & H & H & T & $\mathrm{Tr}$ & Rt & $\mathrm{Vb}$ & $S=T r+R t+V b$ & H-TS & $G=E+(H-T S)$ & $\# E$ & $\# G$ \\
\hline & (au) & $\mathrm{kcal} / \mathrm{mol}$ & {$[\mathrm{kJ} / \mathrm{mol})$} & (kcal/mol) & & (kcal/mol) & (kcal/mol) & [kcal $/ \mathrm{mol}]$ & (kcal/mol) & (kcal/mol) & (kcal/mol) & (kcal/mol) & (kcal/mol) \\
\hline HBpin & -411.4885 & -258209.06 & 509.46 & 121.8804 & 298.15 & 0.0288925 & 0.02853642 & 0.0229582 & 0.08038712 & 97.912962 & -258111.15 & & \\
\hline Benzyldehyde & -345.2693 & -216656.48 & 296.78 & 71 & 298.15 & 0.028333 & 0.02792038 & 0.0124261 & 0.06867951 & 50.523205 & -216605.95 & & \\
\hline ts_-1 & -756.7257 & -474845.4 & 808.8 & 193.4928 & 298.15 & 0.0306966 & 0.03249098 & 0.0479159 & 0.11110354 & 160.3673 & -474685.03 & 20.1383043 & 32.0694419 \\
\hline int_1 & -756.7263 & -474845.78 & 812.19 & 194.3038 & 298.15 & 0.0306966 & 0.03243136 & 0.0502852 & 0.11341321 & 160.48968 & -474685.29 & 19.7544733 & 31.8079848 \\
\hline ts_ 2 & -756.7263 & -474845.78 & 809.98 & 193.7751 & 298.15 & 0.0306966 & 0.03243136 & 0.0465884 & 0.10971642 & 161.06317 & -474684.72 & 19.7591388 & 32.3861413 \\
\hline int_2 & -756.751 & -474861.22 & 815.58 & 195.1148 & 298.15 & 0.0306966 & 0.03253072 & 0.0514173 & 0.11464467 & 160.93352 & -474700.29 & 4.31444292 & 16.8117997 \\
\hline ts_ 3 & -1101.985 & -691495.69 & 1110.77 & 265.7344 & 298.15 & 0.0315379 & 0.03553141 & 0.0813413 & 0.14841061 & 221.48583 & -691274.21 & 26.3229437 & 48.8494003 \\
\hline int_3 & -1102.079 & -691554.41 & 1126.39 & 269.4713 & 298.15 & 0.0315379 & 0.03485576 & 0.0828628 & 0.14925648 & 224.97047 & -691329.44 & -32.394327 & -6.38322445 \\
\hline ts_4 & -1102.055 & -691539.29 & 1118.02 & 267.4689 & 298.15 & 0.0315379 & 0.03541218 & 0.0841452 & 0.15109536 & 222.41982 & -691316.87 & 15.1200604 & 12.5694037 \\
\hline product & -756.8196 & -474904.3 & 820.52 & 196.2967 & 298.15 & 0.0320087 & 0.03302752 & 0.0554706 & 0.12050677 & 160.36756 & -474743.93 & -38.758029 & -26.826638 \\
\hline
\end{tabular}


S10(b) - Calculation for Figure S1

\begin{tabular}{|c|c|c|c|c|c|c|c|c|c|c|c|c|c|}
\hline & $\underset{\text { (au) }}{E}$ & $\begin{array}{c}E \\
\mathrm{kcal} / \mathrm{mol}\end{array}$ & $\stackrel{\mathrm{H}}{\mathrm{H} / \mathrm{mol})}$ & $\underset{(\mathrm{kcal} / \mathrm{mol})}{\mathrm{H}}$ & $\begin{array}{ll}\mathrm{T} \\
\mathrm{s}\end{array}$ & $\begin{array}{c}\mathrm{Tr} \\
(\mathrm{kcal} / \mathrm{mol})\end{array}$ & $\begin{array}{c}\mathrm{Rt} \\
\text { (kcal/mol) }\end{array}$ & $\begin{array}{c}\mathrm{Vb} \\
\text { (kcal/mol) }\end{array}$ & $\left.\begin{array}{c}S=T r+R t+V b \\
(k c a l / m o l\end{array}\right)$ & $\begin{array}{c}\text { H-TS } \\
\text { (kcal/mol) }\end{array}$ & $\begin{array}{l}\mathrm{G}=\mathrm{E}+(\mathrm{H}-\mathrm{TS}) \\
(\mathrm{kcal} / \mathrm{mol})\end{array}$ & $\begin{array}{c}\# E \\
\text { (kcal/mol) }\end{array}$ & $\begin{array}{c}\# G \\
(\mathrm{kcal} / \mathrm{mol})\end{array}$ \\
\hline HBpin & -411.4888 & -258209.2 & 509.43 & 121.8732 & 298.15 & $2.78 \mathrm{E}-02$ & $2.85 E-02$ & $2.29 \mathrm{E}-02$ & 0.079186 & 98.26391 & -258111 & & \\
\hline nzyldehyde & -345.2696 & -216656.7 & 296.83 & 71.01196 & 298.15 & $2.72 \mathrm{E}-02$ & $2.79 \mathrm{E}-02$ & $1.24 \mathrm{E}-02$ & 0.067476 & 50.8941 & -216605.8 & & \\
\hline ts_1 & -756.7263 & -474845.7 & 808.79 & 193.4904 & 298.15 & $2.96 \mathrm{E}-02$ & $3.25 \mathrm{E}-02$ & $4.78 \mathrm{E}-02$ & 0.109871 & 160.7325 & -474685 & 20.19206 & 31.76655 \\
\hline int_1 & -756.7269 & -474846.1 & 812.15 & 194.2943 & 298.15 & $2.96 \mathrm{E}-02$ & $3.24 \mathrm{E}-02$ & $5.04 \mathrm{E}-02$ & 0.112389 & 160.7854 & -474685.3 & 19.83288 & 31.46026 \\
\hline ts_2 & -756.7268 & -474846.1 & 809.97 & 193.7727 & 298.15 & $2.96 \mathrm{E}-02$ & $3.24 \mathrm{E}-02$ & $4.66 \mathrm{E}-02$ & 0.108638 & 161.3822 & -474684.7 & 19.85569 & 32.07987 \\
\hline int_2 & -756.7513 & -474861.4 & 815.52 & 195.1005 & 298.15 & $2.96 \mathrm{E}-02$ & $3.25 \mathrm{E}-02$ & $5.15 E-02$ & 0.113621 & 161.2243 & -474700.2 & 4.485987 & \\
\hline ts $s_{-}$ & -1101.986 & -691496.1 & 1110.78 & 265.7368 & 298.15 & 3.07E-02 & $3.55 \mathrm{E}-02$ & $8.13 \mathrm{E}-02$ & 0.147507 & 221.7577 & -691274.4 & 26.51161 & 48.21724 \\
\hline int_-3 & -1102.079 & -691554.7 & 1126.35 & 269.4617 & 298.15 & $3.07 E-02$ & $3.49 \mathrm{E}-02$ & $8.30 \mathrm{E}-02$ & 0.148549 & 225.1719 & -691329.6 & -32.12016 & -7.000406 \\
\hline ts_4 & -1102.055 & -691539.7 & 1117.96 & 267.4545 & 298.15 & $3.07 E-02$ & $3.54 \mathrm{E}-02$ & $8.41 \mathrm{E}-02$ & 0.150212 & 222.669 & -691317.1 & 15.02048 & 12.51761 \\
\hline product & -756.82 & 9904.6 & 0.12 & 196.2943 & 298.15 & $2.96 \mathrm{E}-02$ & $3.30 \mathrm{E}-02$ & $5.54 \mathrm{E}-02$ & 0.117976 & 161.1197 & -474743.5 & -38.66196 & -26.70027 \\
\hline
\end{tabular}

S10(c) - Calculation for Figure 5 and S2

\begin{tabular}{|c|c|c|c|c|c|c|c|c|c|c|c|c|c|}
\hline & $\begin{array}{c}E \\
\text { (au) }\end{array}$ & $\begin{array}{c}E \\
\mathrm{kcal} / \mathrm{mol}\end{array}$ & $\stackrel{\stackrel{H}{(k J / m o l})}{ }$ & $\begin{array}{c}\mathrm{H} \\
(\text { kcal } / \mathrm{mol})\end{array}$ & $\begin{array}{llll} & \end{array}$ & $\begin{array}{c}\mathrm{Tr} \\
(\mathrm{kcal} / \mathrm{mol})\end{array}$ & $\begin{array}{c}\mathrm{Rt} \\
\text { (kcal/mol) }\end{array}$ & $\begin{array}{c}\mathrm{Vb} \\
{[\mathrm{kcal} / \mathrm{mol})}\end{array}$ & $\begin{array}{l}\mathrm{s}=\mathrm{Tr}+\mathrm{Rt}+\mathrm{Vb} \\
(\mathrm{kcal} / \mathrm{mol})\end{array}$ & $\begin{array}{c}\mathrm{H}-\mathrm{TS} \\
\text { (kcal/mol) }\end{array}$ & $\begin{array}{l}\mathrm{G}=\mathrm{E}+(\mathrm{H}-\mathrm{TS}) \\
(\mathrm{kcal} / \mathrm{mol})\end{array}$ & $\begin{array}{c}\text { \#E } \\
(\mathrm{kcal} / \mathrm{mol})\end{array}$ & $\begin{array}{c}\# \mathrm{G} \\
{[\mathrm{kcal} / \mathrm{mol})}\end{array}$ \\
\hline HBpin & 411.4888 & -258209.2 & 509.43 & 121.8732 & 298.15 & 0.02776 & 0.028536 & 0.0228895 & 0.079186 & 98.26391 & -258111 & & \\
\hline benzyldehyde & 345.2696 & -216656.7 & 296.83 & 71.01196 & 298.15 & 0.027201 & 0.02792 & 0.0123547 & 0.067476 & 50.8941 & -216605.8 & & \\
\hline 2_HBpin & 322.9809 & -516420.5 & 1023.96 & 244.9665 & 298.15 & 0.029831 & 0.033962 & 0.0728354 & 0.136628 & 204.2309 & -516216.3 & -2.029131 & 5.673972 \\
\hline 4_mem_ts (in red) & -756.719 & -474841.2 & 803.99 & 192.3421 & 298.15 & 0.029564 & 0.033187 & 0.0538919 & 0.116643 & 157.5651 & -474683.6 & 24.73621 & 33.14333 \\
\hline 6_mem_ts (Figure 5) & -1168.236 & -733068.2 & 1318.52 & 315.4354 & 298.15 & 0.030867 & 0.035849 & 0.0985616 & 0.165278 & 266.1577 & -732802 & 7.00419 & 25.74002 \\
\hline Product' & -1168.318 & -733119.6 & 1335.24 & 319.4354 & 298.15 & 0.030867 & 0.035671 & 0.1094044 & 0.175942 & 266.9783 & -732852.6 & -42.3583 & -30.50505 \\
\hline
\end{tabular}

S10(d) - Calculation for Figure S3 and S4

\begin{tabular}{|c|c|c|c|c|c|c|c|c|c|c|c|c|c|}
\hline & $\begin{array}{c}E \\
\text { (au) }\end{array}$ & $\begin{array}{c}E \\
\mathrm{kcal} / \mathrm{mol}\end{array}$ & $\begin{array}{c}\mathrm{H} \\
{[\mathrm{kJ} / \mathrm{mol})}\end{array}$ & $\begin{array}{c}\mathrm{H} \\
\text { (kcal/mol) }\end{array}$ & T & $\begin{array}{c}\operatorname{Tr} \\
\text { (kcal//mol) }\end{array}$ & $\begin{array}{c}\mathrm{Rt} \\
(\mathrm{kcal} / \mathrm{mol})\end{array}$ & $\begin{array}{c}\mathrm{Vb} \\
\text { (kcal/mol) }\end{array}$ & $\begin{array}{l}S=T r+R t+V b \\
(k c a l / m o l)\end{array}$ & $\begin{array}{c}\text { H-TS } \\
\text { (kcal/mol) }\end{array}$ & $\begin{array}{l}\mathrm{G}=\mathrm{E}+(\mathrm{H}-\mathrm{TS}) \\
(\mathrm{kcal} / \mathrm{mol})\end{array}$ & $\begin{array}{c}\# E \\
{[\text { kcal } / \mathrm{mol})}\end{array}$ & $\begin{array}{c}\# G \\
\text { [kcal } / \mathrm{mol})\end{array}$ \\
\hline HBpin & -411.4885 & -258209.1 & 509.46 & 121.8804 & 298.15 & 0.028892 & 0.028536 & 0.0229582 & 0.080387 & 97.91296 & -258111.1 & & \\
\hline benzyldehyde & -345.2693 & -216656.5 & 296.78 & 71 & 298.15 & 0.028333 & 0.02792 & 0.0124261 & 0.06868 & 50.5232 & -216606 & & \\
\hline 2_HBpin & -822.9809 & -516420.5 & 1023.99 & 244.9737 & 298.15 & 0.030963 & 0.033962 & 0.0793244 & 0.144249 & 201.9658 & -516218.5 & -2.387842 & 3.752023 \\
\hline 4_mem_ts (in red) & -756.7179 & -474840.5 & 804.14 & 192.378 & 298.15 & 0.032009 & 0.033107 & 0.0563365 & 0.121452 & 156.167 & -474684.3 & 25.06658 & 32.79743 \\
\hline 6_mem_ts (Figure S3) & -1168.234 & -733067.1 & 1318.21 & 315.3612 & 298.15 & 0.031459 & 0.035869 & 0.100498 & 0.167826 & 265.3239 & -732801.7 & 7.529418 & 26.50424 \\
\hline Product & -756.8196 & -474904.3 & 820.52 & 196.2967 & 298.15 & 0.032009 & 0.033028 & 0.0554706 & 0.120507 & 160.3676 & -474743.9 & -38.75803 & -26.82664 \\
\hline Product' & -1168.317 & -733119.1 & 1335.31 & 319.4522 & 298.15 & 0.031459 & 0.035671 & 0.1094875 & 0.176617 & 266.7939 & -732852.3 & -42.12781 & -27.8229 \\
\hline
\end{tabular}

S10(e) - Calculation for Figure 6 and 7

\begin{tabular}{|c|c|c|c|c|c|c|c|c|c|c|c|c|c|}
\hline & $\begin{array}{c}\mathrm{E} \\
\text { (au) }\end{array}$ & $\begin{array}{c}E \\
\mathrm{kcal} / \mathrm{mol}\end{array}$ & $\begin{array}{c}\mathrm{H} \\
{[\mathrm{kJ} / \mathrm{mol})}\end{array}$ & $\begin{array}{c}\mathrm{H} \\
{[\mathrm{kcal} / \mathrm{mol})}\end{array}$ & $T$ & $\begin{array}{c}\mathrm{Tr} \\
\text { (kcal/mol) }\end{array}$ & $\begin{array}{c}\text { Rt } \\
\text { (kcal/mol) }\end{array}$ & $\begin{array}{c}\mathrm{Vb} \\
\text { (kcal/mol) }\end{array}$ & $\begin{array}{l}S=T r+R t+V b \\
(k c a l / m o l)\end{array}$ & $\begin{array}{c}\text { H-TS } \\
\text { (kcal/mol) }\end{array}$ & $\begin{array}{l}\mathrm{G}=\mathrm{E}+(\mathrm{H}-\mathrm{TS}) \\
(\mathrm{kcal} / \mathrm{mol})\end{array}$ & $\begin{array}{l}\text { \#E } \\
(\mathrm{kcal} / \mathrm{mol})\end{array}$ & $\begin{array}{c}\# \mathrm{G} \\
(\mathrm{kcal} / \mathrm{mol})\end{array}$ \\
\hline HBpin & -411.4885 & -258209.1 & 523.93 & 125.3421 & 373.15 & 0.02889 & 0.029212 & 0.0313622 & 0.089464 & 91.95848 & -258117.1 & & \\
\hline 2_HBpin & -822.9804 & -516420.2 & 1054.2 & 252.201 & 373.15 & 0.030166 & 0.034637 & 0.0989005 & 0.163703 & 191.115 & -516229.1 & -2.051786 & 5.146276 \\
\hline 4_mem_ts & -833.9781 & -523321.2 & 919.14 & 219.89 & 373.15 & 0.03101 & 0.034796 & 0.0846025 & 0.150408 & 163.765 & -523157.5 & 29.43675 & 39.6862 \\
\hline Product & -834.1062 & -523401.6 & 935.98 & 223.9187 & 373.15 & 0.03101 & 0.034975 & 0.0828807 & 0.148866 & 168.3695 & -523233.3 & -50.96595 & -36.11202 \\
\hline Product' & -1245.604 & -781616.8 & 1466.51 & 350.8397 & 373.15 & 0.032205 & 0.037141 & 0.1498895 & 0.219235 & 269.032 & -781347.8 & -55.02106 & -38.66116 \\
\hline
\end{tabular}




\begin{tabular}{|c|c|c|c|c|c|c|c|c|c|c|c|c|c|}
\hline & $\begin{array}{c}\text { E } \\
\text { (au) }\end{array}$ & $\begin{array}{c}E \\
\mathrm{kcal} / \mathrm{mol}\end{array}$ & $\begin{array}{c}\mathrm{H} \\
(\mathrm{kJ} / \mathrm{mol})\end{array}$ & $\begin{array}{c}\mathrm{H} \\
(\mathrm{kcal} / \mathrm{mol})\end{array}$ & T & $\begin{array}{c}\mathrm{Tr} \\
{[\mathrm{kcal} / \mathrm{mol})}\end{array}$ & $\begin{array}{c}\text { Rt } \\
(\mathrm{kcal} / \mathrm{mol})\end{array}$ & $\begin{array}{c}\mathrm{Vb} \\
{[\text { (kcal/mol) }}\end{array}$ & $\begin{array}{l}\mathrm{S}=\mathrm{Tr}+\mathrm{Rt}+\mathrm{Vb} \\
(\mathrm{kcal} / \mathrm{mol})\end{array}$ & $\begin{array}{c}\mathrm{H}-\mathrm{TS} \\
(\mathrm{kcal} / \mathrm{mol})\end{array}$ & $\begin{array}{l}\mathrm{G}=\mathrm{E}+(\mathrm{H}-\mathrm{TS}) \\
(\mathrm{kcal} / \mathrm{mol})\end{array}$ & $\begin{array}{c}\text { \#E } \\
{[\mathrm{kcal} / \mathrm{mol})}\end{array}$ & $\begin{array}{c}\# G \\
(\mathrm{kcal} / \mathrm{mol})\end{array}$ \\
\hline HBpin & -411.4888 & -258209.2 & 523.9 & 125.3349 & 373.15 & 0.027758 & 0.029212 & 0.0313337 & 0.088303 & 92.38451 & -258116.9 & & \\
\hline alkyne & -422.5368 & -265141.8 & 397.68 & 95.13876 & 373.15 & 0.027855 & 0.030126 & 0.0308168 & 0.088798 & 62.0039 & -265079.8 & & \\
\hline 4_mem_ts & -833.9787 & -523321.6 & 916.15 & 219.1746 & 373.15 & 0.029877 & 0.034796 & 0.0787793 & 0.143453 & 165.6452 & -523156 & 29.45354 & 40.71032 \\
\hline 6_mem_ts (Figure S5) & -1245.484 & -781541.3 & 1446.06 & 345.9474 & 373.15 & 0.031073 & 0.03724 & 0.1448822 & 0.213195 & 266.3936 & -781274.9 & 21.09075 & 34.28229 \\
\hline Product' & -1245.603 & -781615.7 & 1465.95 & 350.7057 & 373.15 & 0.031073 & 0.037419 & 0.1527605 & 0.221252 & 268.1454 & -781347.6 & -53.3829 & -38.43953 \\
\hline
\end{tabular}

\section{S10 (g) - Calculation for Figure S7}

\begin{tabular}{|c|c|c|c|c|c|c|c|c|c|c|c|c|c|}
\hline & E & E & H & H & $\begin{array}{ll}T \\
\end{array}$ & $\mathrm{Tr}$ & Rt & $\mathrm{Vb}$ & $S=T r+R t+V b$ & H-TS & $G=E+(H-T S)$ & \#E & $\# G$ \\
\hline & (au) & $\mathrm{kcal} / \mathrm{mol}$ & $(\mathrm{kJ} / \mathrm{mol})$ & $(\mathrm{kcal} / \mathrm{mol})$ & & (kcal/mol) & (kcal/mol) & (kcal/mol) & (kcal/mol) & (kcal/mol) & (kcal/mol) & [kcal/mol) & (kcal/mol) \\
\hline HBpin & -411.4888 & -258209.2 & 519.76 & 124.3445 & 353.15 & 0.02776 & 0.029053 & 0.029069 & 0.0858818 & 94.01533 & -258115.2 & & \\
\hline ketone & -384.5494 & -241304.8 & 380.11 & 90.93541 & 353.15 & 0.027571 & 0.029292 & 0.023943 & 0.0808056 & 62.39889 & -241242.4 & & \\
\hline 4_mem_ts & -795.9996 & -499489.7 & 897.38 & 214.6842 & 353.15 & 0.029738 & 0.033842 & 0.072533 & 0.1361131 & 166.6159 & -499323.1 & 24.2727 & 34.47435 \\
\hline 6_mem_ts & -1207.513 & -757714.3 & 1421.75 & 340.1316 & 353.15 & 0.030981 & 0.036406 & 0.122851 & 0.1902371 & 272.9493 & -757441.3 & 8.963036 & 31.48282 \\
\hline Product & -796.0952 & -499549.7 & 913.31 & 218.4952 & 353.15 & 0.029738 & 0.034041 & 0.074816 & 0.1385954 & 169.5502 & -499380.2 & -35.7455 & -22.60949 \\
\hline
\end{tabular}

S10 (h) - Calculation for Figure S8

\begin{tabular}{|c|c|c|c|c|c|c|c|c|c|c|c|c|c|}
\hline & $\begin{array}{c}E \\
\text { (au) }\end{array}$ & $\begin{array}{c}E \\
\mathrm{kcal} / \mathrm{mol}\end{array}$ & $\begin{array}{c}\mathrm{H} \\
{[\mathrm{kJ} / \mathrm{mol})}\end{array}$ & $\begin{array}{c}\mathrm{H} \\
{[\mathrm{kcal} / \mathrm{mol})}\end{array}$ & $T$ & $\begin{array}{c}\mathrm{Tr} \\
{[\mathrm{kcal} / \mathrm{mol})}\end{array}$ & $\begin{array}{c}\text { Rt } \\
\text { (kcal/mol) }\end{array}$ & $\begin{array}{c}\mathrm{Vb} \\
\text { (kcal/mol) }\end{array}$ & $\begin{array}{l}S=T r+R t+V b \\
(k c a l / m o l)\end{array}$ & $\begin{array}{c}\text { H-TS } \\
\text { (kcal/mol) }\end{array}$ & $\begin{array}{l}G=E+(H-T S) \\
(\mathrm{kcal} / \mathrm{mol})\end{array}$ & $\begin{array}{c}\# E \\
\text { (kcal/mol) }\end{array}$ & $\begin{array}{c}\# \mathrm{G} \\
\text { (kcal/mol) }\end{array}$ \\
\hline HBpin & -411.4887 & -258209.2 & 519.76 & 124.3445 & 353.15 & 0.028379 & 0.029053 & 0.029094 & 0.0865261 & 93.78782 & -258115.4 & & \\
\hline 4_mem_ts & -795.9993 & -499489.6 & 897.42 & 214.6938 & 353.15 & 0.030357 & 0.033842 & 0.072495 & 0.1366943 & 166.4202 & -499323.1 & 23.15573 & 33.54355 \\
\hline 6_mem_ts & -1207.513 & -757714.4 & 1422.2 & 340.2392 & 353.15 & 0.0316 & 0.036426 & 0.123029 & 0.1910547 & 272.7683 & -757441.6 & 7.51957 & 30.46765 \\
\hline
\end{tabular}

S10 (i) - Calculation for Figure S9 (a)

\begin{tabular}{|c|c|c|c|c|c|c|c|c|c|c|c|c|c|}
\hline & $\begin{array}{c}\mathbf{E} \\
\text { (au) }\end{array}$ & $\begin{array}{c}E \\
\mathrm{kcal} / \mathrm{mol}\end{array}$ & $\begin{array}{c}\mathrm{H} \\
(\mathrm{kJ} / \mathrm{mol})\end{array}$ & $\begin{array}{c}\mathrm{H} \\
(\mathrm{kcal} / \mathrm{mol})\end{array}$ & $\begin{array}{ll}T \\
\end{array}$ & $\begin{array}{c}\mathrm{Tr} \\
(\mathrm{kcal} / \mathrm{mol})\end{array}$ & $\begin{array}{c}\mathrm{Rt} \\
(\mathrm{kcal} / \mathrm{mol})\end{array}$ & $\begin{array}{c}\mathrm{Vb} \\
\text { (kcal/mol) }\end{array}$ & $\begin{array}{r}\mathrm{S}=\mathrm{Tr}+\mathrm{Rt}+\mathrm{Vb} \\
(\mathrm{kcal} / \mathrm{mol})\end{array}$ & $\begin{array}{c}\mathrm{H}-\mathrm{TS} \\
{[\mathrm{kcal} / \mathrm{mol})}\end{array}$ & $\begin{array}{l}\mathrm{G}=\mathrm{E}+(\mathrm{H}-\mathrm{TS}) \\
(\mathrm{kcal} / \mathrm{mol})\end{array}$ & $\begin{array}{c}\text { \#E } \\
\text { (kcal/mol) }\end{array}$ & $\begin{array}{c}\# G \\
{[\mathrm{kcal} / \mathrm{mol})}\end{array}$ \\
\hline Carboxylic acid & -420.4754 & -263848.3 & 309.5 & 74.04306 & 298.15 & 0.027833 & 0.028735 & 0.0123957 & 0.068964 & 53.48153 & -263794.8 & & \\
\hline Hbpin & -411.4878 & -258208.6 & 509.63 & 121.9211 & 298.15 & 0.027973 & 0.028536 & 0.0229633 & 0.079472 & 98.22634 & -258110.4 & & \\
\hline ts1 & -831.9178 & -522028.4 & 811.24 & 194.0766 & 298.15 & 0.029974 & 0.033167 & 0.0612027 & 0.124344 & 157.0035 & -521871.4 & 28.46674 & 33.76234 \\
\hline int_1 & -830.8222 & -521340.9 & 773.64 & 185.0813 & 298.15 & 0.02995 & 0.033107 & 0.0585772 & 0.121634 & 148.816 & -521192.1 & -15.73569 & -16.68071 \\
\hline $\mathrm{H} 2$ & -1.166068 & .731 .7075 & 34.38 & 8.22488 & 298.15 & 0.015572 & 0.005485 & $3.607 E-11$ & 0.021057 & 1.946824 & .729 .7607 & & \\
\hline ts 2 & -1242.274 & -779526.9 & 1280.29 & 306.2895 & 298.15 & 0.031193 & 0.03571 & 0.0995959 & 0.166499 & 256.6477 & .779270 .2 & 6.931756 & 15.5921 \\
\hline int_2 & -1242.356 & .779578 .3 & 1295.69 & 309.9737 & 298.15 & 0.031193 & 0.035849 & 0.104106 & 0.171148 & 258.9458 & .779319 .4 & -44.5338 & -33.57541 \\
\hline ts_3a & -1653.802 & -1037761 & 1799.72 & 430.555 & 298.15 & 0.032068 & 0.037181 & 0.1422878 & 0.211537 & 367.4853 & -1037394 & -18.61978 & 2.65182 \\
\hline ts_-3b & -1242.322 & -779557 & 1287.15 & 307.9306 & 298.15 & 0.031193 & 0.035671 & 0.0998715 & 0.166735 & 258.2186 & -779298.7 & -23.14842 & -12.91725 \\
\hline Benzyldehyde & -345.2684 & -216655.9 & 296.83 & 71.01196 & 298.15 & 0.027413 & 0.02792 & 0.0123126 & 0.067646 & 50.84321 & -216605.1 & -40.48565 & -41.01661 \\
\hline 4_mem_ts & -756.7161 & -474839.3 & 804.41 & 192.4426 & 298.15 & 0.029777 & 0.033067 & 0.0561471 & 0.118991 & 156.9653 & -474682.4 & -15.25622 & -7.891426 \\
\hline Product & .756 .8184 & -474903.6 & 820.31 & 196.2464 & 298.15 & 0.029777 & 0.032869 & 0.0571595 & 0.119805 & 160.5265 & -474743 & .79 .49435 & -68.56832 \\
\hline Product' & -897.0811 & .562918 .4 & 989.79 & 236.7919 & 298.15 & 0.030203 & 0.033703 & 0.0708542 & 0.13476 & 196.6132 & -562721.7 & & \\
\hline
\end{tabular}




\begin{tabular}{|c|c|c|c|c|c|c|c|c|c|c|c|c|c|}
\hline & $\begin{array}{c}E \\
\text { (au) }\end{array}$ & $\begin{array}{c}E \\
\mathrm{kcal} / \mathrm{mol}\end{array}$ & $\begin{array}{c}\mathrm{H} \\
(\mathrm{kJ} / \mathrm{mol})\end{array}$ & $\begin{array}{c}\mathrm{H} \\
{[(\mathrm{kcal} / \mathrm{mol})}\end{array}$ & $\begin{array}{l}T \\
\end{array}$ & $\begin{array}{c}\mathrm{Tr} \\
(\mathrm{kcal} / \mathrm{mol})\end{array}$ & $\begin{array}{c}\text { Rt } \\
{[(\mathrm{kcal} / \mathrm{mol})}\end{array}$ & $\begin{array}{c}\mathrm{Vb} \\
(\mathrm{kcal} / \mathrm{mol})\end{array}$ & $\begin{array}{l}\mathrm{S}=\mathrm{Tr}+\mathrm{Rt}+\mathrm{Vb} \\
(\mathrm{kcal} / \mathrm{mol})\end{array}$ & $\begin{array}{c}\text { H-TS } \\
([\mathrm{kcal} / \mathrm{mol})\end{array}$ & $\begin{array}{l}\mathrm{G}=\mathrm{E}+(\mathrm{H}-\mathrm{TS}) \\
(\mathrm{kcal} / \mathrm{mol})\end{array}$ & $\begin{array}{c}\# E \\
(\mathrm{kcal} / \mathrm{mol})\end{array}$ & $\begin{array}{c}\# \mathrm{G} \\
\text { (kcal/mol) }\end{array}$ \\
\hline Carboxylic acid & -420.4857 & -263854.8 & 313.34 & 74.96172 & 298.15 & 0.02762 & 0.028715 & 0.0161023 & 0.072438 & 53.36442 & -263801.4 & & \\
\hline Hbpin & -411.4888 & -258209.2 & 509.43 & 121.8732 & 298.15 & 0.02776 & 0.028536 & 0.0228895 & 0.079186 & 98.26391 & -258111 & & \\
\hline $\mathrm{ts} 1$ & -831.9199 & -522029.7 & 811.42 & 194.1196 & 298.15 & 0.029762 & 0.033187 & 0.0612972 & 0.124245 & 157.0758 & -521872.6 & 34.33208 & 39.7796 \\
\hline int_1 & -830.8243 & -521342.3 & 773.45 & 185.0359 & 298.15 & 0.029738 & 0.033107 & 0.0585038 & 0.121348 & 148.8559 & -521193.4 & -9.952105 & -10.7167 \\
\hline $\mathrm{H}_{2}$ & -1.166112 & .731 .7351 & 34.37 & 8.222488 & 298.15 & 0.015359 & 0.005485 & $3.633 \mathrm{E}-11$ & 0.020844 & 2.007853 & -729.7273 & & \\
\hline$t s_{-} 2$ & -1242.276 & -779528.3 & 1279.9 & 306.1962 & 298.15 & 0.03098 & 0.03571 & 0.0997371 & 0.166428 & 256.5757 & -779271.8 & 13.20653 & 21.89789 \\
\hline int_2 & -1242.358 & .779580 & 1295.42 & 309.9091 & 298.15 & 0.03098 & 0.035849 & 0.1036862 & 0.170516 & 259.0698 & -779320.9 & -38.40652 & -27.22112 \\
\hline ts_3a & -1653.806 & -1037763 & 1801.45 & 430.9689 & 298.15 & 0.031855 & 0.037201 & 0.1519533 & 0.221009 & 365.075 & -1037398 & -12.24803 & 6.678642 \\
\hline ts_3b & -1242.323 & -779557.9 & 1286.25 & 307.7153 & 298.15 & 0.03098 & 0.03569 & 0.101488 & 0.168159 & 257.5788 & -779300.4 & -16.38811 & -6.693695 \\
\hline Benzyldehyde & -345.2696 & -216656.7 & 296.83 & 71.01196 & 298.15 & 0.027201 & 0.02792 & 0.0123547 & 0.067476 & 50.8941 & -216605.8 & -34.69567 & -35.00266 \\
\hline 4_mem_ts & -756.719 & -474841.2 & 803.99 & 192.3421 & 298.15 & 0.029155 & 0.033187 & 0.0538919 & 0.116233 & 157.6872 & -474683.5 & -9.959455 & -1.737256 \\
\hline Product & -756.8201 & -474904.6 & 820.51 & 196.2943 & 298.15 & 0.029155 & 0.033028 & 0.0553843 & 0.117567 & 161.2418 & -474743.4 & -73.35763 & -61.58086 \\
\hline Product' & -897.0829 & -562919.6 & 989.48 & 236.7177 & 298.15 & 0.02999 & 0.033703 & 0.0705831 & 0.134276 & 196.6833 & -562722.9 & & \\
\hline
\end{tabular}

\section{S10 (k) - Calculation for Figure S10}

Carboxylic
acid
Hbpin
ts1
int_1
H2
ts_2
int_2
ts_3
Benzyldehyde
6_mem_ts
Product
Product'

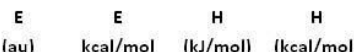

$\begin{array}{llcc}-420.4857 & -263854.8 & 313.34 & 74.96172 \\ -411.4888 & -258209.2 & 509.43 & 121.8732 \\ -831.9598 & -522054.8 & 812.73 & 194.433 \\ -830.8243 & -521342.3 & 773.45 & 185.0359 \\ -1.166112 & -731.7351 & 34.37 & 8.222488 \\ -1653.779 & -1037747 & 1793.26 & 429.0096 \\ -1242.358 & -779580 & 1295.42 & 309.9091 \\ -1242.323 & -779557.9 & 1286.25 & 307.7153 \\ -345.2696 & -216656.7 & 296.83 & 71.01196 \\ -1168.236 & -733068.2 & 1318.52 & 315.4354 \\ -756.8201 & -474904.6 & 820.51 & 196.2943 \\ -897.0829 & -562919.6 & 989.48 & 236.7177\end{array}$

Tr Rt Vb $S=T r+R t+V b \quad H-T S \quad G=E+(H-T S)$ \#E \#G (kcal/mol) (kcal/ $/ \mathrm{mol}) \quad(\mathrm{kcal} / \mathrm{mol}) \quad(\mathrm{kcal} / \mathrm{mol}) \quad(\mathrm{kcal} / \mathrm{mol}) \quad(\mathrm{kcal} / \mathrm{mol}) \quad(\mathrm{kcal} / \mathrm{mol}) \quad(\mathrm{kcal} / \mathrm{mol})$

$\begin{array}{llllll}0.02762 & 0.028715 & 0.0161023 & 0.072438 & 53.36442 & -263801.4\end{array}$

$\begin{array}{llllllll}298.15 & 0.02776 & 0.028536 & 0.0228895 & 0.079186 & 98.26391 & -258111\end{array}$

$\begin{array}{llllllllll}298.15 & 0.029762 & 0.033504 & 0.0579768 & 0.121243 & 158.2844 & -521896.5 & 9.282705 & 15.9388\end{array}$ $\begin{array}{llllllllll}298.15 & 0.029738 & 0.033107 & 0.0585038 & 0.121348 & 148.8559 & -521193.4 & -9.952105 & -10.7167\end{array}$ $\begin{array}{llllllll}298.15 & 0.015359 & 0.005485 & 3.633 \mathrm{E}-11 & 0.020844 & 2.007853 & -729.7273\end{array}$

$\begin{array}{llllllllll}298.15 & 0.031855 & 0.03734 & 0.1459535 & 0.215149 & 364.863 & -1037382 & 4.227314 & 22.94202\end{array}$ $\begin{array}{llllllllll}298.15 & 0.03098 & 0.035849 & 0.1036862 & 0.170516 & 259.0698 & -779320.9 & -38.40652 & -27.22112\end{array}$ $\begin{array}{llllllllll}298.15 & 0.03098 & 0.03569 & 0.101488 & 0.168159 & 257.5788 & -779300.4 & -16.38811 & -6.693695\end{array}$ $\begin{array}{lllllllllll}298.15 & 0.027201 & 0.02792 & 0.0123547 & 0.067476 & 50.8941 & -216605.8 & -34.69567 & -35.00266\end{array}$ $\begin{array}{llllllllll}298.15 & 0.030867 & 0.035849 & 0.0985616 & 0.165278 & 266.1577 & -732802 & -27.69148 & -9.262638\end{array}$ $\begin{array}{lllllllllll}298.15 & 0.029155 & 0.033028 & 0.0553843 & 0.117567 & 161.2418 & -474743.4 & -73.35763 & -61.58086\end{array}$

$\begin{array}{llllllll}298.15 & 0.02999 & 0.033703 & 0.0705831 & 0.134276 & 196.6833 & -562722.9\end{array}$

S10 (I) - Calculation for Figure S11

Carboxylic acid
Hbpin
ts1
int_1
H2
ts_2
int_2
ts_3
Benzyldehyde
6_mem_ts
Product
Product'

$\begin{array}{cccc}E & \text { E } & \text { H } & \text { H } \\ \text { (au) } & \mathrm{kcal} / \mathrm{mol} & (\mathrm{kJ} / \mathrm{mol}) & (\mathrm{kcal} / \mathrm{mol})\end{array}$ $\begin{array}{cccc}-420.4754 & -263848.3 & 309.5 & 74.04306\end{array}$ $\begin{array}{llll}-411.4878 & -258208.6 & 509.63 & 121.9211\end{array}$ $\begin{array}{llll}-831.9579 & -522053.6 & 813.06 & 194.512\end{array}$ $\begin{array}{llll}-830.8222 & -521340.9 & 773.64 & 185.0813\end{array}$ $\begin{array}{llll}-1.166068 & -731.7075 & 34.38 & 8.22488\end{array}$ $\begin{array}{llll}-1242.274 & -779526.9 & 1280.29 & 306.2895\end{array}$ $\begin{array}{llll}-1242.356 & -779578.3 & 1295.69 & 309.9737\end{array}$ $\begin{array}{llll}-1242.322 & -779557 & 1287.15 & 307.9306\end{array}$ $\begin{array}{llll}-345.2684 & -216655.9 & 296.83 & 71.01196\end{array}$ $\begin{array}{llll}-1168.232 & -733065.7 & 1318.35 & 315.3947\end{array}$ $\begin{array}{llll}-756.8184 & -474903.6 & 820.31 & 196.2464\end{array}$ $\begin{array}{lllll}-897.0811 & -562918.4 & 989.79 & 236.7919\end{array}$

\section{S10 (m) - Calculation for Figure 8}

E E

(au) $\quad \mathrm{kcal} / \mathrm{mol} \quad(\mathrm{kJ} / \mathrm{mol}) \quad[\mathrm{kcal} / \mathrm{mol})$

TMSCN

2_TMSCN

TS_1

Int_1

Benzyldehyde

TS_2

Int_2

TS_3

Product $\begin{array}{llll}-501.7677 & -314859.2 & 339.07 & 81.11722\end{array}$ $\begin{array}{lllll}-1003.535 & -629718.1 & 681.09 & 162.9402\end{array}$ $\begin{array}{llll}-1003.495 & -629692.9 & 676.14 & 161.756\end{array}$ $\begin{array}{llll}-1003.532 & -629716.4 & 683.57 & 163.5335\end{array}$ $\begin{array}{lllll}-345.2693 & -216656.5 & 303.57 & 72.6244\end{array}$ $\begin{array}{llll}-1348.763 & -846348.6 & 991.49 & 237.1986\end{array}$ $\begin{array}{lllll}-1348.805 & -846375.3 & 995.75 & 238.2177\end{array}$ $\begin{array}{lllll}-1348.768 & -846351.7 & 985.04 & 235.6555\end{array}$ $\begin{array}{llll}-1348.836 & -846394.7 & 996.53 & 238.4043\end{array}$
Tr Rt Vb $S=T r+R t+V b \quad H-T S \quad G=E+(H-T S) \quad \# E \quad \# G$ (kcal $/ \mathrm{mol}) \quad(\mathrm{kcal} / \mathrm{mol}) \quad(\mathrm{kcal} / \mathrm{mol}) \quad(\mathrm{kcal} / \mathrm{mol}) \quad(\mathrm{kcal} / \mathrm{mol}) \quad(\mathrm{kcal} / \mathrm{mol}) \quad(\mathrm{kcal} / \mathrm{mol}) \quad(\mathrm{kcal} / \mathrm{mol})$ $\begin{array}{llllllll}298.15 & 0.027833 & 0.028735 & 0.0123957 & 0.068964 & 53.48153 & -263794.8\end{array}$ $\begin{array}{lllllllll}298.15 & 0.027973 & 0.028536 & 0.0229633 & 0.079472 & 98.22634 & -258110.4\end{array}$ $\begin{array}{lllllllllll}298.15 & 0.029974 & 0.033504 & 0.0579079 & 0.121387 & 158.3205 & -521895.3 & 3.30351 & 9.916124\end{array}$ $\begin{array}{llllllllll}298.15 & 0.02995 & 0.033107 & 0.0585772 & 0.121634 & 148.816 & -521192.1 & -15.73569 & -16.68071\end{array}$ $\begin{array}{llllllll}298.15 & 0.015572 & 0.005485 & 3.607 E-11 & 0.021057 & 1.946824 & -729.7607\end{array}$ $\begin{array}{lllllllllll}298.15 & 0.031193 & 0.03571 & 0.0995959 & 0.166499 & 256.6477 & -779270.2 & 6.931756 & 15.5921\end{array}$ $\begin{array}{lllllllllll}298.15 & 0.031193 & 0.035849 & 0.104106 & 0.171148 & 258.9458 & -779319.4 & -44.5338 & -33.57541\end{array}$ $\begin{array}{lllllllllll}298.15 & 0.031193 & 0.035671 & 0.0998715 & 0.166735 & 258.2186 & -779298.7 & -23.14842 & -12.91725\end{array}$ $\begin{array}{lllllllllll}298.15 & 0.027413 & 0.02792 & 0.0123126 & 0.067646 & 50.84321 & -216605.1 & -40.48565 & -41.01661\end{array}$ $\begin{array}{lllllllllll}298.15 & 0.03108 & 0.035869 & 0.101614 & 0.168563 & 265.1376 & -732800.5 & -33.00181 & -15.69103\end{array}$ $\begin{array}{lllllllllll}298.15 & 0.029777 & 0.032869 & 0.0571595 & 0.119805 & 160.5265 & -474743 & -79.49435 & -68.56832\end{array}$ $\begin{array}{lllllll}298.15 & 0.030203 & 0.033703 & 0.0708542 & 0.13476 & 196.6132 & -562721.7\end{array}$ 


\begin{tabular}{|c|c|c|c|c|c|c|c|c|c|c|c|c|c|}
\hline & $\begin{array}{c}E \\
\text { (au) }\end{array}$ & $\begin{array}{c}E \\
\mathrm{kcal} / \mathrm{mol}\end{array}$ & $\begin{array}{c}\mathrm{H} \\
{[\mathrm{kJ} / \mathrm{mol})}\end{array}$ & $\begin{array}{c}\mathrm{H} \\
{[\mathrm{kcal} / \mathrm{mol})}\end{array}$ & T & $\begin{array}{c}\mathrm{Tr} \\
(\mathrm{kcal} / \mathrm{mol})\end{array}$ & $\begin{array}{c}\text { Rt } \\
\text { (kcal/mol) }\end{array}$ & $\begin{array}{c}\mathrm{Vb} \\
{[\mathrm{kcal} / \mathrm{mol})}\end{array}$ & $\begin{array}{l}\mathrm{S}=\mathrm{Tr}+\mathrm{Rt}+\mathrm{Vb} \\
(\mathrm{kcal} / \mathrm{mol})\end{array}$ & $\begin{array}{c}\mathrm{H}-\mathrm{TS} \\
(\mathrm{kcal} / \mathrm{mol})\end{array}$ & $\begin{array}{l}\mathrm{G}=\mathrm{E}+(\mathrm{H}-\mathrm{TS}) \\
(\mathrm{kcal} / \mathrm{mol})\end{array}$ & $\begin{array}{c}\# E \\
\text { (kcal/mol) }\end{array}$ & $\begin{array}{c}\# G \\
{[\text { kcal } / \mathrm{mol} \text { ) }}\end{array}$ \\
\hline TMSCN & -501.7677 & -314859.2 & 339.07 & 81.11722 & 353.15 & 0.028132 & 0.028258 & 0.030147 & 0.086537 & 50.55671 & -314808.7 & & \\
\hline TS_1 & -501.722 & -314830.5 & 333.92 & 79.88517 & 353.15 & 0.028132 & 0.027861 & 0.0282674 & 0.08426 & 50.1288 & -314780.4 & 28.67823 & 28.25032 \\
\hline Int_1 & -501.7578 & -314853 & 338.36 & 80.94737 & 353.15 & 0.028132 & 0.028099 & 0.0304421 & 0.086673 & 50.33878 & -314802.7 & 6.221883 & 6.003955 \\
\hline nzyldehyde & -345.2693 & -216656.5 & 303.57 & 72.6244 & 353.15 & 0.028333 & 0.028437 & 0.0159127 & 0.072683 & 46.95648 & -216609.5 & & \\
\hline TS_2 & -846.9853 & -531483.3 & 645.79 & 154.4952 & 353.15 & 0.030305 & 0.032948 & 0.0696214 & 0.132874 & 107.5707 & -531375.7 & 32.40759 & 42.46507 \\
\hline Int_2 & -847.031 & -531511.9 & 650.73 & 155.677 & 353.15 & 0.030305 & 0.032491 & 0.067114 & 0.12991 & 109.7994 & -531402.1 & 3.753717 & 16.03991 \\
\hline TS_3 & -846.9919 & -531487.4 & 645.23 & 154.3612 & 353.15 & 0.030305 & 0.032849 & 0.0701238 & 0.133277 & 107.2943 & -531380.1 & 28.27768 & 38.05884 \\
\hline Product & -847.0616 & -531531.1 & 651.21 & 155.7919 & 353.15 & 0.030305 & 0.032531 & 0.0667442 & 0.12958 & 110.0308 & -531421.1 & -15.44683 & -2.929265 \\
\hline
\end{tabular}

S10 (o) - Calculation for Figure S13

\begin{tabular}{|c|c|c|c|c|c|c|c|c|c|c|c|c|c|}
\hline & $\begin{array}{c}\text { E } \\
\text { (au) }\end{array}$ & $\begin{array}{c}E \\
\mathrm{kcal} / \mathrm{mol}\end{array}$ & $\begin{array}{c}\mathrm{H} \\
(\mathrm{kJ} / \mathrm{mol})\end{array}$ & $\begin{array}{c}\mathrm{H} \\
(\mathrm{kcal} / \mathrm{mol})\end{array}$ & T & $\begin{array}{c}\operatorname{Tr} \\
\text { (kcal/mol) }\end{array}$ & $\begin{array}{c}\text { Rt } \\
(\mathrm{kcal} / \mathrm{mol})\end{array}$ & $\begin{array}{c}V b \\
\text { (kcal/mol) }\end{array}$ & $\begin{array}{l}S=T r+R t+V b \\
(k c a l / m o l)\end{array}$ & $\begin{array}{c}\text { H-TS } \\
\text { (kcal/mol) }\end{array}$ & $\begin{array}{l}G=E+(H-T S) \\
(k c a l / m o l)\end{array}$ & $\begin{array}{c}\text { \#E } \\
(\text { kcal } / \text { mol) }\end{array}$ & $\begin{array}{c}\# G \\
\text { (kcal/mol) }\end{array}$ \\
\hline TMSCN & -501.7677 & -314859.2 & 339.07 & 81.11722 & 353.15 & 0.028132 & 0.028258 & 0.030147 & 0.086537 & 50.55671 & -314808.7 & & \\
\hline TS_1 & -1003.495 & -629692.9 & 676.14 & 161.756 & 353.15 & 0.030305 & 0.089205 & 0.0332262 & 0.152736 & 107.8174 & -629585.1 & 25.47928 & 32.18325 \\
\hline Int_1 & -501.7578 & -314853 & 338.36 & 80.94737 & 353.15 & 0.028132 & 0.028099 & 0.0304421 & 0.086673 & 50.33879 & -314802.7 & 6.221883 & 6.003965 \\
\hline enzyldehyde & -345.2693 & -216656.5 & 303.57 & 72.6244 & 353.15 & 0.028333 & 0.028437 & 0.0159127 & 0.072683 & 46.95648 & -216609.5 & & \\
\hline TS__2 & -1348.763 & -846348.6 & 991.49 & 237.1986 & 353.15 & 0.031483 & 0.036088 & 0.1324378 & 0.200008 & 166.5657 & -846182 & 26.34786 & 44.84367 \\
\hline Int_2 & -847.031 & -531511.9 & 650.73 & 155.677 & 353.15 & 0.030305 & 0.032491 & 0.067114 & 0.12991 & 109.7994 & -531402.1 & 3.753717 & 16.03991 \\
\hline TS_3 & -1348.768 & -846351.7 & 985.04 & 235.6555 & 353.15 & 0.031483 & 0.036247 & 0.1271091 & 0.194838 & 166.8483 & -846184.9 & 23.16067 & 41.93908 \\
\hline Product & -847.0616 & -531531.1 & 651.21 & 155.7919 & 353.15 & 0.030305 & 0.032531 & 0.0667442 & 0.12958 & 110.0308 & -531421.1 & -15.44683 & -2.929265 \\
\hline
\end{tabular}

\section{References}

1. Kozuch, S.; Martin, J. M. L. What Makes for a Bad Catalytic Cycle? A Theoretical Study on the Suzuki-Miyaura Reaction within the Energetic Span Model. ACS Catal. 2011, 1, 246-253.

2. Uhe, A.; Kozuch, S.; Shaik, S. Software News and Update Automatic Analysis of Computed Catalytic Cycles. Comput. Chem. 2010, 32, 978-985.

3. Kozuch, S.; Shaik, S. How to Conceptualize Catalytic Cycles? The Energetic Span Model. Acc. Chem. Res. 2011, 44, 101-110.

4. Wang, W.; Luo, M.; Yao, W.; Ma, M.; Pullarkat, S. A.; Xu, L.; Leung, P.H. Catalystfree and solvent-free hydroboration of ketones. New J. Chem. 2019,43, 10744-10749.

5. (a) Harinath, A.; Bhattacharjee, J.; Panda, T. K. Facile Reduction of Carboxylic Acids to Primary Alcohols under Catalyst-Free and Solvent-Free Conditions. Chem.

Commun. 2019, 55, 1386-1389. (b) Wang, W.; Luo, M.; Zhu, D.; Yao, W.; Xu, L.; Ma, M. Green Hydroboration of Carboxylic Acids and Mechanism Investigation. Org. Biomol. Chem. 2019, 17, 3604-3608. (c) Xu, X.; Yan, D.; Zhu, Z.; Kang, Z.; Yao, Y.; Shen, Q.; Xue, M. Catalyst-Free Approach for Hydroboration of Carboxylic Acids under Mild Conditions. ACS Omega, 2019,4, 6775-6783. 
6. Johnson, E. R.; Keinan, S.; Mori-Sanchez, P.; Contreras- Garcia, J.; Cohen, A. J.; Yang, W. Revealing Noncovalent Interactions. J. Am. Chem. Soc. 2010, 132, 64986506.

7. Contreras-Garcia, J.; Johnson, E. R.; Keinan, S.; Chaudret, R.; Piquemal, J.-P.; Beratan, D. N.; Yang, W. NCIPLOT: A Program for Plotting Noncovalent Interaction Regions. J. Chem. Theory Comput. 2011, 7, 625-632.

8. Ufimtsev, S. ; T. J. Martinez, J. Chem. Theory Comput., 2009, 5, 2619-2628.

9. Ufimtsev, S.; Luehr, N.; Martinez, T. J., J. Phys. Chem. Lett., 2011, 2, 1789-1793.

10. Isborn, C. M.; Luehr, N.; Ufimtsev, I. S.; Martinez, T. J., J. Chem. Theory Comput., 2011, 7, 1814-1823.

11. Titov, A.V.; Ufimtsev, I. S.; Luehr, N.; Martinez, T. J., J. Chem. Theory Comput., 2013, 9, 213-221.

12. Ufimtsev I. S.; Martinez, T. J., Comput. Sci. Eng., 2008, 10, 26-34.

13. Ufimtsev, I. S. ; Martinez, T. J., J. Chem. Theory Comput., 2008, 4, 222-231.

14. Ufimtsev, S.; Martinez., T. J., J. Chem. Theory Comput., 2009, 5, 1004-1015.

15. Becke, I. D. J. Chem. Phys., 1993, 98, 5648-5652.

16. Binkley, J. S.; Pople, J. A.; Hehre, W. J., J. Am. Chem. Soc., 1980, 102, 939-947.

17. Hu, X.; Yang, W., J. Chem. Phys., 2010, 132, 054109-054116.

18. Pulay, P.,Chem. Phys. Lett., 1980, 73, 393-398.

19. Wang, L.P.; Titov, A.; McGibbon, R.; Liu, F.; Pande, V.S.; Martínez, T.J., Nat Chem., 2014, 6, 12, 1044-1048.

20. Further references for hydroboration-

1) Bisai, M. K.; Yadav, S.; Das, T.; Vanka, K.; Sen, S. S. Lithium compounds as single site catalysts for hydroboration of alkenes and alkynes. Chem. Commun. 2019, 55, 11711-11714.

2) Magre, M.; Maity, B.; Falconnet, A.; Cavallo, L.; Rueping, M. MagnesiumCatalyzed Hydroboration of Terminal and Internal Alkynes. Angew. Chem. Int. Ed. 2019, 58, 7025-7029.

3) Jang, W. J.; Kang, B. N.; Lee, J. H.; Choi, Y. M.; Kim, C. H.; Yun, NHCCopper-Thiophene-2-Carboxylate Complex for the Hydroboration of Terminal Alkynes. J. Org. Biomol. Chem. 2019, 17, 5249-5252 
4) Mandal, S.; Verma, K. P.; Geetharani, K. Lewis Acid Catalysis: Regioselective Hydroboration of Alkynes and Alkenes Promoted by Scandium Triflate. Chem. Commun. 2018, 54, 13690-13693.

5) Curto, S. G.; Esteruelas, M. A.; Montserrat, O.; Onate, E. Rhodium-Mediated Dehydrogenative Borylation-Hydroborylation of Bis(Alkyl)Alkynes: Intermediates and Mechanism. Organometallics 2019, 389, 2062-2074.

6) Ang, N. W. J.; Buettner, C. S.; Docherty, S.; Bismuto, A.; Carney, J. R.; Docherty, J. H.; Cowley, M. J.; Thomas, S. P. Borane-Catalysed Hydroboration of Alkynes and Alkenes. Synthesis 2018, 50, 803-808.

7) Wang, Q.; Li, L.; Li, P.; Yue, X.; Yang, Z.; Pu, M.; Lei, M. RutheniumCatalyzed Deoxygenative Hydroboration of Carboxylic Acids: A DFT Mechanistic Study. New J. Chem. 2019, 43, 11493-11496.

8) Kisan, S.; Krishnakumar, V.; Gunanathan, C. Selective Hydrogenation of Carboxylic Acids to Alcohols or Alkanes Employing a Heterogeneous Catalyst. ACS Catal. 2018, 8, 4772-4776.

9) Barman, M. K.; Das, K.; Maji, B. Selective Hydroboration of Carboxylic Acids with a Homogeneous Manganese Catalyst. J. Org. Chem. 2019, 84, 1570-1579.

10) Dasgupta, R.; Das, S.; Hiwase, S.; Pati, S. K.; Khan S. N-Heterocyclic Germylene and Stannylene Catalyzed Cyanosilylation and Hydroboration of Aldehydes. Organometallics 2019, 38, 1429-1435.

11)Zhang, G.; Cheng, J.; Davis, K.; Bonifacio, M. G.; Zajaczkowski C. Practical and selective hydroboration of aldehydes and ketones in air catalysed by an iron (II) coordination polymer. Green Chem. 2019, 21, 1114-1121.

12) Sinhababu, S.; Singh, D.; Sharma, M. K.; Siwatch, K. R.; Mahawar P.; Nagendran S. Ge(II) cation catalyzed hydroboration of aldehydes and ketones. Dalton Trans. 2019, 48, 4094-4100.

13) Ma, D. H.; Jaladi, A. K.; Lee, J. H.; Kim, T. S.; Shin, W. K.; Hwang, H.; An, D. K. Catalytic Hydroboration of Aldehydes, Ketones, and Alkenes Using Potassium Carbonate: A Small Key to Big Transformation. ACS Omega 2019, 14, 15893-15903.

14) Bisai, M. K.; Das, T.; Vanka, K.; Sen, S. S., Easily accessible lithium compounds catalyzed mild and facile hydroboration and cyanosilylation of aldehydes and ketones. Chem. Commun. 2018, 54, 6843-6846. 
15) Bisai, M. K.; Pahar, S.; Das, T.; Vanka K.; Sen, S. S. Transition metal free catalytic hydroboration of aldehydes and aldimines by amidinato silane. Dalton Trans. 2017, 46, 2420-2424.

16) Yadav, S.; Pahar, S.; Sen, S. S. Benz-amidinato calcium iodide catalyzed aldehyde and ketone hydroboration with unprecedented functional group tolerance. Chem. Commun. 2017, 53, 4562-4564.

17) Zeng, H.; Wu, J.; Li, S.; Hui, C.; Ta, A.; Cheng, S. Y.; Zheng, S.; Zhang, G. Copper (II)-Catalyzed Selective Hydroboration of Ketones and Aldehydes. Org. Lett. 2019, 21, 401-406.

18) Kucinski, K.; Hreczycho, G. Lithium triethylborohydride as catalyst for solvent free hydroboration of aldehydes and ketones. Green Chem. 2019, 21, 1912-1915.

19) Yadav, S.; Dixit, R.; Bisai, M. K.; Vanka, K.; Sen, S. S. Alkaline Earth Metal Compounds of Methylpyridinato $\beta$-diketiminate Ligands and their Catalytic Application in Hydroboration of Aldehydes and Ketones. Organometallics 2018, 37, 4576-4584.

20) Lampland, N. L.; Hovey, M.; Mukherjee, D.; Sadow, A. D. MagnesiumCatalyzed Mild Reduction of Tertiary and Secondary Amides to Amines. ACS Catal. 2015, 5, 4219-4226.

21) Barger, C. J.; Dicken, R. D.; Weidner, V. L.; Motta, A.; Lohr, T. L.; Marks, T. J. $\mathrm{La}\left[\mathrm{N}\left(\mathrm{SiMe}_{3}\right)_{2}\right]_{3}$-Catalyzed Deoxygenative Reduction of Amides with Pinacolborane. Scope and Mechanism. J. Am. Chem. Soc. 2020, 142, 80198028 .

22) Bhunia, M.; Sahoo, S. R.; Das, A.; Ahmed, J.; Sreejyothi P.; Mandal, S. K. Transition metal-free catalytic reduction of primary amides using an abnormal NHC based potassium complex: integrating nucleophilicity with Lewis acidic activation. Chem. Sci. 2020, 11, 1848-1854.

23) Weetman, C.; Hill, M. S.; Mahon, M. F.; Magnesium Catalysis for the Hydroboration of Carbodiimides. Chem. Eur. J. 2016, 22, 7158 - 7162.

24) Rauch, M.; Ruccolo, S.; Parkin, G. Synthesis, Structure, and Reactivity of a Terminal Magnesium Hydride Compound with a Carbatrane Motif, [TismPriBenz]MgH: A Multifunctional Catalyst for Hydrosilylation and Hydroboration. J. Am. Chem. Soc. 2017, 139, 13264-13267. 
25) Mukherjee, D.; Shirase, S.; Spaniol, T. P.; Mashima, K.; Okuda, J.; Magnesium hydridotriphenylborate $\left[\mathrm{Mg}(\mathrm{thf})_{6}\right]\left[\mathrm{HBPh}_{3}\right]_{2}:$ a versatile hydroboration catalyst. Chem. Commun. 2016, 52, 13155-13158.

26) Rao, B.; Chong, C. C.; Kinjo, R. Metal-Free Regio- and Chemoselective Hydroboration of Pyridines Catalyzed by 1,3,2-Diazaphosphenium Triflate. $J$. Am. Chem. Soc. 2018, 140, 652-656.

27) Barger, C. J.; Motta, A.; Weidner, V. L.; Lohr , T. L.; Marks, T. J. $\mathrm{La}\left[\mathrm{N}\left(\mathrm{SiMe}_{3}\right)_{2}\right]_{3}$-Catalyzed Ester Reductions with Pinacolborane: Scope and Mechanism of Ester Cleavage. ACS Catal. 2019, 9, 9015-9024.

28) Barman, M. K.; Baishya, A.; Nembenna, S. Dalton Trans. 2017, 46, 41524156.

29) Wang, Z. C.; Shen, D.; Gao, J.; Jia, X.; Xu, Y.; Sh, S. L. Base-catalysed reductive relay hydroboration of allylic alcohols with pinacolborane to form alkylboronic esters. Chem. Commun. 2019, 55, 8848-8851.

30) Harinath, A.; Bhattacharjee, J.; Panda, T. K. Catalytic Hydroboration of Organic Nitriles Promoted by Aluminum Complex. Adv. Synth. Catal. 2019, $361,850-857$.

31) Liu, W.; Ding, Y.; Jin, D.; Shen, Q.; Yan, B.; Ma, X.; Yang, Z. Organic Aluminum Hydrides Catalyze Nitrile Hydroboration. Green Chem. 2019, 21, 3812-3815.

32) Shirakawa, K.; Arase, A.; Hoshi, M. Preparation of (E)-1-Alkenylboronic Acid Pinacol Esters via Transfer of Alkenyl Group from Boron to Boron. Synthesis 2004, 11, 1814-1820.

33) Obligacion, J. V.; Chirik, P. J. Highly Selective Bis(imino)pyridine IronCatalyzed Alkene Hydroboration. Org. Lett. 2013, 15, 2680-2683.

34) Romerero, E. A.; Peltier, J. L.; Jazzar R.; Bertrand, G. Catalyst-free dehydrocoupling of amines, alcohols, and thiols with pinacol borane and 9borabicyclononane (9-BBN). Chem. Commun. 2016, 52, 10563-10565.

35) Kucinski, K.; Hreczycho, G. Chemoselective and Catalyst-Free O-Borylation of Silanols: A Facile Access to Borasiloxanes. ChemSusChem. 2017, 10, 4695-4698.

36) Kazmierczak, J.; Kucinski, K.; Stachowiak H.; Hreczycho, G. Introduction of Boron Functionalities into Silsesquioxanes: Novel Independent Methodologies. Chem. Eur. J. 2018, 24, 2509-2514. 
37) Kucinski, K.; Hreczycho, G. Hydrosilylation and hydroboration in a sustainable manner: from Earth-abundant catalysts to catalyst-free solutions. Green Chem. 2020, 22, 5210-5224.

38) Kucinski, K.; Hreczycho, G. Potassium Fluoride-Catalyzed Hydroboration of Aldehydes andKetones: Facile Reduction to Primary and Secondary Alcohols. Eur. J. Org. Chem. 2020, 552-555.

The supplemental file codinates.xyz contains the computed Cartesian coordinates of all of the molecules reported in this study. The file may be opened as a text file to read the coordinates, or opened directly by a molecular modeling program such as Mercury (version 3.3 or later, http://www.ccdc.cam.ac.uk/pages/Home.aspx) for visualization and analysis. 